Portland State University

PDXScholar

Summer 8-29-2014

\title{
The Impact of Wiki-based Collaborative Writing on English L2 Learners' Individual Writing Development
}

Gina Christina Caruso

Portland State University

Follow this and additional works at: https://pdxscholar.library.pdx.edu/open_access_etds

Part of the First and Second Language Acquisition Commons Let us know how access to this document benefits you.

\section{Recommended Citation}

Caruso, Gina Christina, "The Impact of Wiki-based Collaborative Writing on English L2 Learners' Individual Writing Development" (2014). Dissertations and Theses. Paper 2004.

https://doi.org/10.15760/etd.2003

This Thesis is brought to you for free and open access. It has been accepted for inclusion in Dissertations and Theses by an authorized administrator of PDXScholar. Please contact us if we can make this document more accessible: pdxscholar@pdx.edu. 
The Impact of Wiki-based Collaborative Writing on English L2 Learners' Individual

Writing Development

\author{
By \\ Gina Caruso
}

A thesis submitted in partial fulfillment of the requirements for the degree of

\author{
Master of Arts \\ in \\ Teaching English to Speakers of Other Languages
}

Thesis Committee:

Nike Arnold, Chair

Susan Conrad

Tanya Sydorenko

Portland State University

2014 


\begin{abstract}
Although the benefits of group and pair work in the second language (L2) classroom have been extensively studied, most documented research has focused on the use of oral tasks and spoken interaction between learners. Recently however, researchers have begun to investigate the advantages of collaboration on written work. More specifically, with the advancements in computer technology and webbased collaborative platforms like wikis, there has been a growing awareness of the educational possibilities of wikis to enhance L2 writing instruction. This study followed a pretest/posttest repeated measures design to investigate the impact and students' perceptions of wiki-based collaborative writing activities on individual writing performance. The study involved 12 university students in a TOEFL preparation course at a large university in Bogota, Colombia. Students were divided into two groups: the experimental group $(n=8)$ engaged in a series of wiki-based collaborative writing activities and focused practice between pre and posttests, while the control $(n=4)$ received no treatment. Two individual writing samples (pre and posttest) composed by each participant under timed conditions were quantitatively analyzed using the three linguistic developmental measures of complexity, accuracy, and fluency. While statistically significant differences were not evident for measures of fluency or accuracy, descriptive statistics showed an overall positive impact for collaborative writing on individual learners' written fluency. Analysis of complexity measures revealed mixed results with respect to learning gains. Further analysis of perception data reported by learners in an exit
\end{abstract}


survey disclosed their positive attitude towards perceived linguistic benefits with regard to the wiki-based collaborative writing activities. Both theoretical and pedagogical implications of the study, limitations, and directions for future research are presented. 


\section{DEDICATION}

I dedicate this work to all those who have encouraged, supported, and inspired me throughout my three years at Portland State University. 


\section{ACKNOWLEDGEMENTS}

I'd like to extend my gratitude to my dear friend and colleague Domminick

McParland. Without his help and cooperation, this study would not have been possible. 


\section{TABLE OF CONTENTS}

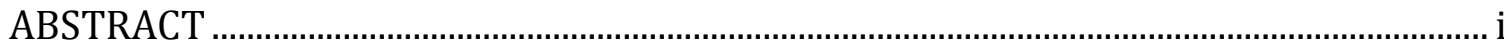

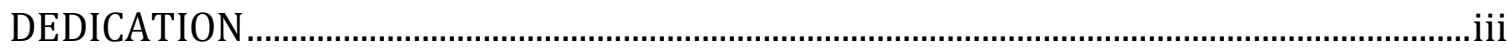

ACKNOWLEDGEMENTS ............................................................................................................ iv

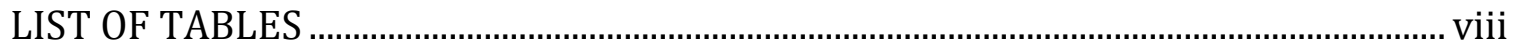

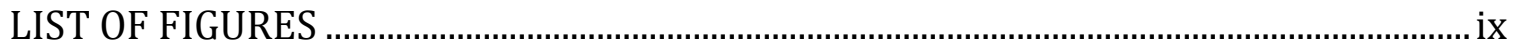

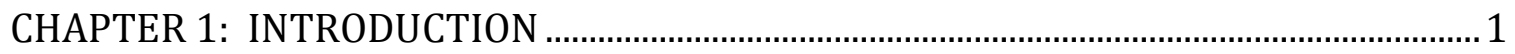

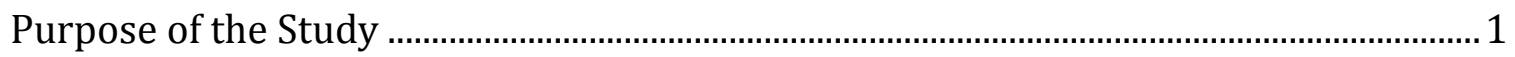

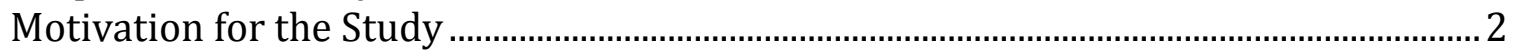

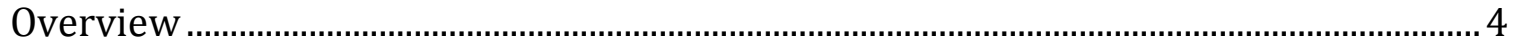

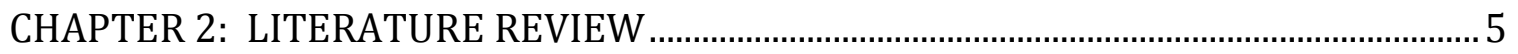

Collaboration in the L2 Classroom ..................................................................................... 5

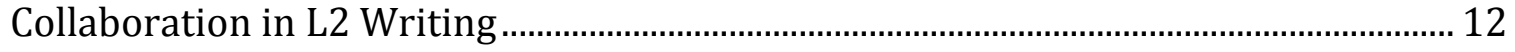

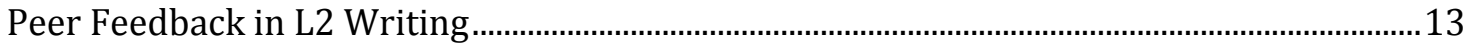

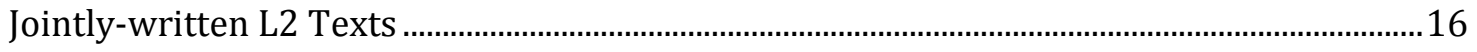

Defining the Developmental Measures of CAF........................................................................17

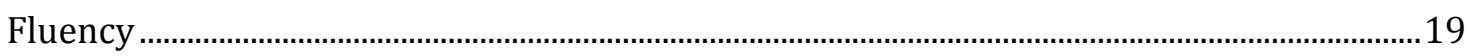

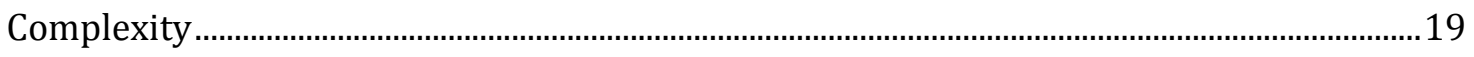

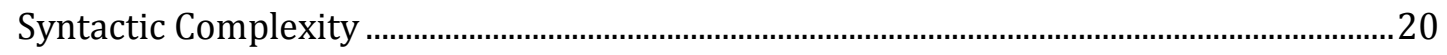

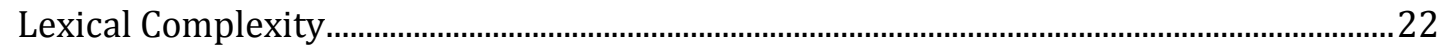

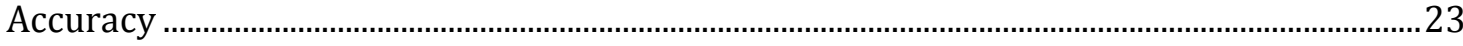

Learner Perceptions of Collaborative Writing Activities ................................................................30

Wikis: Background and Use for Collaborative Writing ................................................... 31

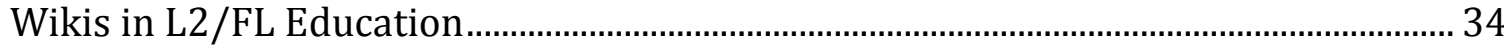

Tasks in Wiki-based Collaborative Writing ……............................................................................

Perceptions of Wiki-based Collaborative Writing.........................................................................36

Product-oriented Collaborative Writing .......................................................................................... 38

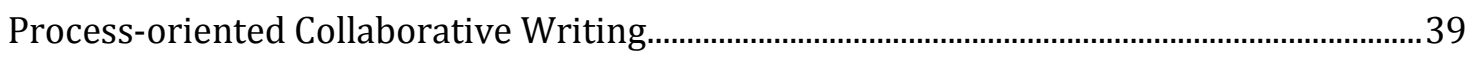

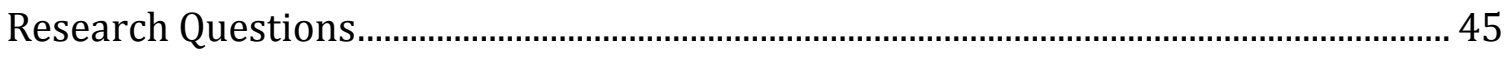

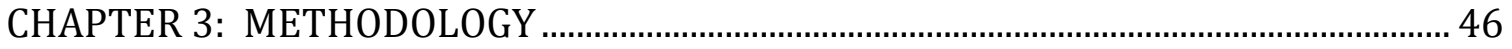

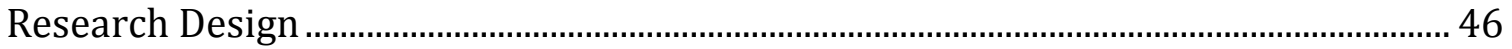

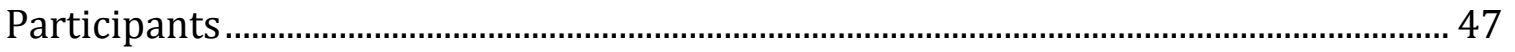

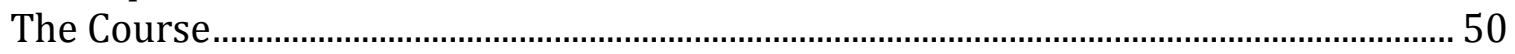

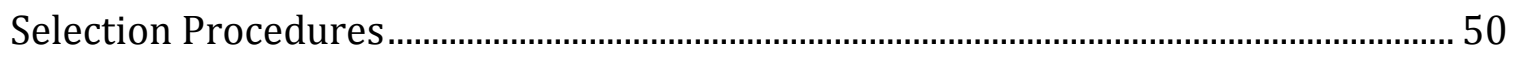

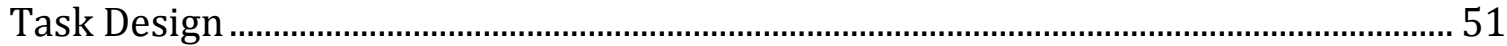

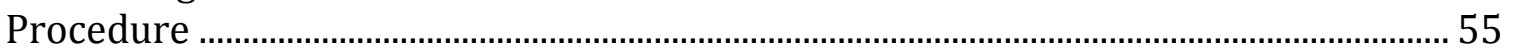

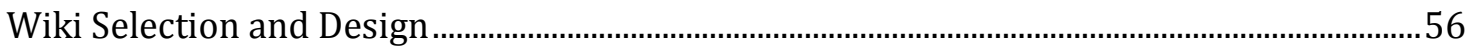




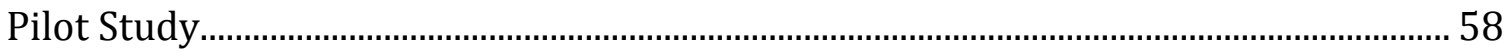

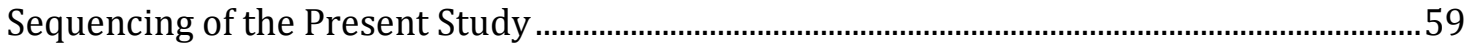

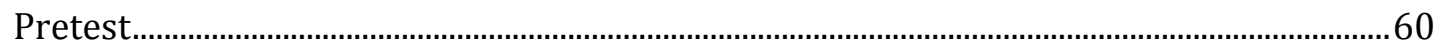

Orientation/Wiki Training Session .....................................................................................61

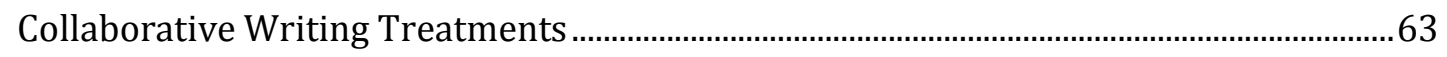

Participant Attendance ......................................................................................................................65

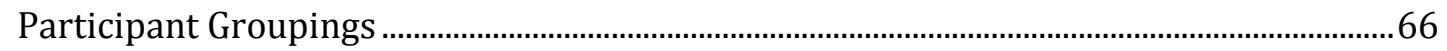

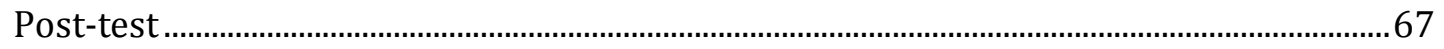

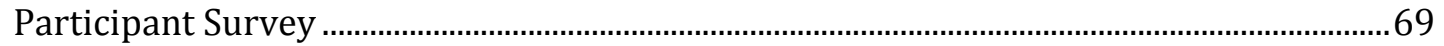

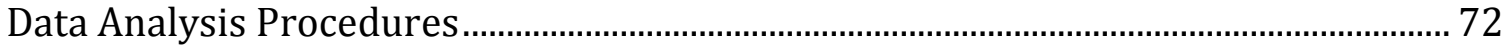

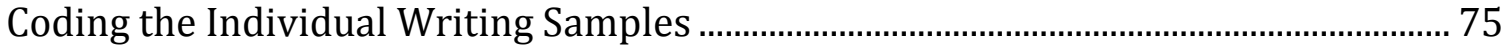

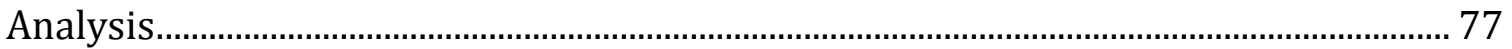

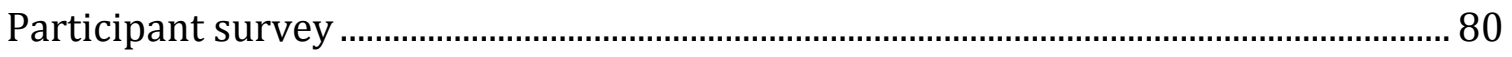

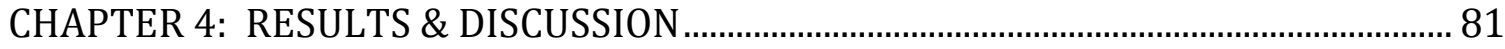

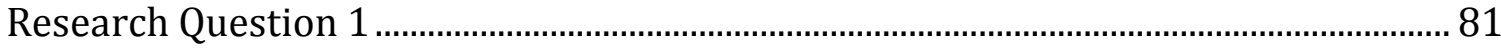

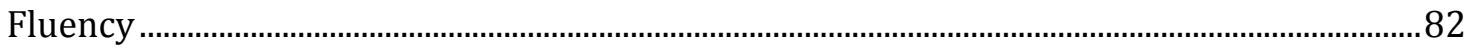

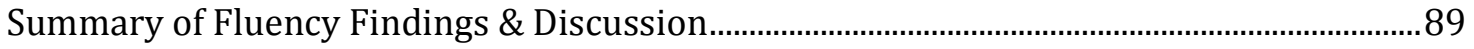

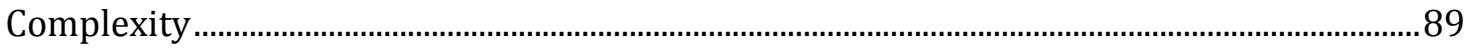

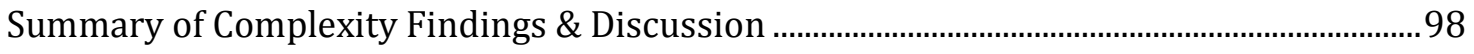

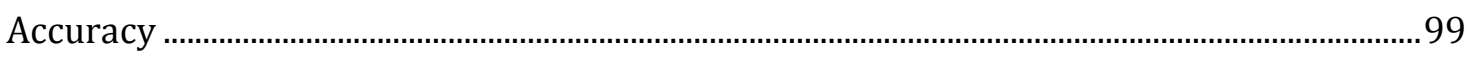

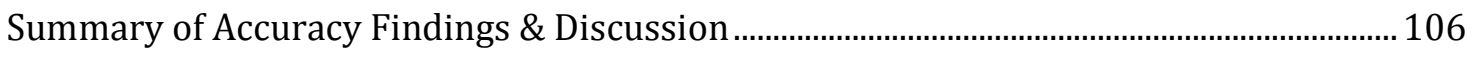

Summary of Findings \& Discussion for Research Question 1......................................106

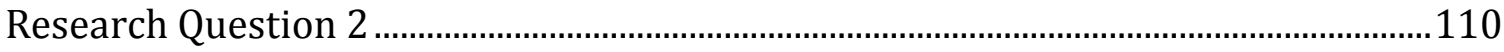

Summary of results pertaining to research question 2 ..............................................114

Conclusion of results and discussion ........................................................................114

CHAPTER 5: CONCLUSION ...........................................................................................116

Summary of Findings ……………………………………………………………....116

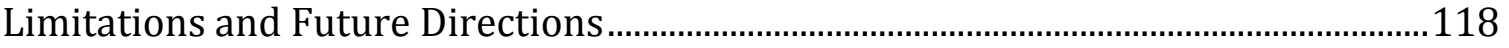

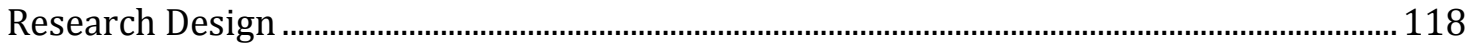

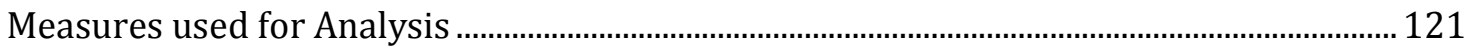

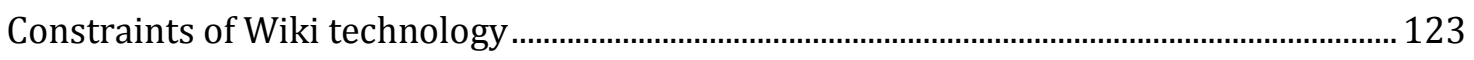

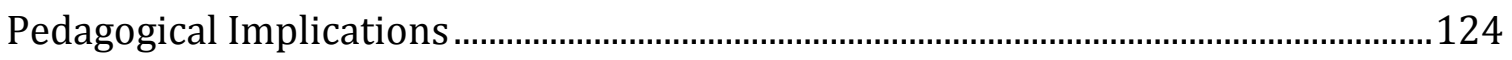

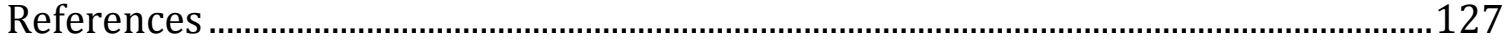

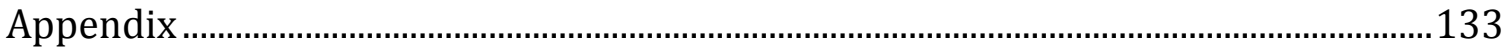

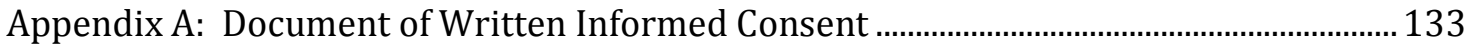

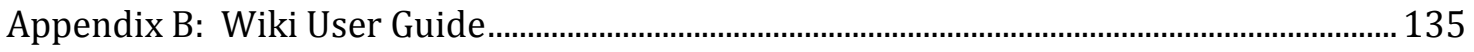

Appendix C: Lesson Plan for Orientation and Collaborative Writing Treatment 1...........144 
Appendix D: A Sampling of Screen Captures from Treatment 1

Appendix E: Lesson Plan and Sampling of Screen Captures for Collaborative Writing Treatment 2

Appendix F: Lesson Plan and Sampling of Screen Captures for Collaborative Writing Treatment 3

Appendix G: Lesson Plan and Sampling of Screen Captures for Collaborative Writing Treatment 4

Appendix H: Practice Exercises-Connecting Ideas and Transitioning for Collaborative Writing Treatment 4

Appendix I: Practice Exercises-Using Vocabulary for Giving Opinions and Connecting Ideas for Collaborative Writing Treatment 4

Appendix K: Writing the Independent Response-Guiding Hand-out for Collaborative Writing Treatment 5

Appendix L: Items for Control Group Participant Survey. 170

Appendix M: Items for Experimental Group Participant Survey ... 171

Appendix N: Guidelines for Coding and Quantifying Textual Features 


\section{LIST OF TABLES}

Table 1: Research Design of the Present Study............................................................... 47

Table 2: General Information about Participants ........................................................ 49

Table 3: Overview of the TOEFL iBT Independent Writing Task.................................. 52

Table 4: Writing Prompts for the Pre/Posttest Task and Collaborative Writing

Treatments ................................................................................................................... 55

Table 5: Sequencing and Content of Activities and Collaborative Writing Treatments for Experimental Group .................................................................................................. 64

Table 6: Experimental Group Participant Attendance at Treatment Sessions........... 65

Table 7: Pairings of Experimental Group Participants for Wiki-based Collaborative

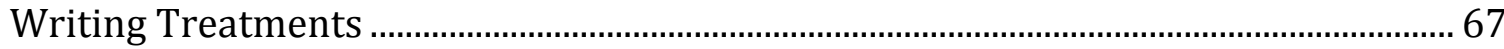

Table 8: Quantitative Measures for Analysis of Pre/Posttest Writing Samples......... 74

Table 9: Descriptive Statistics for Averaged Scores on Fluency Measures by Group

Table 10: Results of Wilcoxon Test on Treatment Group Pre and Posttest Fluency Measures. 85

Table 11: Mean Ranks of Treatment and Control Group on Pre and Posttest Fluency

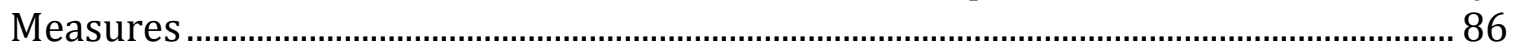

Table 12: Results of Mann-Whitney U Test for Between Group Comparisons on

Fluency Measures.

Table 13: Descriptive Statistics for Averaged Scores on Complexity Measures by

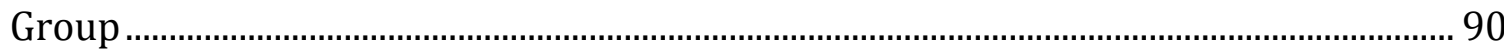

Table 14: Results of Wilcoxon Test on Treatment Group Pre and Posttest

Complexity Measures.

Table 15: Mean Ranks of Treatment and Control Group on Pre and Posttest

Complexity Measures ..................................................................................................... 96

Table 16: Results of Mann-Whitney U Test for Between Group Comparisons on

Complexity Measures.

Table 17: Descriptive Statistics for Averaged Scores on Accuracy Measures by

Group.

Table 18: Results of Wilcoxon Test on Treatment Group Pre and Posttest Accuracy

Measures..

Table 19: Mean Ranks of Treatment and Control Group on Pre and Posttest

Accuracy Measures 102

Table 20: Results of Mann-Whitney U Test for Between Group Comparisons on Accuracy Measures

Table 21: Descriptive Statistics for Averaged Error Type Frequencies by Group .. 104 Table 22: Summary of Statistical Findings for each Linguistic Dimension by Group

Table 23: Mean Scores of Exit Survey on Perceptions of Wiki-based Collaborative Writing 


\section{LIST OF FIGURES}

Figure 1: A Screen Capture of the Wiki Main Page ............................................................... 57 


\section{CHAPTER 1: INTRODUCTION}

\section{Purpose of the Study}

My thesis research study addresses the central question of how to utilize technology tools to develop second language (L2) learners' writing ability. The historical context behind this study can be traced through three major bodies of literature including collaboration in the L2 classroom, collaboration in L2 writing, and wikis in L2 and foreign language (FL) education. Research in the second language context has provided empirical support for the use of group and pair work to foster second language development (Ellis, 2003; Garcia Mayo, 2007; Lantolf, 2000). While much of this early research focused on the benefits of collaborative talk (Donato, 1994; Swain \& Lapkin, 1998), more recently the focus has shifted to writing and exploring how collaboration in written work promotes learner interaction, peer feedback, and rich linguistic experiences (Dobao, 2012; Shehadeh, 2011; Storch, 2013). With the advancement of computer-based technologies, online tools like the wiki - a web-based platform to promote written collaboration - have provided virtual environments to support collaborative writing in the L2 classroom (Arnold, Ducate, \& Kost, 2009; Elola \& Oskoz, 2010; Kessler, 2009; Kessler \& Bikowski, 2010; Lee, 2010). Thus from a sociocultural perspective, collaborative writing in a wiki can help engage students in task-based activities and promote peer feedback and scaffolding (Arnold \& Ducate, 2011).

Since research supports the benefits of collaborative writing for co-authored L2 texts (Dobao, 2012; Storch \& Wigglesworth, 2007; Wigglesworth \& Storch, 2009) 
and the wiki provides an environment to facilitate written collaboration (Lafford \& Lafford, 2005), one might wonder whether collaborative writing in a wiki might also have benefits for the individual L2 writer. The main goal of the present study is to explore that possibility.

\section{Motivation for the Study}

Although my focus on this particular area of research began developing about two years ago, my interest in technology enhanced language learning dates back much further. While teaching English to high school students in Korea, I realized what an important role technology played in these learners' lives. The little free time they had outside of class they almost always spent in Internet cafes around the city, absorbed in massively multiplayer online games (MMOG) where they could simultaneously interact with other players around the world. I frequently heard my students gossiping about netizens (i.e., avid and habitual Internet users), usergenerated content on the web, and social networking sites. It became very clear to me that students were using technology to mediate their communication and interaction with the world around them. Thus I began to wonder how I, as their English teacher, might design lessons and deliver instruction that incorporated the technology they were all so familiar with and inherently attached to. Little did I know there was an ever-evolving body of theoretically sound, empirical literature just waiting for me to explore. 
My desire to further explore the field of second language learning and teaching brought me to graduate school at Portland State University (PSU). During the winter term of 2012 I was enrolled in the Computer Assisted Language Learning (CALL) course as part of the MATESOL program in the Department of Applied Linguistics. It was there in Dr. Nike Arnold's class that I found many answers to the questions I had been pondering as I struggled to engage my tech-savvy Korean students. I learned about the many applications of the computer in language teaching and learning and how these were connected to pedagogical principles and theories of second language acquisition.

As I began to explore the field of CALL through engagement with the research and its classroom applications, I became increasingly interested in CALL's ability to enhance second language writing instruction. More specifically, I was intrigued by the educational potential of the wiki and thus decided to dedicate my thesis work to investigating the impact of wiki-based collaborative writing activities on the individual development of L2 writers. Based on my interest in teaching English for academic purposes (EAP) and preparing learners for high stakes tests such as TOEFL iBT, I chose to explore the wiki's affordances for this particular learner profile. In order to incorporate the elements of EAP and TOEFL preparation, I designed collaborative writing treatment tasks that focused on the rhetorical style of argumentation central to the TOEFL iBT independent writing task. 


\section{Overview}

In chapter 2, I present a review of the relevant literature on collaboration in the L2 classroom, collaboration in L2 writing, and wiki-based collaborative writing in L2 contexts. This allows me to position the present study within the larger bodies of research and create a space for my investigation. Chapter 3 includes the detailed methodology of task design, data collection and data analysis procedures. In chapter 4, I present and discuss the results of both quantitative and qualitative analyses. I end with a conclusion chapter where I discuss the pedagogical implications and limitations of the present study, as well as offer suggestions for future research. The appendices include detailed descriptions of each wiki-based collaborative writing treatment session, step-by-step instructions for administering the treatments and creating wiki pages, the participant perception survey, and the detailed guidelines for coding and quantifying textual features in the compositions, so that other researchers can readily replicate this study. 


\section{CHAPTER 2: LITERATURE REVIEW}

A prerequisite to the investigation into the impact of wiki-based collaborative writing on second language (L2) learners' individual writing development is a discussion of three bodies of research literature: collaboration in the L2 classroom, collaboration in L2 writing, and the use of wikis in L2 and foreign language (FL) education. The literature review begins by situating the concept of peer interaction in the language learning classroom within a sociocultural framework. Narrowing the context to collaboration in L2 writing, the concepts of peer feedback, jointly-written L2 texts, and learner perceptions of collaborative writing activities are presented and discussed in light of empirical findings. Finally, a descriptive examination of the research literature surrounding wikis and their uses, affordances, and potential challenges in L2 and FL education situates the present study and makes a case for further investigation into the potential impact of wiki-based collaborative writing treatments on individual L2 writers' linguistic development.

\section{Collaboration in the L2 Classroom}

Current trends in communicative language learning and teaching emphasize the centrality of pair and group work in the classroom. Strongly supported by theoretical underpinnings as well as pedagogical research, the use of small group and pair activities has become increasingly common in a variety of language learning contexts across the globe. Grounded in a sociocultural perspective of 
language acquisition and learning originally based on the work of Vygotsky (1978), cognitive and linguistic development are seen as emerging from social interaction (Lantolf, 2000). More specifically, the interaction of second language (L2) learners with other speakers and users of the language can create supportive conditions which enable these individuals to participate in communicative exchanges and negotiations that extend their current linguistics skills and knowledge to higher levels of competence (Gass \& Varonis, 1994; Long \& Porter, 1985). That is, according to Vygotsky (1978), the assistance and guidance, including the language provided by more capable peers, can help stretch the cognitive and linguistic development of novice peers beyond their current level and toward their potential linguistic level. This metaphorical venue where the stretching of learners' cognitive and linguistic development occurs is the zone of proximal development, or ZPD (Vygotsky, 1978, p. 86). It is here that, with sustained practice and time, learners can internalize the linguistic functions of their peers, and eventually perform them individually. In a language learning context, this assistance provided by either a teacher or peer has come to be referred to as scaffolding (Donato, 1994; Van Lier, 1988).

When scaffolding occurs between peers, it is generally realized by the processes of collaboration and cooperation. These terms are often defined synonymously, yet some researchers make a clear distinction between the constructs with regard to the degree of labor division. For example, Roschelle \& Teasley (1995) define collaboration as "a coordinated, synchronous activity that is 
the result of a continued attempt to construct and maintain a shared conception of a problem" (p. 70). That is, learners work together in small groups or pairs taking joint responsibility for the creation of a product from start to finish. Cooperation on the other hand, as defined by Dillenbourg (1999), involves partners dividing the work, individually solving sub-tasks, and then assembling the parts into the final product. Regardless of the process employed by learners in the L2 classroom, both have shown to be advantageous for language learning.

A large body of research to date emphasizes the use of both cooperative and collaborative tasks in the L2 classroom to further the processes of learner engagement and peer scaffolding (Batstone, 2010; Donato, 1994; Ellis, 2003; Lantolf, 2000; Swain \& Lapkin, 1998). Tasks are "activities that call for primarily meaningfocused language use" (Ellis, 2003, p. 3) and promote both language production and interaction among learners. The aforementioned L2 researchers working within a sociocultural framework have focused primarily on investigating the effects of this peer interaction on language development, where a high degree of mutuality exists between the participants engaged in the tasks. Most studies have looked at how learners of relatively similar proficiency levels scaffold one another throughout the learning process and execution of the task. Swain (2000) emphasized the importance of collaborative dialogue, or "dialogue that constructs linguistic knowledge" (p.97) in promoting L2 development. Dialogue of this type involves a blending of cognitive and social activity where language use mediates language learning. Thus, Swain concluded that tasks which encourage learners to reflect on 
language form while still orienting toward meaning making, are useful for L2 development.

Donato's landmark study (1994) looked at the use of tasks to facilitate supportive interactions and collaborative dialogues between language learners. Specifically, the research aimed to examine how social interactions among peers in the classroom can developmentally influence their language systems and lead to the appropriation of linguistic knowledge by individuals. Transcripts of one hour oral interactions between three participants, who assumed collective responsibility for the planning and presentation of a skit, were analyzed to determine the degree to which collective scaffolding afforded individual learners opportunities for linguistic development. Results revealed that 24 of the 32 structures discussed during the peer scaffolding were observed in the subsequent output of individual learners when the assistance was no longer available. Thus, Donato concluded that the process of peer scaffolding can contribute to the expansion of individual L2 knowledge while simultaneously boosting the linguistic development of other peers involved.

In light of Donato's promising findings, numerous other studies have investigated the use of collaborative dialogues to facilitate the co-construction of linguistic knowledge (Anton \& DiCamilla, 1998; Kim, 2008; Ohta, 1997; Storch, 1999). Ohta (1997), for example, examined how social interactions of L2 learners provide assistance as well as facilitate internalization processes which lead to L2 
development. Focusing on oral production and accurate use of grammatical constructions, her study revealed that through collaborative and individual activity, one participant was able to use new structures independently, albeit in a limited context. Similarly, Storch (1999) found the use of collaborative tasks to have a positive impact on the overall grammatical accuracy of intermediate to advanced L2 proficiency level university students. However, unlike Ohta (1997), who focused on learners' oral output, Storch examined students' collaborative and individual written production of language in the form of three grammar-focused tasks (i.e., a cloze exercise, a text reconstruction and a short composition). In all three language exercises, Storch found that texts completed in pairs were more grammatically accurate overall as opposed to those texts produced individually. That is, when learners worked collaboratively, their writing contained a lower average number of errors and a greater proportion of error-free clauses than when they wrote individually. These findings provide some degree of support for the benefits of collaborative dialogs and joint tasks in the L2 classroom on overall linguistic accuracy.

Narrowing the focus from linguistic accuracy in general, Kim (2008) investigated the impact of collaborative pair and group work on the acquisition of L2 vocabulary in particular. Through examination of learner-learner collaborative dialogues and think-aloud protocols, Kim identified the occurrence and resolution of lexical language-related episodes, or LREs. LREs, defined by Swain \& Lapkin (1998), include "any part of a dialogue where the students talk about the language they are 
producing, question their language use, or correct themselves or others" (p. 326). Additionally, Kim used a repeated measures research design to determine the effects of a collaborative dictogloss task on learners' L2 vocabulary acquisition. Through the analysis of transcribed collaborative dialogues and think-aloudprotocols, Kim found that while the number of lexical LREs for students working collaboratively and individually was similar, those learners who participated in the collaborative tasks performed significantly better on immediate and delayed vocabulary post-tests than those who worked individually. Thus, Kim's (2008) study made a case for the use of group work to promote second language vocabulary acquisition.

Anton \& DiCamilla (1998) took a slightly different approach to examining the impact of collaborative dialogue on language development and looked at the influence of first language (L1) collaborative speech on L2 written discourse. Their research did not aim to identify linguistic gains through textual analysis, but rather sought to find pedagogical support for the use of L1 and collaboration as powerful learning tools. Based on analysis of collaborative dialogues between participants who discussed the composition of L2 texts, Anton \& DiCamilla concluded that the use of L1 mediated the activity in several ways, including the maintenance of learners' engagement and focus, the development of task management strategies, and the provision of access to L2 linguistic forms through evaluation and meaningmaking. 
Recognizing the potential benefits of both L1 and L2 collaborative dialogue for language learning, Swain \& Lapkin (1998) investigated the use of such dialogues in the process of peer co-construction of written stories. Contrary to previous research, yet aligned with the aim of the present study, the researchers were not only interested in the nature of the dialogues, but the relationship between peer interaction and individual performance. Drawing on the findings of Donato (1994), Swain and Lapkin (1998) sought to determine whether or not collaborative tasks influence the developing language systems of the individuals involved. Similar to the research design of the current study, Swain and Lapkin conducted pre- and posttests, as well as a collaborative treatment. This treatment involved a pair jigsaw task where learners jointly developed a written story line. While the pre- and posttests were completed individually and used measures of grammatical accuracy, grammaticality judgment, and lexical knowledge, the jigsaw task was used to facilitate collaborative dialogue and language-related episodes (LREs) among participants. These LREs, where students talked about, questioned, or corrected the use of their own as well as others' language, were seen to positively influence L2 written discourse. Moreover, similar to the findings of Kim (2008), analysis revealed a significant, positive correlation between post-test scores and the number of LREs, suggesting that linguistic knowledge gained from these LREs can perhaps be internalized and self-regulated by individuals who adopt it as their own.

The previous research reviewed here on collaboration in the language learning classroom indicates that from both theoretical and pedagogical 
perspectives, language-mediated cognitive activities promoting interaction and collaboration between learners serve to facilitate the co-construction of linguistic knowledge and foster language development. While many of these studies have focused on the benefits of peer scaffolding and group work for L2 spoken discourse, research investigating the effects of peer collaboration on the development of L2 writing is limited. Thus, in light of this paucity, my thesis research study attempts to extend the affordances of collaborative writing to the individual L2 writer. As I will illustrate in the section below, there is a somewhat scant but currently evolving body of literature on collaborative writing in the L2 classroom.

\section{Collaboration in L2 Writing}

Previous research supported by sociocultural perspectives on L2 acquisition has clearly indicated the benefits of interaction and peer collaboration in the language learning classroom. Although Swain \& Lapkin (1998) and Anton \& DiCamilla (1998) found promising evidence to support the positive impact of collaborative dialogues on L2 writing, until recently, few studies had explored the use of collaborative writing as a pedagogical strategy to foster the process of language development. To date, literature concerning the use of group and pair work in L2 writing has looked at the topic from various perspectives. One strand of research has looked at peer interaction and group feedback primarily during the revision process, whereas another has examined learner interaction and collaboration throughout the entire writing process. Meanwhile, yet another trend 
in the research literature involved the investigation of learner perceptions of collaborative writing activities. While much of the research surrounding these jointly written texts has progressed in the direction of measuring the effects collaborative efforts have on single pieces of L2 writing, none to my knowledge have assessed the potential short-term effects on individuals' writing development. In this section of the literature review, I will discuss the previous research on collaborative writing in the L2 and illustrate that there is a need for future research to fill the existing gaps.

\section{Peer Feedback in L2 Writing}

Multiple studies investigating the use of group and pair work in L2 writing have focused mainly on the dimension of peer feedback and what impact learner interaction during the revision process may have on the final versions of individually written texts (e.g., Connor \& Asenavage, 1994; Leki, 1990b; Nelson \& Murphy, 1993; Storch, 2002; Villamil \& De Guerrero, 1998; Zhu, 2001). Nelson \& Murphy (1993) investigated whether or not L2 students incorporated the feedback provided by their peers into their individual writing. The researchers organized peer response groups of four members each, where participants exchanged weekly drafts of their writing, made comments and suggestions to their peers, and discussed the feedback orally. Revisions, however, were conducted individually and outside of the classroom setting. Through analysis of final drafts, Nelson and Murphy found that while writers composing texts in the L2 did indeed use their peers' comments in the revision process, they did so inconsistently. Analysis of the 
transcribed verbal interactions among peers in their response groups helped inform the researchers about potential explanations for these revision inconsistencies. While the quality of peers' suggestions did not factor into the explanation, Nelson and Murphy concluded that the degree to which the students heeded suggestions of their peers depended on the nature of the interaction; cooperative or defensive. Cooperative interactions were characterized by participants' negotiation and constructive engagement in the discussion whereas defensive interactions revealed expressions of disagreement or justification. The findings suggested that cooperative interactions were more likely to facilitate the incorporation of peer feedback into individual writing, thus making a case for the potential impact of interactional dynamics on peer review processes.

In a similar vein, Storch (2002) examined various patterns of didactic interaction and the impact the nature of the interaction had on L2 development outcomes over time. In a class focused on academic writing and grammatical structures, students' worked in pairs to complete three tasks including a composition, an editing task, and a text reconstruction. Data analysis revealed that while learners were able to scaffold each others' performance when working in pairs, collaborative or expert/novice interactional patterns were more likely than other interactional dynamics to facilitate such scaffolding. Furthermore, with respect to L2 development, a comparison of pre- and post-test results from the editing task proved inconclusive. 
While findings from Nelson \& Murphy's (1993) study helped to support the importance of meaningful and constructive interaction between L2 learners during the writing revision process, considering that compositions were written and revised individually, and no joint responsibility was taken for their creation, construction, or revision, makes it difficult to classify this type of writing as collaborative. Moreover, the researchers did not look at whether or not the incorporated feedback affected the quality of the text. In an attempt to answer exactly this question, Villamil \& De Guerrero (1998) explored the impact of peer revision on L2 writing. Although the composition and final revision processes were conducted individually, peers interacted during two revision sessions where they provided assistance to one another in the form of oral discussions and written commentary. The researchers characterized revision sessions as joint efforts between writers who were able to advance in their respective zones of proximal development and produce final written drafts reflecting a higher level of achievement. Achievement was measured by the number of textual trouble sources revised during the interaction and subsequently incorporated into the final versions. Although Villamil \& DeGuerrero contend that peer assistance had a substantial impact on revising, some of the revisions included instances of false repair, or incorrect suggestions and solutions. While the researchers suggested that false repairs be viewed as potential opportunities for language growth, they acknowledged the fact that this is merely tentative and recommended future research take the direction of testing independent performance on writing tasks 
following peer interaction. The present study aims to explore this avenue of research.

\section{Jointly-written L2 Texts}

Building on the research suggesting that peer interaction and group feedback positively impact individual's L2 writing revisions, a number of studies have taken to investigating the effects learner collaboration has on the quality of jointly written texts (e.g., Dobao, 2012; Shehadeh, 2011; Storch, 1999, 2005, 2007; Storch \& Wigglesworth, 2007; Wigglesworth \& Storch, 2009). This body of literature has focused primarily on comparing the products of individual writing to those of pair writing. Additionally, many of these studies concerning co-authored texts investigated the interaction of pairs throughout the writing process as well as their approaches to the task. Before discussing the findings of these studies, it's important to understand the methods that previous researchers have used to evaluate and compare the final products of individually written texts to those written collaboratively.

Many L2 researchers have used the constructs of accuracy, fluency, and complexity, as dependent variables to measure both linguistic development and proficiency in SLA (Foster \& Skehan, 1998; Foster et al., 2000; Housen \& Folkert, 2009; Larsen-Freeman, 2006, 2009; Pallotti, 2009). These measures have been considered indicators of language development since they are not typically monitored consciously by the learner, nor are they necessarily tied to specific linguistic structures 
(Wolfe-Quintero et al, 1998). When it comes to second language writing in particular, the triad of developmental measures has been a useful research tool for evaluating the effects of a pedagogical intervention or treatment on the development of grammar, writing ability, or both; the effects of task design on L2 writing; and to assess differences in L2 texts composed by learners working under various conditions, across proficiency levels, or longitudinally (Ortega, 2003).

Given that many L2 studies employing the three constructs as research variables have tended to define them rather vaguely, they have been used and interpreted with various meanings across studies. Thus, despite the fact that a number of large-scale research syntheses have been conducted to inform about the most appropriate and useful analysis measures to quantify textual features and assess L2 writing in particular (Norris \& Ortega, 2009; Ortega, 2003; Polio, 1997; Wolfe-Quintero et al, 1998), the empirical findings have been somewhat inconsistent (Norris \& Ortega, 2009). What follows is a definition of each of construct as it has been interpreted and used in previous empirical research literature. A review of these interpretations will help to frame the analysis measures chosen for the present study.

\section{Defining the Developmental Measures of CAF}

The three notions of complexity, accuracy, and fluency came about shortly following the birth of the field of second language acquisition (Larsen-Freeman, 2009). Researchers, in an attempt to find an alternative to standardized proficiency 
tests for gauging second language development, began a quest to construct a developmental index for SLA (Hakuta, 1976; Larsen-Freeman, 1978). LarsenFreeman began by looking at Hunt's (1970) research which aimed to track the linguistic development of L1 writers. Hunt proposed the construct of a T-unit, or minimal terminable unit which he contended was the "shortest unit into which a piece of discourse could be cut without leaving any sentence fragments as residue" (Hunt, 1970, p. 737). In other words, the T-unit was defined by Hunt as "one main clause plus whatever subordinate clauses are attached to that main clause" (Hunt, 1970, p. 737). He argued that T-units, as opposed to sentence length, were a more suitable unit of analysis given that children writing in their native language could and would write long sentences relying entirely on coordination (Larsen-Freeman, 2009). Throughout the next 20 years, a plethora of studies followed suit in attempts to devise an index of metrics that could be used to capture second language development.

Before turning to the discussion of construct definition, I will briefly address the broader issue of validity when it comes to the measures of CAF. When attempting to identify the 'best' measures of language performance, Wolfe-Quintero et al., (1998), in their research synthesis examining more than 100 linguistic developmental measures, contend that best measures are typically those that most clearly show variance among subjects. This variance should be apparent both over time and across tasks, and should exhibit correlation with other equally varying measures. However, they note that even if measures fail to show any difference 
among groups, it does not mean they are invalid or uninformative. Rather, research should be equally concerned with observing constants and similarities among groups following an experimental treatment (Wolfe-Quintero et al, 1998). Finally, they conclude that for a measure to be valid, adequate representation of its underlying construct is more important than variance across subjects. With this in mind, I now turn to the issue of defining the constructs of complexity, accuracy, and fluency.

\section{Fluency}

Foster \& Skehan (1996) define fluency as the "processing of language in real time" (p. 304) but this may be problematic as rapidity is not the only construct included but rather coherence, appropriateness, and creativity. In a narrower sense, Lennon (1990) used the term fluency to mean only rate and length of output. Similarly, in their vast research synthesis of developmental index studies, WolfeQuintero et al. (1998) found that fluency ratios were much more successful than frequencies at indicating language development. Thus, the researchers support Lennon (1990) and restrict their understanding of the measure to issues of rate and length. That is to say that the more words or structures that an L2 writer can access in a limited time is indicative of their fluency in the second language.

\section{Complexity}

Complexity refers to the degree of variance and sophistication in the structures and vocabulary used by the L2 writer (Foster \& Skehan, 1996; Ortega, 
2003; Wolfe-Quintero et al., 1998). That is, complexity can be measured both lexically and syntactically. This multidimensionality of complexity is important to note, especially as it is applied to various aspects of language production. In the past, researchers have distinguished between both lexical and grammatical complexity, each of which has its own sub-constructs within syntactic complexity (Norris \& Ortega, 2009). In the subsequent two sections, I briefly examine each of these sub-constructs to establish working definitions for the present study.

\section{Syntactic Complexity}

Previous research literature indicates that syntactic complexity can be measured in a multitude of ways. However, from the perspectives of both computation and interpretation, none of the complexity measures is unproblematic (Housen \& Kuiken, 2009). While most measures have quantified length of production units (clauses, sentences, T-units), amount of subordination or embedding, amount of coordination, or degree of sophistication (Ortega, 2003), operationalization of these production units remains ambiguous, particularly the clause. For some researchers, a clause is defined by the presence of a subject and a finite verb (Hunt, 1965; Polio, 1997) and for others, non-finite verbs may also head a clause, provided that an additional clause element is present (Foster et al., 2000). In terms of measurement, Wolfe-Quintero et al., (1998) point out that "ratio measures, in which the presence of one type of unit is expressed as a percentage of another type of unit, or one type of unit is divided by the total number of comparable units," (p. 10) have shown to be more valid than frequency counts since 
frequency counts vary as a function of the amount of time allotted to the writer or the nature of the task.

Ortega's (2003) synthesis of $21 \mathrm{~L} 2$ writing studies found six metrics most frequently used to quantify syntactic complexity. These included three length of production measures (mean length of sentence, mean length of T-unit, and mean length of clause), one degree of coordination measure (mean number of T-units per sentence) and two measures concerning the amount of subordination (mean number of clauses per T-unit and mean number of dependent clauses per clause). Norris \& Ortega (2009) indicate that in early stages of L2 development, syntactic complexity is initially established through coordination and thus, with lower proficiency L2 learners, a metric such as Bardovi-Harlig's (1992) coordination index may be more revealing of linguistic complexity. On the other hand, in more advanced stages of development, syntactic complexity may be most realized through increased complexity at the phrasal level. Therefore, when measuring the syntactic complexity of intermediate or advanced proficiency L2 learners, choosing a metric such as mean length of clause is able to better capture complexity at the phrasal level (Norris \& Ortega, 2009).

Norris \& Ortega's (2009) exemplary treatment of syntactic complexity provides empirical support for the multidimensional measurement of the construct. Given the variety of distinctly measurable sub-constructs of complexity, they argue for researchers to select multiple metrics which are complementary as opposed to 
redundant. That is, CAF researchers, when examining grammatical complexity should be aware of which measures tap into which dimensions of the construct.

\section{Lexical Complexity}

Lexical complexity is apparent in writing primarily in the forms of range (lexical variation) and size (lexical sophistication) (Wolfe-Quintero et al, 1998). Therefore L2 learners who can access a wide variety of both basic and sophisticated words are said to have a more complex vocabulary than those who have only a basic range available. It is however, crucial to distinguish the difference between the notions of lexical complexity and fluency. That is, an analysis of lexical complexity in L2 writing should not be concerned with how many words are present, but rather the degree of variance and sophistication of the words that are.

Measures of lexical richness have been of interest to L2 researchers primarily because they help distinguish writing quality as well as provide a means to examine the relationship between vocabulary knowledge and use. Most researchers have measured lexical variation in second language writing through type/token ratios. However, as Laufer \& Nation (1995) and Wolfe-Quintero et al., (1998) caution, this measure is sensitive to length and may not be suitable for shorter texts. As an alternative, Laufer \& Nation proposed the Lexical Frequency Profile which measures an individual's productive vocabulary by comparing the words used in a text to the 1000 most frequent words of English, the next 1000 most frequent words, and words on a university word list. Words which appeared on the university word list were considered rich and sophisticated vocabulary. They found the measure to be 
reliable in discriminating between proficiency levels as well as texts of varying length.

The concept of lexical sophistication has become appealing as an indicator of L2 vocabulary development. Following Laufer \& Nation's (1995) comparison of words written to those on a university word list, a web program called VocabProfile was developed to perform automated lexical analyses of texts (Cobb, 2002). This program divides words in a text into four categories including the most frequent 1000 words of English, the second most frequent 1000 words of English, the academic words of English, and the remainder which are not found on other lists. Thus the tool conveniently provides a quantitative profile of the percentages of basic and sophisticated words in a text.

\section{Accuracy}

Accuracy is defined by Foster and Skehan (1996) as "freedom from error" or error-free production (p. 304). Essentially, it refers to the extent to which an L2 individual's oral or written production deviates from the native speaker norm (Pallotti, 2009; Wolfe-Quintero et al, 1998). While conceptually, accuracy may seem simple and easy to define, Pallotti (2009) cautions that the challenge of accuracy measurement lies in its application to L2 data. That is, clearly indicating the criteria used to identify deviation and the degree of an error is essential to the validity and reliability of the calculation method. Unfortunately, previous researchers who have investigated measures of linguistic accuracy have employed a variety of techniques and at the same time failed to discuss them in great detail, making replication or use 
of a particular measure very challenging (Polio, 1997). Given these challenges of determining what exactly constitutes an error, very recently, Housen, Kuiken, \& Vedder (2012) suggested that the "A" in CAF be extended to include appropriateness and acceptability.

An analysis of linguistic accuracy involves the counting of errors in a text. A multitude of CAF studies have approached this by focusing on error-free structural units, whether they be clauses, sentences, or T-units (Wolfe-Quintero et al, 1998). However, this approach has been met with criticism by researchers who point out its failure to recognize not only the number of errors within the structural unit, but also the types of errors involved. In light of these criticisms, a second approach to accuracy measurement has been employed in developmental index studies by Bardovi-Harlig \& Boffman (1989) and Polio (1997). Their approaches were not concerned with strings of error-free production units but rather with the quantity of errors occurring in relation to production units. This type of approach is advantageous in that it reveals and distinguishes between different error types as well as their distribution across the unit of measurement.

Analyses of findings synthesized in Wolfe-Quintero et al. (1998) reveal that the T-unit may not be the best in capturing short-term changes in accuracy since it has shown to correlate more with holistic ratings. Instead, Bardovi-Harlig \& Bofman (1989) proposed the use of clauses as opposed to T-units as the basic measure of error analysis. The researchers contended that using the clause as the production 
unit for accuracy eliminated complexity as a factor considering that an essay could contain a multitude of error-free T-units made up of very simplistic sentences (Polio, 1997).

Based on the literature discussed in the previous section, it's clear that researchers have used a variety of measures to capture linguistic performance with regard to the constructs of fluency, accuracy, and complexity, which makes it difficult to compare the findings. This is something to keep in mind as the forthcoming empirical studies are reviewed.

I now return to a discussion of the research literature which has compared individually and collaboratively written compositions. To begin, Storch (2005) for example compared the linguistic accuracy, fluency, and complexity of participants' individually and collaboratively written responses to graphic prompts. The analysis measures revealed that written texts composed by pairs were more accurate in terms of the proportion of error free clauses to total clauses than those composed individually. Moreover, despite the fact that pairs produced shorter texts than individuals, they tended to write with more complexity, as measured by the length in words of T-units, the ratio of clauses to T-units, and the percentage of dependent clauses in the entire text. While no statistically significant differences were found between the learners who worked independently and those who worked in pairs, Storch emphasized that the quantitative findings were merely suggestive given the small sample size of 23 participants. In addition to the 
linguistic developmental measures, Storch qualitatively analyzed transcripts of the pair dialogues that ensued throughout the collaborative writing process. This analysis revealed instances of collective scaffolding as learners combined their linguistic resources to negotiate more grammatically accurate compositions. Additionally, analysis of time spent on the different phases of writing indicated that pairs spent the most time generating ideas and giving and receiving immediate feedback on language. Furthermore, it was shown that pairs took longer to complete the writing tasks than individuals. These findings serve as important pedagogical considerations for future applications of L2 collaborative writing instruction.

In a similar study, Storch \& Wigglesworth (2007) again compared the writing produced by learners working in pairs with that of learners working individually on two tasks: a graphic commentary and an argumentative essay. Employing the triad of developmental index measures, the researchers randomly selected and analyzed six texts (approximately $12.5 \%$ of the entire data set). Comparing the quantitative analyses of individually and jointly written texts, they found no differences on any of the measures of fluency (number of words per text, number of T-units per text, number of clauses per text, and number of words per T-unit). This finding was unlike the earlier study of Storch (2005) who found pair texts to be shorter than individual texts. Yet, similar to Storch (2005), the measures for complexity exhibited no significant differences between jointly written and individually written texts. In terms of accuracy, however, the pairs produced more error-free T-units 
and more error-free clauses than the individuals. Qualitative analysis showed that unlike Storch (2005), participants spent the most time working on the composition phase of writing, and LREs generated by collaborative interaction tended to focus on lexical and grammatical issues. One could speculate that this difference might be attributed to the nature of argumentative essay tasks versus the graphic prompts used in Storch (2005).

In yet another study based on the same data from Storch \& Wigglesworth (2007), Wigglesworth \& Storch (2009) again compared the writings of participants working individually and in pairs on argumentative essays under timed conditions. Informed by the previous research of Storch (2005), pairs were given more time to compose the text than individuals. Quantitative analyses revealed that while collaboration during the writing process positively impacted the linguistic accuracy of pairs' texts, the variables of fluency and syntactic complexity were not significantly affected. Analyses of the LREs that emerged from the collaborative dialogues during text co-construction revealed the nature of the participants' approach to the task. Similar to Storch \& Wigglesworth (2007), it appeared that pairs spent most of their time in the composition phase (77\%) as opposed to planning (15\%) and revising (7\%). Thus, Wigglesworth and Storch concluded that collaboration during the writing process itself afforded learners opportunities to discuss various dimensions of the text, and in particular, engender ideas related to content. 
With an aim to extend the scope of collaborative writing research and its benefits from second to foreign language contexts, Shehadeh's (2011) longitudinal study explored the effectiveness of collaborative writing activities on texts produced by first year university students in the United Arab Emirates. Continuing the trend of previous research, the study compared written texts composed individually (control group) to those written collaboratively (experimental group). However, unlike the data analysis methods of these previously mentioned studies, participants' writing in Shehadeh's research was evaluated holistically in five component areas including content, organization, grammar, vocabulary, and mechanics.

Similar to the findings of Storch (2005) and Wigglesworth \& Storch (2009), Shehadeh found that while collaboration had a significant impact on the improvement of students' writing in the L2, the effect varied depending on the specific area of language examined. For example, collaborative writing was shown to positively impact content, organization, and vocabulary, but not grammar or mechanics. In an attempt to speculate a reason for this, the researcher considered the issues of proficiency level as well as the analysis methodology chosen. Given that participants in the study were of low English proficiency levels as measured by their scores on the Common English Proficiency Assessment (CEBA) test, the researcher posited that they may have simply lacked the language ability necessary to assist each other with grammatical accuracy judgments. Concerning the issue of analysis measures, Shehadeh speculated that the holistic grading scale used for 
evaluation may have been too global in nature. That is, choosing a narrower measure of accuracy such as the proportion of error-free clauses to total clauses in the text (used by Storch (2005) and Storch \& Wigglesworth (2007)) may have been more revealing of learners' linguistic development.

While the studies reviewed here until now have looked at collaborative writing tasks completed in pairs, Dobao (2012) examined how the number of participants involved in the collaborative writing task may affect the process and product of co-constructed written discourse. Using the dependent variables of accuracy, fluency, and complexity measures, Dobao compared the performance of identical writing tasks by groups of four learners, pairs, and individual learners. Results showed that individually written texts were considerably longer than those written collaboratively. Similar to the findings of previous studies, collaboration was shown to have a positive influence on linguistic accuracy. However, significantly fewer errors were identified in texts written by small groups than in those composed by pairs, suggesting that the number of participants engaged in the activity may in fact affect the quality of English L2 collaborative writing.

Although collaboration seems well supported theoretically and the findings from previous empirical research studies have shown that collaborative work has the potential to positively influence the written discourse of second and foreign language learners, certainly more research is needed to confirm this. Moreover, future research directions must go beyond the comparison of individually and 
collaboratively written texts and look at how the dynamics of collaborative work can be transferred to the individual English L2 writer's development.

\section{Learner Perceptions of Collaborative Writing Activities}

In addition to comparative studies measuring the linguistic impacts of collaborative writing on L2 texts, another strand of research has aimed to investigate learners' perceptions of these writing activities (e.g., Storch, 2005; Shehadeh, 2011). For example, Storch (2005) interviewed participants upon completion of the pair writing tasks to gain an understanding of their perceptions regarding the activity. Qualitative data analysis of the interviews indicated a positive tone toward the use of group tasks, although some students noted that pair/group work was better suited to oral activities rather than written. Aligned with these findings, students in Shehadeh's (2011) study also expressed positive perceptions about the collaborative writing activities. Some learners commented that the writing tasks also contributed to the improvement of their speaking skills. Additionally, participants commented on how collaborating with their peers helped to foster a positive social atmosphere in the classroom suggesting that collaboration may benefit not only linguistic factors but affective dimensions as well.

The research literature discussed thus far seems to provide tentative pedagogical support for the use of pair and group tasks in the L2 writing classroom. Nevertheless, this relatively small body of research alone cannot suffice to extend firm conclusions about the impact of collaborative writing activities on individuals' 
writing development. Moreover, given the recent and increasingly innovative collaborative opportunities afforded by technological advancements, it is necessary to diversify the scope of research and explore how the use of web based tools, specifically the wiki, might enrich the collaborative writing experience of language learners.

To frame the present study which looks at the potential of wiki-based collaborative writing treatments on individual L2 learners' writing development, the forthcoming section of the literature review scrutinizes the research to date surrounding the use of wikis in second and foreign language education. The body of literature is initially approached from a broad perspective; first providing crucial background information about the educational possibilities of the wiki, and then noting how previous researchers have explored its specific ability to support and enhance collaborative language learning. Finally, the findings of previous studies focusing particularly on collaborative writing in a wiki space are reviewed and a case is built for future research to shed light on one largely unexplored area.

\section{Wikis: Background and Use for Collaborative Writing}

The advancement in social technologies and computer mediated communication (CMC) has prompted recent attention to how web-based tools may be effectively implemented in classroom and educational contexts. One such tool of particular relevance is the wiki. Wiki refers to an asynchronous mode of CMC, defined by Lafford and Lafford (2005) as "collaborative web pages that can be 
edited by anyone visiting the page using basic, simple text editing" (p. 687).

According to Goodwin-Jones (2003), the web-based tool's name originates from the Hawaiian word "wiki-wiki" meaning quick. The primary goal of the wiki is to create a website which functions as an open repository of knowledge that can be continuously updated through user contributions. Additionally, a record of these contributions is kept, thus making the evolution of content in the wiki more salient. A wiki is organized according to content rather than chronology, making it easier to edit. Each wiki page contains an "Edit" function at the top that when clicked on, allows users to immediately initiate modifications to the current content. As well, all wikis are equipped with a page history feature allowing users to view when changes were made, the specifics of those changes, and who made them. Furthermore, all wikis contain a "Discussion" tab which enables contributors to talk about the text they are co-authoring and negotiate meaning and content prior to, during, and following composition. From a pedagogical perspective, the fact that most wikis are free of charge and user-friendly is advantageous. Furthermore, it means that any individual with computer and internet access has the potential to create a virtual environment for a group of choice users to conceive of, create, and subsequently edit and revise written discourse.

Early implementations of wikis in L1 educational contexts have shown how the tool affords users and learners opportunities for negotiation of content, meaning, accuracy, and relevance in a democratic manner (Richardson, 2010). More recently, researchers in L2 contexts have become interested in how wikis may be used to 
promote collaborative writing activities among language learners. Previous studies investigating the interaction of learners in collaborative writing tasks relied on transcribed tape-recorded interactions of student dialogue and the comparison of paper-based texts (e.g., Anton \& DiCamilla, 1998; Shehadeh, 2011; Storch, 2005; Swain \& Lapkin, 1998; Wigglesworth \& Storch, 2009). Contemporary communication technologies like the wiki, however, enable interaction among learners in an online environment where texts can be edited, updated, tracked, and archived for analysis. Additionally, from a sociocultural perspective, facilitating task-based or communicative activities involving negotiation of meaning and peer scaffolding, the wiki can help students engage in more self-directed, collaborative writing, where sharing with and receiving feedback from peers can greatly enhance the L2 writing process and outcomes (e.g., Arnold \& Ducate, 2011; Lafford \& Lafford, 2005).

While previous research has shown the benefits of collaborative writing to promote small group and pair peer review practices (Nelson \& Murphy, 1993; Villamil \& De Guerrero, 1998), contributions in wikis are quite different since rather than simply commenting on specific areas of the text, users have the potential to completely alter and revise the text itself. In this way, texts composed in a wiki are constantly changing as the technology affords larger groups of learners the opportunity to collaborate from initial conception to the final draft. Thus, unlike L2 collaborative writing research focusing on the final text product while the actual process of writing remained private (Nelson \& Murphy, 1993; Villamil \& De 
Guerrero, 1998), wikis allow researchers to carefully examine collaboration throughout the entire writing process. Therefore, aligned with Vygotsky's sociocultural theory of learning, collaborative writing activities in a wiki integrate social, linguistic, and cognitive processes of language learning. Through computer mediated interaction via the wiki discussion board, learners engage in collaborative scaffolding which results in the emergence of a ZPD where individuals combine their linguistic resources to co-construct L2 knowledge.

\section{Wikis in L2/FL Education}

The use of wikis in L2 learning contexts seems theoretically supported, but to date, the body of empirical research surrounding the pedagogical affordances of wikis in both $\mathrm{L} 2$ and foreign language (FL) writing instruction remains limited. However, studies that have been conducted in a wide range of educational contexts with learners of various language proficiency levels have shed light on the wiki's potential to positively influence L2 writing development. A review of the current literature suggests that research surrounding the use of wikis for collaborative writing has focused predominantly on four central themes including: the importance of tasks in wiki-based collaborative writing instruction, perceptions of wiki-based collaborative writing, collaborative writing process, and collaborative writing product. What follows is a discussion of the major empirical findings in light of these four research trends. 


\section{Tasks in Wiki-based Collaborative Writing}

Considering the theoretical and pedagogical support for task-based language learning and instruction (Ellis, 2003, Garcia Mayo, 2007), it is not surprising that a major theme emerging from the literature on wiki-based collaborative writing is the use of tasks. More specifically, researchers have looked at the effects of tasks on collaborative behavior (e.g., Lee, 2010; Lund, 2008; Mak \& Coniam, 2008). Mak \& Coniam (2008) suggested that learners engaging in an authentic task which required a presentational mode of writing for a specific audience (their parents), were prompted to strive for greater creativity than they would have in an ordinary classroom composition. Both Lee (2010) and Lund (2008) emphasized the importance of task design with regard to topic choice and authenticity, noting that the task type greatly impacts the degree of learner interaction and meaningful use of the target language. For example, participants in Lee's (2010) study engaged in four wiki-mediated collaborative writing activities, one of which was composing a letter to a famous newspaper columnist asking for advice. While this task allowed for substantial creativity on behalf of the learners, it also required the use of specific grammatical constructions (i.e. modals, conditional, subjunctive mood) to achieve appropriate social conventions. Lee noted that the multi-dimensional nature of the task not only required learners to focus on both meaning and form, but was a crucial factor influencing the degree of student involvement in the wiki-based collaborative writing project. These findings seem to suggest that the design of tasks is significant for the successful implementation of wikis in collaborative writing activities. Owing 
to the empirical findings and pedagogical recommendations of Lee (2010) and Lund (2008), the current study gives careful consideration to collaborative writing taskdesign in a wiki-mediated environment.

\section{Perceptions of Wiki-based Collaborative Writing}

A second major trend in wiki-based collaborative writing research studies is that of teachers' and learners' perceptions of the activities (e.g., Chao \& Lo, 2009; Elola \& Oskoz, 2010; Kost, 2011; Lee, 2010; Lee \& Wang, 2013; Lund, 2008; Mak \& Coniam, 2008; Woo et al., 2011). In general, like the perception studies of non-wikibased collaborative writing, the tone has been positive. Specifically, these studies have investigated how the educational, social (collaborative), and technological capabilities of the wiki have been perceived by all those involved. For example, young learners (ages 10-11) in Woo et al.'s (2011) study noted that the wiki gave them an opportunity to write in English, share ideas with their peers, and receive feedback about their lexical and grammatical choices. With regard to social benefits, some shy learners thought the wiki allowed them to communicate more freely and without embarrassment. As for the perceived technological advantages, participants cited the ease with which they could amend their writing in a transparent way, and add photos to supplement the text.

Participants have also expressed enjoyment for collaborative teamwork in the wiki (e.g., Kost, 2011; Lee, 2010; Lee \& Wang, 2013; Mak \& Coniam, 2008) with many citing the opportunity to share knowledge and gain multiple perspectives on a 
topic. Additionally, participants in Lee's (2010) study emphasized their satisfaction with writing for a broad audience in the wiki, noting that this factor increased their motivation for learning. Moreover, learner responses to the perception survey suggested that the wiki helped build their confidence in L2 writing, enhance their organizational skills, and promote critical reflection (Lee, 2010, p. 266).

Despite the benefits of wikis perceived in the body of literature, some drawbacks and challenges have also surfaced. Most of these have been related to technical glitches in the wiki, involving issues of formatting. For example, participants in Lund's (2008) study noted difficulties saving their edits in the selected font or color. Additionally, since the wiki does not support synchronous chat, these learners expressed their preference for using another tool, such as messenger, to exchange instant messages while writing collaboratively. This finding was later supported by Lee and Wang (2013) who explored the degree of student engagement in a collaborative wiki project with the aim of identifying factors that facilitate and hinder participation. Based on learner responses to surveys and follow-up interviews, the researchers concluded that the clunky nature of asynchronous computer mediated communication (ACMC) was a major factor inhibiting student engagement in the project.

Finally, while most learners have expressed that collaborative writing in wikis helped them compose better essays in terms of content, structure, and grammar (e.g., Elola \& Oskoz , 2010; Lee, 2010, Woo et al., 2011), some opinions 
appear somewhat divided with regard to the benefits of wikis for grammar improvement. For example, participants in Elola \& Oskoz's (2010) study noted their discomfort in defending their grammatical choices in order to avoid disagreements with their partners. However, this dissatisfaction seems more related to the nature of collaborative work in general rather than specific to collaborative writing in a wiki-based environment.

\section{Product-oriented Collaborative Writing}

A third strand of research on the use of wikis in L2 writing contexts is that of product-oriented collaborative writing. However, contrary to the vast scholarship published on collaborative writing without the wiki, only a small number of studies, with mixed results, have taken this research approach with the aid of the wiki (e.g., Elola \& Oskoz, 2010; Mak \& Coniam, 2008). Mak \& Coniam (2008) for example, used wikis to support the English writing instruction of secondary school students in Hong Kong. The researchers implemented a school project where students collaboratively composed texts in the form of a school brochure for a particular audience. Their results indicated that when writing collaboratively, students produced more text than required by the assignment, as well as writing of increased complexity (as measured by t-unit length). Thus, although preliminary, the researchers addressed the positive impacts of wikis on students' writing product.

Elola \& Oskoz (2010) on the other hand, did not find the collaborative writing product to be superior when comparing wiki-mediated collaborative and 
individual writing composed by advanced learners of L2 Spanish. Participants completed two argumentative essays: the first one collaboratively and the second one individually. While working collaboratively, learners accessed the wiki from multiple sites and interacted via oral and written chat. Essay drafts, questionnaires, wiki drafts and chat logs were collected as data sources for analysis. Using the constructs of accuracy, fluency, and complexity as measured variables, the researchers evaluated and compared linguistic aspects of both collaborative and individual writing. Although they found no statistically significant differences between the individually and collaboratively written products in terms of the three measures, depending on individual or collaborative composition, they noted observable trends in learner behavior with regard to essay structure and organization, as well as approaches to the writing process. For example, the researchers found that learners working collaboratively tended to address structural issues at the onset of the joint work whereas those working alone consistently revisited their essay structure throughout the drafting process. Additionally, participants working individually were inclined to focus on grammar and vocabulary edits in the final drafts while those working collaboratively made adjustments on these aspects over the course of the entire writing process.

\section{Process-oriented Collaborative Writing}

A fourth, and perhaps more dominant trend in the research literature surrounding wikis in L2 writing instruction is a focus on the collaborative writing process. Numerous researchers have approached wikis from a process-oriented 
perspective to text construction (e.g., Arnold, Ducate, \& Kost, 2012; Chao \& Lo, 2011; Kessler, 2009; Kessler \& Bikowski, 2010; Kost, 2011; Lee, 2010; Mak \& Coniam, 2007; Woo, Chu, Ho, \& Li, 2011; Woo, Chu, \& Li, 2013). These studies have focused on trends in collective group behavior as well as individual revising behaviors and informed researchers about the various approaches learners take when engaging in wiki-based collaborative writing.

For example, Lee (2010) explored wiki-mediated collaborative writing in an elementary Spanish language course at the university level and demonstrated how the use of a wiki in L2 writing classes promoted effective social interaction among learners as they engaged in extensive peer scaffolding. Participants in Lee's study shared grammatical knowledge and were able to collectively offer suggestions to their peers. Instances of peer scaffolding were evident in the asynchronous computer mediated communication via the wiki's discussion board. Specifically, students made posts to the page asking their partners about the form of particular structures and their opinions regarding content. Peers then responded to these comments and inquiries, paying attention to form and reflecting on language while collaboratively correcting errors to improve the overall accuracy of the discourse. Despite the promising findings, Lee observed through survey data analysis that more than $40 \%$ of the participants were reluctant to edit their co-participants' entries due to lack of confidence in their own writing. 
As discussed in the previous section, although Elola \& Oskoz's (2010) study did not provide support for the superiority of collaborative writing products in a wiki-mediated environment, it did provide insight into L2 writers' composition processes and revision behaviors. The researchers observed learners interacting via a wiki-space and noted their various approaches to the writing task. Specifically, they found that when working individually, learners tended to focus on grammar in the final stages of revision whereas those working collaboratively did so at various stages throughout the writing process. Mak \& Coniam (2008), Woo et al., (2011), and Woo et al (2013) also examined student revision types in wiki-based writing tasks. Data analyses in all three studies indicated that learners' focus tended to be on content and style, specifically the expanding and reorganizing of text, as opposed to form and accuracy.

Similarly, Kessler's (2009) study also reported students' lack of attention to language form when involved in a collaborative wiki-based writing project. The study involved the use of a wiki by a large group of participants who were not divided into pairs. While the wiki task was initiated by an instructor, participants then acted autonomously as they attempted to correct their own grammatical errors as well as those of their 40 co-participants. Since findings revealed that slightly more grammatical errors were overlooked than attended to, the researcher speculated that participants perceived the collaborative writing activity as meaning rather than form focused. As well, Kessler observed a need for increased teacher involvement in the project to provide participants with scaffolding and encourage 
collaborative participation. In Kessler \& Bikowski's (2010) follow up study, Kessler's (2009) data were reexamined to identify trends in the co-authoring of a text by a large group of participants. Their findings revealed participants' unequal contributions as some students remained highly involved in all phases of the composition while others exhibited lurking tendencies. Thus, preliminary implications were posited with regard to the elusive nature of text ownership in a large-group project as opposed to in pairs.

In another study concerned with the collaborative writing process, Kost (2011) aimed to identify learners' revision strategies at various phases throughout the process. Using the wiki's archive function to compare various drafts of the coauthored texts, Kost concluded that learners employed strategies of brainstorming labor division, and discussion about grammatical issues. Similarly, Arnold, Ducate, \& Kost's (2012) study analyzed participants' revision behaviors, but focused on patterns of interaction which they characterized in terms of a cooperative or collaborative nature. Results indicated that learners engaged in revision of both their own writing, and their peers'; however, similar to Lee (2010) and Lund (2008), far more revisions were made only to individuals' texts, suggesting that learners have different working styles and preferences.

Woo, Chu, \& Li (2013) examined not only the process of wiki-mediated collaborative writing, but the product as well. The researchers investigated the nature of comments and revision types made on the wiki platform by young 
learners in a Chinese primary school. They found that content and meaning level comments dominated, followed by surface level comments and those related to project management. Similarly, with regard to revisions, content and meaning changes prevailed as participants focused on global rather than local textual issues. This echoed the findings of previous wiki-based collaborative writing studies where participants' focus tended to be on content and style over accuracy (Kessler \& Bikowski, 2010; Mak \& Coniam, 2008; Woo et al., 2011). Furthermore, the researchers found a significant and moderate positive correlation between the number of comments posted in the wiki and the revisions per 100 words. Finally, analysis of learners' collaboratively written texts using an analytic scoring rubric revealed a significant improvement in students' group writing using a wiki as compared to students' non-wiki collaborative writing. However, the researchers caution the interpretation of these findings noting that we cannot simply base revision outcomes on group writing assessment alone.

Despite the fact that process-oriented approaches to wiki-based collaborative writing activities have shown to support revisions and facilitate peer scaffolding in the area of content development, there is mixed support for the wiki's ability to promote attention to form and accuracy in collaborative writing. Moreover, it remains untold whether or not students' joint efforts and pooling of linguistic resources during wiki-based collaborative writing tasks can positively impact their subsequent individual writing products. With the intention to explore this specific niche, the current study set out to extend the body of empirical research 
on wiki-based collaborative writing affordances to the individual L2 writer's development.

In summary, the empirical research studies to date on the use of wikis in both second and foreign language writing instruction indicate that the tool has been increasingly implemented in a variety of educational contexts for multiple purposes. Informed by a sociocultural theoretical perspective, the existing research offers important pedagogical implications for future instructional applications of wikis in L2 and FL education. Although the current body of research literature illustrates the wiki's affordances in terms of collective peer scaffolding, process-oriented writing, and the fostering of learner interaction and negotiation, further investigation is imperative to explore the benefits of wikis for individual language learning and development. While studies on collaborative writing without the wiki seemed to take a product-oriented approach to writing, using developmental measures to evaluate and compare linguistic features of texts produced individually to those constructed collaboratively, studies conducted with the affordance of the wiki have approached collaborative writing from a process-oriented perspective, focusing more on revision behaviors and group dynamics. Thus, what remains scant is empirical research exploring if and how collaborative writing in a wiki might contribute to individuals' linguistic development. Considering the wiki's affordances and the positive influence collaborative writing has shown to have on single, co-authored texts, the question remains what benefits the wiki and collaborative writing have to offer individual learners. Although studies have 
examined distinctions between individual and collaborative writing, none to my knowledge have looked specifically at the impact of wiki-based collaborative writing activities on individual L2 writing development. The present study will therefore investigate whether or not the suggested benefits of collaborative writing can contribute to quantitative gains in individually composed L2 written discourse.

\section{Research Questions}

In an effort to fill the gap in the existing research literature, this study examines the impact of wiki-based collaborative writing activities on individual learners' English L2 writing development. Therefore, the present research is guided by the following questions:

1. Does collaborative writing in a wiki space influence individual writing of intermediate and advanced level English L2 learners on measures of linguistic complexity, accuracy, and fluency? If so, how, and to what extent are these measures affected?

2. How do learners in the study perceive wiki-based collaborative writing activities? 


\section{CHAPTER 3: METHODOLOGY}

In this chapter I explain how I gathered and analyzed written data produced by English L2 learners. This involves a description of the study's overall design, its participants, data collection procedures and instruments (including task design, pretest, posttest, treatment and survey administration), and data analysis procedures. I also discuss pertinent ethical issues related to the recruitment of participants and maintenance of confidentiality.

\section{Research Design}

The present research study followed a pretest-posttest repeated measures design to explore the impact a series of wiki-based collaborative writing treatments had on the development of intermediate to advanced level individuals' English L2 writing. Since one treatment is unlikely to have any effect on writing ability, and participants' compositions were evaluated twice (before and after the treatment), a repeated measures statistical design was chosen. Also, considering the small sample size of the present study $(\mathrm{N}=12)$, incorporating this type of research design is quite desirable as it has the potential to increase the statistical power of a test (Murphy \& Myors, 2004). Table 1 displays the overall design of the study. Individually composed writing samples were completed by students enrolled in a TOEFL preparation course and quantitatively analyzed using developmental measures of linguistic complexity, accuracy, and fluency. Over the course of five weeks, the treatment group $(n=8)$ engaged in wiki-based collaborative writing activities and 
focused writing practice between the pre and posttests. The control group $(n=4)$ did not receive any treatment. Group assignment was not random, but depended solely on participants' availability to attend the collaborative writing sessions. In addition to performance data, this study measured treatment group participants' perceptions of the wiki-based collaborative writing activities and their linguistic performance

Table 1: Research Design of the Present Study

\begin{tabular}{|c|c|}
\hline Experimental Group & Control Group \\
\hline \multicolumn{2}{|c|}{$\begin{array}{l}\text { Pretest Writing Sample: } \\
\text { Individually composed response to TOEFL iBT Independent Writing Task }\end{array}$} \\
\hline $\begin{array}{l}\text { Treatment 1 } \\
\text { Orientation/wiki training session } \\
\text { Wiki-based collaborative writing activity } \\
\text { \& focused practice }\end{array}$ & No treatment or instruction \\
\hline $\begin{array}{l}\text { Treatment } \mathbf{2} \\
\text { Wiki-based collaborative writing activity } \\
\text { \& focused practice }\end{array}$ & No treatment or instruction \\
\hline $\begin{array}{l}\text { Treatment } \mathbf{3} \\
\text { Wiki-based collaborative writing activity } \\
\text { \& focused practice }\end{array}$ & No treatment or instruction \\
\hline $\begin{array}{l}\text { Treatment } 4 \\
\text { Wiki-based collaborative writing activity } \\
\text { \& focused practice }\end{array}$ & No treatment or instruction \\
\hline $\begin{array}{l}\text { Treatment } \mathbf{5} \\
\text { Wiki-based collaborative writing activity } \\
\text { \& focused practice }\end{array}$ & No treatment or instruction \\
\hline $\begin{array}{r}\text { Posttest } \mathbf{W} \\
\text { Individually composed response t }\end{array}$ & $\begin{array}{l}\text { ing Sample: } \\
\text { DEFL iBT Independent Writing Task }\end{array}$ \\
\hline
\end{tabular}

\section{Participants}

In this section I describe the participants for my study, including selection procedures, obtaining informed consent, and maintenance of confidentiality. 
Additionally, I provide some general demographic and background information to create a profile of the learners who participated. Informed consent was obtained from 17 participants but due to the absence of 5 participants on the posttest, the data from only 12 participants was used for the analysis. Learners in the present study were intermediate level English L2 learners, all of whom speak Spanish as their L1. Participants were all undergraduate students at a major university in Bogota, Colombia. All but one of the students was majoring in Engineering and their ages ranged primarily from 20 to 26 years, with the exception of the nonEngineering major whose age was 36 . Among the 12 participants whose data were analyzed, 10 were males and two were females. All of the students were selected by the university's Office of International Relations (ORI) to participate in a TOEFL (Test of English as a Foreign Language) preparation course aimed to support their goals of studying abroad. TOEFL is a criterion-referenced, high-stakes proficiency test taken by non-native English speaking candidates who wish to study at North American universities. Specifically, the iBT TOEFL (internet-based test) is administered via computer and requires test candidates to have strong word processing skills. Students enrolled in the course have all taken an English proficiency test administered by ORI to demonstrate their language ability. However, the exact format and content of that test were not made available to me. All students who were selected to enroll in this TOEFL preparation course were given the opportunity to participate in the study. 
As displayed in Table 2, at the onset of the study, only two of the participants reported having previously taken the iBT TOEFL and their reported scores ranged from 60 to 99 out of a possible 120. Most learners indicated that they felt somewhat comfortable typing in English and the majority indicated that they spent time outside of class writing in English about one or two times per week. Only one of the 12 participants indicated having previous experiences with collaborative writing prior to taking part in the study.

Table 2: General Information about Participants

\begin{tabular}{|c|c|c|c|c|c|c|c|}
\hline Participant & Gender & Age & L1 & $\begin{array}{l}\text { Undergraduate } \\
\text { Major }\end{array}$ & $\begin{array}{l}\text { Time } \\
\text { studying } \\
\text { English }\end{array}$ & $\begin{array}{l}\text { iBT } \\
\text { TOEFL } \\
\text { Score }\end{array}$ & $\begin{array}{l}\text { Currently } \\
\text { enrolled in } \\
\text { other } \\
\text { English } \\
\text { classes }\end{array}$ \\
\hline $1 \mathrm{C}$ & $\mathrm{M}$ & 21 & Spanish & no response & 2 years & $\begin{array}{l}\text { never } \\
\text { taken }\end{array}$ & no \\
\hline $2 \mathrm{C}$ & M & 25 & Spanish & $\begin{array}{l}\text { chemical } \\
\text { engineering }\end{array}$ & 6 months & $\begin{array}{l}\text { never } \\
\text { taken }\end{array}$ & $\begin{array}{l}\text { Yes-TOEIC } \\
\text { prep }\end{array}$ \\
\hline $3 \mathrm{C}$ & M & 20 & Spanish & $\begin{array}{l}\text { chemical } \\
\text { engineering }\end{array}$ & 5 years & $\begin{array}{l}\text { never } \\
\text { taken }\end{array}$ & $\begin{array}{l}\text { Yes-TOEIC } \\
\text { prep }\end{array}$ \\
\hline 4C & $\mathrm{F}$ & 22 & Spanish & no response & $\begin{array}{l}\text { no } \\
\text { response }\end{array}$ & $\begin{array}{l}\text { no } \\
\text { response }\end{array}$ & no response \\
\hline $1 \mathrm{~T}$ & M & 21 & Spanish & $\begin{array}{l}\text { electronics } \\
\text { engineering }\end{array}$ & 2 years & $60-79$ & $\begin{array}{l}\text { Yes-TOEIC } \\
\text { prep }\end{array}$ \\
\hline $2 \mathrm{~T}$ & M & 22 & Spanish & $\begin{array}{l}\text { civil } \\
\text { engineering }\end{array}$ & 5 years & $\begin{array}{l}\text { never } \\
\text { taken }\end{array}$ & no \\
\hline $3 T$ & M & 22 & Spanish & $\begin{array}{l}\text { chemical } \\
\text { engineering }\end{array}$ & 1 year & $\begin{array}{l}\text { never } \\
\text { taken }\end{array}$ & no \\
\hline $4 \mathrm{~T}$ & M & 21 & Spanish & $\begin{array}{l}\text { mechanical } \\
\text { engineering }\end{array}$ & 5 years & $\begin{array}{l}\text { never } \\
\text { taken }\end{array}$ & $\begin{array}{l}\text { Yes-TOEIC } \\
\text { prep }\end{array}$ \\
\hline $5 T$ & M & 21 & Spanish & $\begin{array}{l}\text { civil } \\
\text { engineering }\end{array}$ & 5 years & $\begin{array}{l}\text { never } \\
\text { taken }\end{array}$ & no \\
\hline $6 \mathrm{~T}$ & M & 26 & Spanish & $\begin{array}{l}\text { mechanical } \\
\text { engineering }\end{array}$ & 15 years & $80-99$ & $\begin{array}{l}\text { Yes-TOEIC } \\
\text { prep }\end{array}$ \\
\hline $7 T$ & M & 36 & Spanish & $\begin{array}{l}\text { philosophy and } \\
\text { languages }\end{array}$ & 1.5 years & $\begin{array}{l}\text { never } \\
\text { taken }\end{array}$ & no \\
\hline
\end{tabular}




\begin{tabular}{llllll}
\hline 8T & F & 22 & Spanish no response & $\begin{array}{l}\text { no } \\
\text { response }\end{array}$ & $\begin{array}{l}\text { no } \\
\text { response }\end{array}$ \\
\hline
\end{tabular}

$\mathrm{C}=$ control group participant

$\mathrm{T}=$ treatment group participant

\section{The Course}

The TOEFL preparation course established by the University's Office of International Relations is non-credit bearing and meets for two hours daily, Monday through Friday, with Friday's class being held in a computer lab. The instructor of the course is a personal friend of mine. Since the university did not have a structured curriculum in place for this course, the instructor was given full liberty to design and implement a curriculum as he saw appropriate. The instructor was neither a researcher nor a participant in the study. Instead, he administered the pre and posttests, as well as collaborative writing treatments as part of his course curriculum. Given the daunting task of curriculum development and the challenging nature of the writing component of the iBT TOEFL test, the instructor believes that innovative writing instruction methods are crucial to fostering student success. As well, since iBT TOEFL requires students to have strong writing and word processing skills, a series of wiki-based collaborative writing activities seemed advantageous to these students' preparation.

\section{Selection Procedures}

During the first week of classes at the university in the spring semester of 2014 , the instructor informed his students of the learning objectives and curricular 
design of the TOEFL preparation course. He explained to students that in an effort to help develop their English writing skills and better prepare them for the iBT TOEFL independent writing task (a timed essay where candidates state their opinion or preference and explain and support it), they would have the opportunity to engage in a series of weekly Internet-based collaborative writing activities with various partners in their class. Students were given the choice whether or not to allow me to analyze their written data. They were provided with documents of written informed consent to be sure they were aware of their rights and any potential risks the study might cause them (see Appendix A for the participant consent form). All 17 students in the class agreed to participate but as mentioned earlier, only data from 12 participants were analyzed for the present study. Given the students' busy schedules, some indicated that they would rarely be in attendance on Fridays. To accommodate their anticipated absences, these four students were placed into a control group $(n=4)$ and did not participate in any of the wiki-based collaborative writing activities or focused practice sessions which were administered on Fridays. Participants' identities were kept confidential by allowing each to choose a pseudonym by which they wished to be referred throughout the duration of the study.

\section{Task Design}

TOEFL iBT independent writing task topics published by Educational Testing Services (ETS) were used as a foundation for the individual (pre and posttests) and 
collaborative writing tasks (treatments). These topics demand that learners consider rhetorical structures specific to the genre of argumentation. The independent writing task is one of two tasks constituting the writing portion of the test. As shown in Table 3, candidates are allowed 30 minutes to type an essay that states, explains, and supports their opinion on a given issue. The issues are

indicated in the form of prompts, which require test takers to express an opinion, preference, or explain the significance of an invention, development, or phenomenon. According to ETS, the recommended length of the response is 300 words and does not require candidates to cite outside sources. That is, the response should be based entirely on the test takers' knowledge and personal experience (https://www.ets.org/toefl/ibt/about/). Please refer to Table 4 for some sample prompts.

Table 3: Overview of the TOEFL iBT Independent Writing Task

\begin{tabular}{|c|c|c|}
\hline Task Type & Description & Time \\
\hline $\begin{array}{l}\text { Independent } \\
\text { Writing }\end{array}$ & $\begin{array}{l}\text { - Read a prompt (a topic) and express your opinion, } \\
\text { preference, or choice. }\end{array}$ & $\begin{array}{l}30 \\
\text { minutes }\end{array}$ \\
\hline $\begin{array}{l}\text { Writing from } \\
\text { Experience and } \\
\text { Knowledge }\end{array}$ & $\begin{array}{l}\text { - Support your opinion, preference, or choice with } \\
\text { reasons and examples } \\
\text {-Typical prompts begin with statements such as: } \\
\text {--Do you agree or disagree with the following } \\
\text { statement? Use reasons and specific details to support } \\
\text { your answer. } \\
\text {--Some people believe [X]. Other people believe [Y]. } \\
\text { Which of these two positions do you prefer/agree with? } \\
\text { Provide reasons and specific details. } \\
\text {--There are many important [Xs] in the world. Which } \\
\text { [X] do you think is most important and why? }\end{array}$ & \\
\hline
\end{tabular}


Justification for choosing this task for the present study lies in authenticity and meaningfulness. First, achieving a high score on the TOEFL is a common goal of all students enrolled in the preparation course. Therefore, a task that gives these learners additional practice responding to prompts they will potentially encounter on the test is highly meaningful and authentic. Additionally, word processing and time management are two skills absolutely essential to one's ability to perform well on iBT TOEFL. Since the test is administered in computer labs around the globe and test takers are required to type all of their written responses, providing this group of students with increased opportunities to practice under test-like conditions is invaluable.

Empirical research findings were also a factor in selecting an appropriate task for the present study. L2 researchers who have previously investigated collaborative writing in online environments have emphasized the importance of task type and design with regard to pedagogical practice (Lee, 2005; Lee, 2010; Lund, 2008). Writing tasks requiring learners to focus on both meaning and content have been shown to impact the degree of student engagement during the process of joint composition. Among the 21 empirical studies included in Ortega's (2003) cross-sectional research synthesis of college-level L2 writing, nearly one third used argumentative or persuasive essay prompts collected through in-class writing assignments under timed conditions.

Considering these findings, the writing topics for the present study were chosen purposefully, with an aim at allowing participants opportunities to express 
their ideas and opinions with relative freedom, while still focusing on linguistic structures and rhetorical style. Furthermore, imposing a degree of control over the writing task prompts and limiting participants to a specified time on task allowed me to increase the reliability of both the pre and posttest measures and create an opportunity for comparison across the sample population. Finally, since the number of words written under timed conditions naturally becomes a rate measure, setting a time limit for the compositions allowed me to measure linguistic fluency.

For the pre and posttests, learners were asked to individually write a response to a specified TOEFL iBT independent writing task prompt. They were allowed 30 minutes to complete the individually written pre and posttest essays, thus simulating a testing environment. However, as a result of previous research which has shown that pairs take longer to complete tasks than individuals (Storch, 2005), participants were allotted 60 minutes to complete the collaboratively written responses.

Table 4 contains a list of each prompt and indicates when it was used during the study. A variety of topics were selected from the ETS published list of independent writing task topics available for free download via PDF document at (https://www.ets.org/Media/Tests/TOEFL/pdf/989563wt.pdf). All three types of prompts displayed in Table 2 were incorporated throughout the series of treatments. Using different question prompts for both the pre and posttests as well 
as for the treatment was an effort to control for the extraneous factors of pre and

posttest effect that could potentially compromise the internal validity of the study.

Table 4: Writing Prompts for the Pre/Posttest Tasks and Collaborative Writing Treatments

\begin{tabular}{|c|c|c|c|}
\hline & Task & Time & Writing Prompt \\
\hline $\begin{array}{l}\text { Week } \\
1\end{array}$ & $\begin{array}{l}\text { Pretest Individual } \\
\text { Writing Sample }\end{array}$ & $\begin{array}{l}30 \\
\min .\end{array}$ & $\begin{array}{l}\text { Do you agree or disagree with the following } \\
\text { statement? Technology has made the world a } \\
\text { better place to live. Use specific reasons and } \\
\text { examples to support your opinion. }\end{array}$ \\
\hline $\begin{array}{l}\text { Week } \\
2\end{array}$ & $\begin{array}{l}\text { Collaborative } \\
\text { Writing Treatment } 1\end{array}$ & $\begin{array}{l}60 \\
\min .\end{array}$ & $\begin{array}{l}\text { Is it more important to be able to work with a } \\
\text { group of people on a team or to work } \\
\text { independently? Use reasons and specific } \\
\text { examples to support your answer. }\end{array}$ \\
\hline $\begin{array}{l}\text { Week } \\
3\end{array}$ & $\begin{array}{l}\text { Collaborative } \\
\text { Writing Treatment } 2\end{array}$ & $\begin{array}{l}60 \\
\min .\end{array}$ & $\begin{array}{l}\text { Do you agree or disagree with the following } \\
\text { statement? Modern technology is creating a single } \\
\text { world culture? Use specific reasons and examples } \\
\text { to support your opinion. }\end{array}$ \\
\hline $\begin{array}{l}\text { Week } \\
4\end{array}$ & $\begin{array}{l}\text { Collaborative } \\
\text { Writing Treatment } 3\end{array}$ & $\begin{array}{l}60 \\
\text { min. }\end{array}$ & $\begin{array}{l}\text { It has been said, "Not everything that is learned is } \\
\text { contained in books." Compare and contrast } \\
\text { knowledge gained from experience with } \\
\text { knowledge gained from books. In your opinion, } \\
\text { which source is more important? Why? }\end{array}$ \\
\hline $\begin{array}{l}\text { Week } \\
5\end{array}$ & $\begin{array}{l}\text { Collaborative } \\
\text { Writing Treatment } 4\end{array}$ & $\begin{array}{l}60 \\
\text { min. }\end{array}$ & $\begin{array}{l}\text { A university plans to develop a new research } \\
\text { center in your country. Some people want a } \\
\text { center for business research. Other people want a } \\
\text { center for research in agriculture } \\
\text { (farming). Which of these two kinds of research } \\
\text { centers do you recommend for your country? Use } \\
\text { specific reasons and examples to support your } \\
\text { recommendation. }\end{array}$ \\
\hline $\begin{array}{l}\text { Week } \\
6\end{array}$ & $\begin{array}{l}\text { Collaborative } \\
\text { Writing Treatment } 5\end{array}$ & $\begin{array}{l}60 \\
\min .\end{array}$ & $\begin{array}{l}\text { If you were asked to send one thing representing } \\
\text { your country to an international exhibition, what } \\
\text { would you choose? Why? Use specific reasons } \\
\text { and details to explain your choice. }\end{array}$ \\
\hline $\begin{array}{l}\text { Week } \\
7\end{array}$ & $\begin{array}{l}\text { Posttest Individual } \\
\text { Writing Sample }\end{array}$ & $\begin{array}{l}30 \\
\min .\end{array}$ & $\begin{array}{l}\text { Do you agree or disagree with the following } \\
\text { statement? Face-to-face communication is better } \\
\text { than other types of communication, such as email, } \\
\text { text messaging, or social media. Use specific } \\
\text { reasons and details to support your answer. }\end{array}$ \\
\hline
\end{tabular}

\section{Procedure}

This section provides a detailed account of the data collection procedures and instruments used in the present study. Following a brief description of the wiki 
design, I outline the chronological sequencing of procedures including the pre-test administration and information session, the collaborative writing treatments, and the post-test and survey administration.

\section{Wiki Selection and Design}

The wiki was selected as the medium for the collaborative writing tasks based on several of its unique characteristics that promote online peer collaboration, including user-friendly interface, asynchronous dialogues, and open editing and multi-authorship capabilities. Additionally, the transparency of text within the wiki, made possible by the page history feature, affords both learners and teachers increased awareness of content development, linguistic structures, and revisions. The wiki used for this study is hosted by PBworks and available at http://ibtcollaborativewriting.pbworks.com. This particular wiki was chosen because it is advertisement-free, free of charge, allows for unlimited page revisions, and grants the administrator ultimate authority over page deletion and password control. As the researcher, I functioned as the primary administrator and organized the structure of the wiki.

As illustrated in Figure 1, the main page of the wiki consists of several hypertext links including important information regarding the experiment, a detailed description and structure of the writing task, and tips and strategies to scaffold students throughout the writing process. The main page also contains images detailing how to use the various wiki functions. 
At the bottom of the main page, participants can find a link to the PDF Wiki User-

Guide file (see Appendix B for details). Along the right side of the main page is the navigator bar containing folders where participants saved their collaboratively written essays.

Figure 1: A Screen Capture of the Wiki Main Page

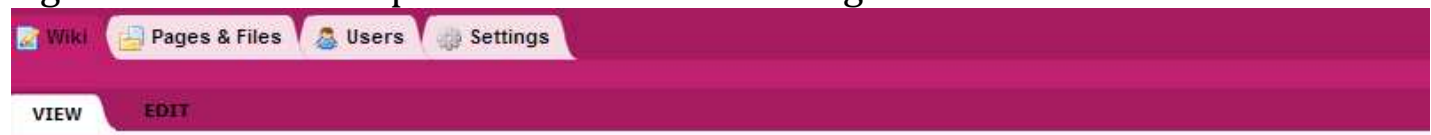

iBT Collaborative Writing

last edited by 5 Gina Caruso 6 days ago

Welcome to our Wiki!

This wiki is a great space to practice your own writing and receive input from others while writing collaboratively! your work space, click on the link below to watch a short video about why wikis are so useful.

http://www.youtube, com/watch?V=-dnL00TdmLY

\section{Get Great Ideas!}

The General Information folder contains pages about the Structure of Collaborative Writing Task, the prompts, at find information and exercises to help you develop strategies for planning and writing. There are pages about pr. effectively expressing and supporting your opinions. You can also learn about how to effectively connect your id, phrases. Other pages will help you understand how to organize your writing in the independent response and ho' your essay.

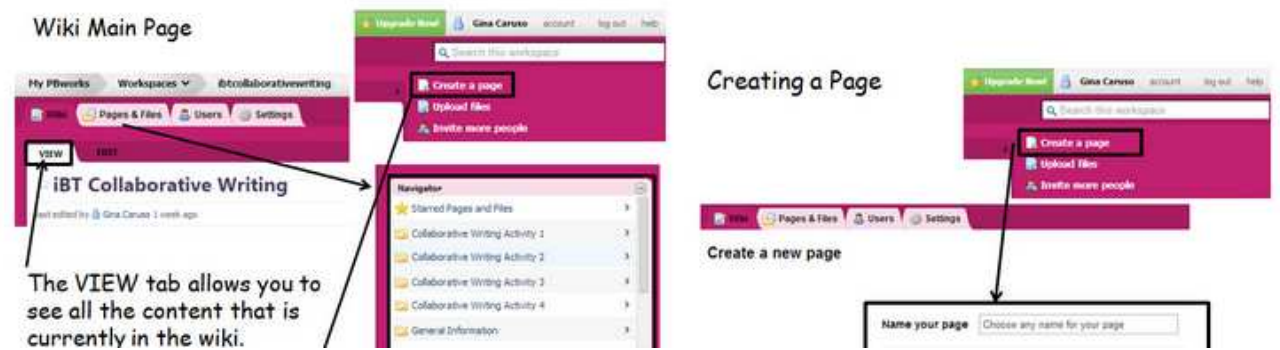




\section{Pilot Study}

In order to inform the design, procedure, and implemes ion of the present study, a small-scale preliminary experiment was conducted with three participants who were members of the relevant population. That is, they were English L2 learners of intermediate to advanced proficiency levels all with Spanish as their L1. These learners were all preparing to take iBT TOEFL in the near future and were enrolled in ESL classes concurrently. The major difference between the pilot study participants and those in the final sample was the context in which they participated: The three pilot study participants were learning English in an ESL context whereas the 17 learners in the full-scale experiment were doing so in an EFL context. As well, given that they were an odd number of individuals with erratic schedules, they did not complete the collaborative writing activities as systematically as the full-scale participants did. This however did not have any effect on the present study as written data produced by these three learners was never analyzed, nor did they form any part of the final sample.

Conducting the pilot study was beneficial in helping me identify design or logistical issues that may have arisen during the actual project. Specifically, I was able to observe the learners as they accessed the wiki and engaged in the collaborative writing treatments, and note any difficulties they had navigating the pages or understanding the tasks. Moreover, given that the present study was administered by the instructor in Bogota, Colombia, detailed written instructions 
regarding the implementation process were absolutely necessary to preserve validity and reliability. Specifically, the pilot study alerted me of questions raised by the participants with regard to adding and editing wiki content, and how to resolve them. I was then able to incorporate this information in the form of both text and screenshots and relay it to the instructor in detailed lesson plans. The instructor agreed that these plans aided tremendously in the smooth sequencing and administration of all aspects of the full-scale study.

\section{Sequencing of the Present Study}

In order to measure the potential impact that wiki-based collaborative writing may have on individual writing development, the participants were divided into two groups; experimental and control. The experimental group $(n=11)$ engaged in both individual and collaborative writing along with structured practice exercises whereas the control group $(n=6)$ completed only the pretest and posttest individual writing samples. Again, this was due to issues of practicality as learners in the control group were unable to attend class on Fridays. The study spanned the course of seven weeks; with weeks 1 and 7 devoted to the pre and posttests, and weeks 2-6 devoted to the collaborative writing activities (refer back to Table 2). A repeated measures design was chosen since it seems highly unlikely that a single treatment of collaborative writing could impact an individual's writing performance.

The study took place in a computer lab on the university campus every Friday throughout the seven week period. Conducting the study in a fixed location 
where learners could participate synchronously was essential to preserve validity and reliability. The instructor was able to control for participants' time spent on task and could be confident of the identity of those composing individual writing samples and making contributions to the wiki page during the collaborative writing treatments. Furthermore, requiring participants to engage in the experiment in a computer lab speaks to the overall reliability of the pre and posttest assessments, as the venue provided for uniform and non-distracting conditions of administration, while insuring that all participants had access to a working computer. It is my hope that taking these careful considerations contributed to the validity of the research.

\section{Pretest}

At the onset of this meeting, participants were instructed to open a Word document and type their pseudonym at the top of the page. Word documents were chosen for this measure as opposed to the wiki, since at this point, many of the participants were unfamiliar with the wiki environment. Thus, requiring these learners to use a new technology while simultaneously composing a writing sample could affect the validity of the measure since it might not be a true assessment of their writing abilities. Being unfamiliar with the wiki might have negatively affected their performance on the pretest. As previously displayed in Table 4, the time on task allotted for the pretest measure was specified at 30 minutes and strictly adhered to in an effort to increase reliability and align with the time constraints issued by ETS on the TOEFL iBT. Participants responded to the pretest prompt indicated in Table 4 which asked their opinion about the impact technology has on 
their life. Upon completion, participants sent their pretest writing samples to me via email attachment. These writing samples constituted the pretest and were used as a baseline for comparison. That is, by comparing the pretest to the posttest, I was able to assess the impact of the collaborative writing treatment on the individuals' writing with regard to complexity, accuracy, and fluency.

\section{Orientation/Wiki Training Session}

Prior to the pretest administration and orientation, I met with the instructor online and conducted a short training session on how to use the various wiki functions such as create a page, edit, and save. This training, coupled with the user guide (see Appendix B) and a detailed lesson plan (see Appendix C) enabled the instructor to conduct the tutorial session for participants. Following the pretest, all participants in the experimental group were granted access to the wiki and received the user guide in PDF form via email. The in-class orientation allowed the learners to gain initial practice using the tool, and emphasized its benefits.

In an effort to promote participant engagement and foster the process of creating jointly-authored texts, participants were informed (via the wiki user guide)

of the difference between cooperation and collaboration. First, Dillenbourg's (1999) definition of cooperation meaning "partners split the work, solve sub-tasks individually and then assemble the partial results into the final output" (p. 11) was presented. Then, Roschelle \& Teasley's (1995) definition of collaboration which involves learner engagement in "a coordinated, synchronous activity that is the 
result of a continued attempt to construct and maintain a shared conception of a problem," (p. 70) was presented with emphasis. According to my request, the instructor emphasized to participants that their common goal was working with their partner to compose the best possible essay. Given the time limit placed on the wiki-based collaborative writing tasks, participants were encouraged to collaborate jointly rather than divide the labor and cooperate.

This careful attention to scaffolding and provision of guidance to learners was informed by previous wiki-based collaborative writing studies which recommended attention to training on collaborative practices (Arnold et al., 2012; Kessler, 2009; Kessler \& Bikowski, 2010; Lee, 2010; Hubbard, 2011). Hubbard (2011) discussed the necessity of learner training when implementing technology tools in the language learning classroom. He emphasized that teachers take careful steps to make learners aware of the technology's purpose and how it can be used to achieve their desired language learning objectives. Arnold et al., (2012) also reminded us that in order to maintain student engagement in a collaborative project, emphasis needs to be placed on task visibility and student accountability. They also suggested that issues of text ownership and self-perceived strengths and weaknesses may hinder the process of collaboration and should be explicitly addressed prior to the start of the project. Similar to the guidelines for wiki contribution discussed in Lee (2010), Arnold et al. mentioned that instructors should discuss issues of acceptable editing and revision practices with regard to content composed by other group members. 
Another pedagogical implication of wiki-based collaborative writing projects was that of instructor involvement noted by Kessler (2009). While he concluded that an autonomous environment in which students can co-construct written texts may seem appealing, in order for students to have increased opportunities for practice and reap all potential affordances, some degree of teacher intervention may be desirable, especially to keep students striving toward accuracy in their compositions. This same dimension was echoed in Kessler and Bikowski's (2010) reexamination of Kessler's (2009) data. The researchers emphasized the importance of increasing students' awareness of the online collaborative learning space and how to manage the expected or unexpected challenges that may arise from the emergent technology. Thus, the orientation and wiki training session for the present study was implemented in light of these pedagogical implications and in an effort to adhere to the true nature of collaborative writing, distinguishing it from peer feedback or generic group work.

\section{Collaborative Writing Treatments}

Participants in the experimental group had the opportunity to engage in five collaborative writing treatments following the pretest. Table 5 displays the sequencing and content of the treatments and activities. The treatments are defined as the process of working collaboratively in pairs to jointly compose responses to specified writing prompts. Also, prior to the collaborative writing tasks the participants engaged in structured, interactive activities guided by content in the wiki pages. These activities were included for practical purposes (length of class 
time) as well as to enhance instruction through the presentation of writing

strategies and motivate learners. Each week, the activities focused on a skill crucial

to the TOEFL iBT independent writing task, and were presented through various

wiki pages and supplementary exercises. Please refer to Appendices D-K for

detailed lesson plans, exercises, and screen captures displaying the content created

and used for the pair activities and collaborative writing treatments.

Table 5: Sequencing and Content of Activities and Collaborative Writing Treatments for Experimental Group

\begin{tabular}{|c|c|c|}
\hline & Activities & Treatment \\
\hline Week 2 & $\begin{array}{l}\text { Writing task structure } \\
\text { - Skills, goals, \& timing } \\
\text { - } \quad \text { Structural outline }\end{array}$ & $\begin{array}{l}\text { Collaborative Essay in response to } \\
\text { prompt (see Table 4) }\end{array}$ \\
\hline Week 3 & $\begin{array}{l}\text { Pre-writing strategies } \\
\text { - Analysis of prompts } \\
\text { - } \quad \text { Brainstorming } \\
\text { - } \quad \text { Outlining }\end{array}$ & $\begin{array}{l}\text { Collaborative Essay in response to } \\
\text { prompt (see Table 4) }\end{array}$ \\
\hline Week 4 & $\begin{array}{l}\text { Expressing opinion \& preference } \\
\text { - Key expressions } \\
\text { - Developing ideas through } \\
\text { reason \& example }\end{array}$ & $\begin{array}{l}\text { Collaborative Essay in response to } \\
\text { prompt (see Table 4) }\end{array}$ \\
\hline Week 5 & $\begin{array}{l}\text { Transition words \& phrases } \\
\text { - } \quad \text { Expressions for listing } \\
\text { examples, showing addition, } \\
\text { result/conclusion, contrast, } \\
\text { similarity } \\
\text { - } \\
\text { Identifying function \& } \\
\text { purpose of transitions }\end{array}$ & $\begin{array}{l}\text { Collaborative Essay in response to } \\
\text { prompt (see Table } 4 \text { ) }\end{array}$ \\
\hline Week 6 & $\begin{array}{l}\text { Essay organization \& editing } \\
\text { - Introductions, hooks, thesis } \\
\text { statements } \\
\text { - } \text { Body \& concluding } \\
\text { paragraphs } \\
\end{array}$ & $\begin{array}{l}\text { Collaborative Essay in response to } \\
\text { prompt (see Table 4) }\end{array}$ \\
\hline
\end{tabular}




\section{Participant Attendance}

As displayed in Table 6 below, participant attendance in the experimental group was rather inconsistent throughout the five week treatment period. Please note that all participants who gave consent $(n=11)$ are included in the table but three were excluded from the data analyzed. Only two of the eleven students in the experimental group attended all five sessions. One participant attended four sessions, two attended three, and another two were in attendance for two. Finally, among the eleven participants in the experimental group, four attended only one collaborative writing treatment session.

Table 6: Experimental Group Participant Attendance at Treatment Sessions

\section{Pedagogical Intervention \& Collaborative Writing} Treatment

\begin{tabular}{|c|c|c|c|c|c|c|}
\hline $\begin{array}{l}\text { Participant } \\
\text { Pseudonym }\end{array}$ & $\begin{array}{c}1 \\
\text { (Week 2) }\end{array}$ & $\begin{array}{c}2 \\
\text { (Week 3) }\end{array}$ & $\begin{array}{c}3 \\
\text { (Week 4) }\end{array}$ & $\begin{array}{c}4 \\
\text { (Week 5) }\end{array}$ & $\begin{array}{c}5 \\
\text { (Week 6) }\end{array}$ & $\begin{array}{c}\text { Total } \\
\text { attended }\end{array}$ \\
\hline AFBP** & $\checkmark$ & $\checkmark$ & $\checkmark$ & $\checkmark$ & & 4 \\
\hline Andres 75 & & & $\checkmark$ & & & 1 \\
\hline Aparecido & $\checkmark$ & & & & & 1 \\
\hline Camduco & $\checkmark$ & $\checkmark *$ & $\checkmark$ & $\checkmark$ & $\checkmark$ & 5 \\
\hline FullHouse & $\checkmark$ & & $\checkmark$ & $\checkmark$ & & 3 \\
\hline Lfmeloa** & & $\checkmark$ & & & & 1 \\
\hline Lucho** & $\checkmark$ & & & & & 1 \\
\hline $\begin{array}{l}\text { Mr. } \\
\text { Awesome }\end{array}$ & $\checkmark$ & $\checkmark$ & $\checkmark$ & $\checkmark$ & $\checkmark$ & 5 \\
\hline Prideras & $\checkmark$ & & & $\checkmark$ & $\checkmark *$ & 3 \\
\hline Raulinho & & $\checkmark$ & $\checkmark$ & & & 2 \\
\hline $\begin{array}{l}\text { Salvador } \\
\text { Dali }\end{array}$ & $\checkmark$ & & & $\checkmark$ & & 2 \\
\hline
\end{tabular}


While the inconsistent participant attendance was certainly not desirable, it was somewhat expected considering the non-credit bearing nature of the course, and the students' heavy academic work-load. Additionally, since the class met rather late in the afternoon, many students who had been in classes all morning were reluctant to stay on campus, especially those who held part-time jobs in the evening.

\section{Participant Groupings}

Participants in the experimental group were, for the most part, paired with a different partner each week. Pairs, as opposed to groups of three or larger were selected for grouping based on the findings of Arnold, et al., (2012). In their study investigating group dynamics in a class wiki project, the researchers observed that group size (dyads as opposed to groups of three or larger) contributed to a decrease in the number of students classified as free riders, or individuals who contributed almost nothing. Of course, the pairings depended on who was in attendance at each weekly treatment. While requiring learners to work with the same partner throughout the course of the five week treatment period would have been advantageous for partner rapport building, inconsistent attendance made this method impractical. Therefore, participants were encouraged by the instructor to work with a different partner each week if possible. Table 7 illustrates the pairing of participants during the five week treatment period. Due to the odd number of participants in attendance during weeks three and six (the second and fifth collaborative writing treatments), one participant worked individually on each of 
these days. Although the instructor proposed the possibility of a group of three, ultimately it was the students' choice to work alone that particular day.

\section{Post-test}

Following the series of five wiki-based collaborative writing treatments, participants composed an individual writing sample in response to a stated TOEFL iBT independent writing task prompt (refer to Table 4 for the specific prompts). In the same manner as the pretest, participants were allowed 30 minutes to compose the posttest individual writing sample in a Word document, which they submitted via email attachment. These writing samples were quantitatively analyzed and compared to the pretest samples to determine if there were any learning gains.

Table 7: Pairings of Experimental Group Participants for Wiki-based Collaborative Writing Treatments

\begin{tabular}{|c|c|c|c|c|}
\hline \multirow[t]{2}{*}{ Treatment } & \multicolumn{4}{|c|}{ Groupings } \\
\hline & Group 1 & Group 2 & Group 3 & Group 4 \\
\hline 1 (Week 2) & $\begin{array}{l}\text { AFBP } \\
\text { Camduco }\end{array}$ & $\begin{array}{l}\text { FullHouse } \\
\text { Salvador Dali }\end{array}$ & $\begin{array}{l}\text { Mr. Awesome } \\
\text { Aparecido }\end{array}$ & $\begin{array}{l}\text { Prideras } \\
\text { Lucho }\end{array}$ \\
\hline 2 (Week 3) & $\begin{array}{l}\text { Mr. Awesome } \\
\text { Raulinho }\end{array}$ & $\begin{array}{l}\text { AFBP } \\
\text { lfmeloa }\end{array}$ & Camduco* & \\
\hline 3 (Week 4) & $\begin{array}{l}\text { Camduco } \\
\text { Mr. Awesome }\end{array}$ & $\begin{array}{l}\text { FullHouse } \\
\text { Andres75 }\end{array}$ & $\begin{array}{l}\text { AFBP } \\
\text { Raulinho }\end{array}$ & \\
\hline 4 (Week 5) & $\begin{array}{l}\text { Camduco } \\
\text { AFBP }\end{array}$ & $\begin{array}{l}\text { FullHouse } \\
\text { Salvador Dali }\end{array}$ & $\begin{array}{l}\text { Mr. Awesome } \\
\text { Prideras }\end{array}$ & \\
\hline 5 (Week 6) & $\begin{array}{l}\text { Mr. Awesome } \\
\text { Camduco }\end{array}$ & Prideras* & & \\
\hline
\end{tabular}

* indicates the participant worked individually 
In order to control for the post-test effect, participants were not informed of how their pretest samples were evaluated. Thus, they were not made aware of specific areas where their writing may be lacking but were encouraged to focus on a globally coherent essay that followed the five paragraph form recommended by ETS for the iBT TOEFL independent writing task responses. Moreover, throughout the series of activities and collaborative writing treatments, participants were not provided with feedback specific to the jointly-written compositions.

It should be noted that all participants (both experimental and control group) did receive some additional writing instruction during the time the study was in progress. The instructor of the course delivered lessons on how to write a quality thesis statement; how to write an effective introduction and conclusion; how to write a quality essay for the iBT TOEFL integrated writing task; and guidelines to following the basic five paragraph essay structure. Due to the non-credit bearing nature of the course, the instructor did not give much explicit writing feedback to the students. Instead, after reading students' informal written assignments, he would identify common problematic issues to cover in subsequent lessons. For example, the instructor noticed that many students struggled with article usage so he implemented a follow-up lesson on articles. It is also worth noting (as previously indicated in Table 2) that while the study was in progress, five of the participants (2 from the control group and 3 from the experimental group) were concurrently 
enrolled in a TOEIC preparation course which may or may not have affected their performance on the posttest.

\section{Participant Survey}

Following the posttest, two types of exit surveys were used to collect data in order to determine the learners' perceptions of the collaborative writing activities. Participants in the experimental group completed a different, and slightly longer survey than those in the control group. Both surveys were created using Google Form and a link containing the appropriate survey was sent to each of the 12 participants who completed the posttest. Appendix L displays the items contained in the control group survey and Appendix M shows the items in the experimental group survey. The control group survey was used primarily as an instrument for collecting demographic data about participants. The purpose of the experimental group survey was to collect not only demographic data, but also data to help understand the participants' experiences and perceptions of the writing instruction and wiki-based collaborative writing treatments. Incorporating a variety of question types including Likert scale ranking, yes/no, and open-ended, the survey aimed to find out whether or not participants felt the collaborative writing activities in the wiki contributed to their individual writing development. Finally, data obtained from the Likert scale survey were analyzed using descriptive statistics while open-ended questions were analyzed qualitatively. While allowing the experimental group participants some time to reflect on the collaborative writing activities prior to completing the survey may seem desirable, administering the 
survey immediately following the posttest was an attempt to facilitate participant response in a timely fashion. Additionally, learners' perceptions regarding the treatment were likely more vivid and accurate immediately following conclusion of the experience.

\section{Analysis of Written Texts}

In order to determine whether there were any identifiable linguistic gains for participants in the experimental and control groups, the pre and posttest essays were analyzed for complexity, accuracy, and fluency. The present study employed four ratio calculations to measure the fluency of participants' pre and posttest timed writing samples. These measures included the number of words per text, the number of words per minute, the number of T-units per text, and the number of clauses per text. Words per minute is an indicator of fluency first reported by Arthur, (1979) who used it to evaluate the short-term gains in measures of fluency on written compositions of ESL students at two points in a writing class. Arthur found significant differences between the two compositions using this rate of production measure (5.84 words per minute at time one; 7.02 words per minute at time two). Since the present study assessed L2 writers' fluency at two points in time, once prior to and once following a series of wiki-based collaborative writing treatments, this measure seemed appropriate and reliable. The other three metrics were used to achieve a multidimensional measure of fluency. 
Syntactic complexity was measured using four metrics. Two metrics aimed to capture the amount of subordination (ratio of dependent clauses to total clauses and ratio of subordinate clauses to total clauses) and two for length of production (mean length of T-unit and mean length of clause). To measure lexical complexity, the present study examined the percentages of both low and high frequency words in participants' compositions as well as a type/token ratio measure. Measuring high frequency words indicated the lexical basicness of the text and measuring low frequency words (academic words list words) indicated lexical sophistication. Type/token ratio shed light on the degree of variation in vocabulary. Given that the TOEFL iBT tests learners on their knowledge of low frequency and specialized vocabulary (Educational Testing Service, 2009) comparing participants' compositions against (AWL) words could help inform about their preparedness to sit the test.

Accuracy measures selected for the present study were not only narrow and focused, but also empirically and pedagogically informed. The present study used both the clause and the T-unit as production unit for measuring accuracy. Given its smaller size relative to the T-unit, the clause might provide learners with increased chances for producing error-free units. This in turn should facilitate higher scores on accuracy measures and as a result, be more revealing of linguistic development over a short period of time. A discussion of the differences in accuracy results depending on the choice of production unit (i.e., clause or T-unit) is discussed in the next chapter. 
In addition to measuring the accuracy of structural units present in L2 writing, I employed an error classification system to count and explicate all errors and their types in the written compositions. Detailed guidelines for error classification and counting can be found in Appendix N. This system was heavily informed by Polio's (1997) discussion of linguistic accuracy measures in second language writing research. In her endeavor to operationalize the construct of linguistic accuracy by calling for researchers to publish detailed information on their measures and techniques, Polio devised an empirically informed error classification system in hopes of increasing the replicability of future research. In light of her recommendations, careful consideration was given throughout the process of outlining and refining the system used for my study. More specific details regarding the coding procedures and error classification are discussed in the following section.

\section{Data Analysis Procedures}

The quantitative measures selected for analysis of the pre and posttest individual compositions are displayed in Table 8. Once the definitions of each construct and their corresponding methods of measurement were established, I devised a detailed coding scheme for analysis of the written data. The coding scheme (see Appendix N) was informed by guidelines published by previous researchers who have used the measures of CAF to evaluate the written discourse of 
L2 learners. Thus, the procedures used in the present study reflect those outlined by Foster et al (2000), Polio (1997) and Storch and Wigglesworth (2007). 
Table 8: Quantitative Measures for Analysis of Pre/Posttest Writing Samples

\begin{tabular}{|c|c|c|}
\hline Construct & Central Focus of Calculation & $\begin{array}{l}\text { Measures } \\
\text { (Dependent Variables) }\end{array}$ \\
\hline \multicolumn{3}{|l|}{ Fluency } \\
\hline & Rate and length of production & $\begin{array}{l}\text { \# of Words per text } \\
\text { Average \# of words per } \\
\text { minute } \\
\text { \# T-units per text } \\
\text { \# Clauses per text }\end{array}$ \\
\hline \multicolumn{3}{|l|}{ Complexity } \\
\hline Grammatical & Amount of Subordination & $\begin{array}{l}\text { Ratio of dependent clauses to } \\
\text { total clauses } \\
\text { Ratio of subordinate clauses to } \\
\text { total clauses }\end{array}$ \\
\hline & Length of Production & $\begin{array}{l}\text { Mean length of T-unit } \\
\text { Mean length of Clause }\end{array}$ \\
\hline Lexical & Variety and sophistication & $\begin{array}{l}\text { Type/token ratio } \\
\% \text { of Academic Word List } \\
\text { words per text } \\
\% \text { of K-1 words per text* }\end{array}$ \\
\hline \multicolumn{3}{|l|}{ Accuracy } \\
\hline & Error-free structural units & $\begin{array}{l}\text { Ratio of error-free clauses to } \\
\text { total clauses }\end{array}$ \\
\hline & $\begin{array}{l}\text { Quantity and distribution of } \\
\text { errors }\end{array}$ & $\begin{array}{l}\text { \# of errors per text } \\
\text { Mean \# of errors per T-unit } \\
\text { Mean \# of errors per clause }\end{array}$ \\
\hline
\end{tabular}

* 1000 most frequent words of English 


\section{Coding the Individual Writing Samples}

The three developmental measures of complexity, accuracy, and fluency all involve counting the amount of production according to a particular unit. Thus, in order to quantify the textual features produced by participants in their individual writing samples, I began by counting all words in the text. The total word counts were obtained by simply copying and pasting the texts into VocabProfile. It is important to note that this system replaces contractions with constituent words; so that won't is treated as will not and therefore counted as two words rather than one.

Additionally, the program replaces all numerical figures with the word number and eliminates all single letters, except for $a$ and $I$. The word counts adopted for analysis in the preset study were those calculated by the web program.

The second step involved the coding of each composition for T-units and clauses. Clauses were identified and classified as either independent or dependent. All dependent clauses were further identified as finite or non-finite, and all finite dependent clauses were then scrutinized and described in terms of their clause type and presence or absence of an overt marker of subordination. While identifying independent clauses was fairly straightforward, given that the research literature using CAF methodology is characterized by ambiguity in clause definition and operationalization (Wolfe-Quintero et al, 1998), the categorization of dependent clauses was a rather daunting task. For the present study, an independent clause is a grammatical structure that contains a subject and tensed or modal verb and can 
stand alone. Dependent clauses were coded following Foster et al. (2000) where a dependent clause was one which contained a finite or non-finite verb and at least one additional clause element of the following: subject, object, complement, or adverbial. This differs slightly from Polio (1997) where only an imperative did not require a subject to be considered a clause. In the present study, however, a subject is not obligatory to establish clausal status, provided that at least one additional clause element appears. Therefore, an -ing or to-infinitive non-finite complement clause standing alone without any other clause element was not coded as a clause and did not factor into the clause count.

Finally, all errors in each composition were coded following the guidelines proposed by Polio (1997) with some modifications made to account for the present data. Errors were classified according to type and instances of error-free clauses were counted. Eighteen error types were used for the coding. These included errors in the lexicon, tense/aspect, noun number, parallel structure, preposition, reference, subject/verb agreement, article, other determiner, word form, verb form, case, missing word, pronoun, coordinator/subordinator, word order, negation, and run-on sentence. Total counts of each error type were calculated within groups for each participant and between groups overall. While the classification of error types was at times difficult, especially when the errors were ambiguous or seemed to overlap categories, I made a principled decision and consistently followed it throughout the subsequent analysis, making the method reliable. 


\section{Analysis}

Prior to presenting the details of the data analysis methodology, a short discussion of statistical concepts and methodology is warranted. One crucial concept to keep in mind is that of variable levels. When dealing with nominal variables, it is possible to have multiple categories or levels of a single variable. In the current study, the independent variable is nominal (group membership) and has two levels (control group and treatment group). Understanding this definition of levels is crucial when selecting the appropriate statistical test for quantitative analysis because if the variable levels are made up of two different groups of people, they are said to be independent whereas if they are the same people, they are said to lack independence (Brown, 1992). When attempting to answer the research question which asks whether a series of wiki-based collaborative writing treatments impacted individual writing development, participants in the treatment group can be said to lack independence and will be compared within their group. However, when answering the question of whether participants in the treatment group performed significantly different than participants in the control group on the dependent measures of accuracy, fluency, and complexity, group membership is treated as the independent variable and the outcome measures are compared between groups rather than within.

In order to examine whether the group of learners who participated in wikibased collaborative writing activities (treatment group) performed better or worse than learners who did not (control group), quantitative analyses were conducted 
using a Mann-Whitney $\mathrm{U}$ test for each of the 15 dependent variables displayed in Table 8. This statistical test was only used to analyze performance data within the treatment group. While it would have been interesting to conduct the same analyses for control group performance data, given that the investigation focused on the impact of collaborative writing on individual writing, and the control group did not write collaboratively, this procedure was not obligatory to answer the research question.

The Mann-Whitney U test is a non-parametric alternative to the independent samples t-test. It was selected for the present study based on the repeated measures research design, the grouping of participants, and the non-normal distribution of data. Although the median is thought to be the best measure of central tendency to reflect a non-normally distributed set of data, given the small sample size and following the lead of other researchers, means were reported as the descriptive statistic for measures of central tendency. The assumptions for MannWhitney U were checked and confirmed. The data were not normally distributed, the independent variable consisted of two categorical independent groups (i.e. treatment and control), and observations were independent (i.e., no participant was in both control and treatment groups. The Mann-Whitney U test produced the following pieces of information for each dependent variable: whether the distribution of pretest and posttest scores was significantly different between the treatment and control groups and whether the groups differed on gains from pretest to posttest. 
A Wilcoxon matched pairs signed rank test was used to determine whether the individually written compositions of participants in the wiki-based collaborative writing treatment group improved significantly from pretest to posttest. Whereas the Mann-Whitney U test compared differences between groups' performances (treatment v. control), the Wilcoxon test compared the differences within groups' performance. That is, the Wilcoxon test analyzed the repeated measures of participants within the same group (treatment group only). For the present study, the treatment group participants' written compositions were evaluated twice (i.e. pretest and posttest) and their mean scores on each of the 15 dependent measures were compared to determine if there were statistically significant differences in terms of fluency, accuracy, and complexity from pretest to posttest.

Assumptions for the Wilcoxon test were checked. The distribution of data violated the assumption of normality and the independent variable consisted of the same subjects (treatment group participants) tested on repeated measures. This statistical test provided with two useful pieces of information: the Z score and Asymp.Sig value. For the Wilcoxon test, the Asymp.Sig (2-tailed) is simply the pvalue, or associated probability against the Null Hypothesis. The Z score can be interpreted as the standard score of zero and tells us how far away a particular score is from the mean. A negative $\mathrm{Z}$ score indicates that a particular score is below the group mean whereas a positive $\mathrm{Z}$ score tells us that the score is above the mean. Therefore Z scores can help us to understand how typical a score is within a sample 
of other scores and will indicate whether or not there is a reasonable amount of variation in scores with respect to the mean.

\section{Participant survey}

Data collected from the exit survey was used to obtain general demographic information about the participants and to help understand their perceptions regarding the effectiveness of the collaborative writing treatments in the wiki. Descriptive statistics along with qualitative analysis were used to examine and interpret the responses to survey questions. Specifically, participants' responses to open-ended questions were discussed in light of common themes gleaned from direct quotations. 


\section{CHAPTER 4: RESULTS \& DISCUSSION}

The primary aim of the present study was to explore the impact a series of wiki-based collaborative writing activities had on the individual writing development of intermediate to advanced proficiency English L2 learners. A secondary aim was to determine these learners' perceptions of collaborative writing via wiki technology and elicit feedback and suggestions regarding the tool and its affordances. This chapter begins by presenting the quantitative findings based on the data analysis procedures discussed in the previous chapter. First, results for each of the 15 dependent measures used to examine fluency, complexity, and accuracy are presented and discussed in light of the first research question. This is followed by a presentation and subsequent discussion of results of the participant perception survey. Finally, the major findings and key discussion points are synthesized and interpreted with regard to practical significance and meaningfulness.

\section{Research Question 1}

Does collaborative writing in a wiki space impact the individual writing of intermediate to advanced level English L2 learners on measures of linguistic complexity, accuracy, and fluency? If so, how, and to what extent are these measures affected?

This research question investigates the impact of wiki-based collaborative writing treatments on individual writing development. As discussed in the 
methodology chapter, the treatments included more than simply collaborative writing tasks. This is important to keep in mind when interpreting the impact of the treatment on individual writing development. Writing development was measured according to the constructs of fluency, accuracy, and complexity (both grammatical and lexical) or CAF. The pretest and posttest compositions written by individual participants in both the experimental and control groups were coded, analyzed, and compared on 15 dependent measures: number of words per text, average number of words per minute, number of T-units per text, number of clauses per text, ratio of dependent clauses to total clauses, ratio of subordinate clauses to total clauses, mean length of T-unit, mean length of clause, type/token ratio, $\%$ of Academic Word List words per text, \% of K-1 words per text, ratio of error-free clauses to total clauses, number of errors per text, mean number of errors per t-unit, and mean number or errors per clause. Both between group (treatment and control) and within group (treatment) comparisons were conducted on repeated measures (pre and posttests) to find out whether the writing produced by participants in the treatment group was significantly different from pretest to posttest, and also whether there was a significant difference between the treatment and control groups' performances across both measures. The subsequent sections present and discuss the quantitative findings by construct.

\section{Fluency}

Mean scores on the pre and posttests (i.e., the scores averaged across all participants) were calculated for four outcome measures: average number of words 
per text, average number of words per minute, average number of T-units per text, and average number of clauses per text. Gain scores (i.e., the improvement from pretest to posttest) were also calculated and reported along with standard deviations (SD) (i.e. amount of variation from the mean). Table 9 displays the means, gain scores, and standard deviations by group.

One trend that stands out from the descriptive statistics is the overall increase of mean scores from pretest to posttest for both the treatment and control groups. The mean scores in the treatment group increased from pretest to posttest on all four measures of fluency and the mean scores in the control group increased on three of the four fluency measures, with the exception being the number of Tunits per text which had a gain score of -2.75 .

Table 9: Descriptive Statistics for Averaged Scores on Fluency Measures by Group

\begin{tabular}{llllllll}
\hline $\begin{array}{c}\text { Dependent } \\
\text { Variable }\end{array}$ & Test & \multicolumn{9}{c}{ Group } \\
& & \multicolumn{3}{c}{ Treatment } & \multicolumn{5}{c}{ Control } \\
& & $\underline{\text { Mean }}$ & $\underline{\mathbf{S D}}$ & $\underline{\text { Gain }}$ & $\underline{\text { Mean }}$ & $\underline{\text { ND }}$ & $\underline{\text { Gain }}$ \\
Words / Text & Pre & 281.37 & 75.91 & & 308.00 & 118.07 & \\
& Post & 341.75 & 56.40 & +60.38 & 331.25 & 70.17 & +23.2 \\
& & & & & & & 5 \\
Words / Min. & Pre & 9.37 & 2.53 & & 10.25 & 3.92 & \\
& Post & 11.39 & 1.88 & +2.02 & 11.04 & 2.34 & +.79 \\
T-units / Text & Pre & 14.75 & 5.80 & & 19.50 & 7.05 & \\
& Post & 18.37 & 4.47 & +3.62 & 16.75 & 4.57 & -2.75 \\
& & & & & & & \\
Clauses/Text & Pre & 36.37 & 13.14 & +11.75 & 42.75 & 17.29 & +5.5 \\
& Post & 48.12 & 9.31 & & 48.25 & 12.68 & \\
\hline
\end{tabular}


The greatest increase was achieved by the treatment group on the outcome measure of words per text with a gain score of 60.38. This means that on average, participants in the treatment group wrote about 60 more words in the 30 minute timed posttest than they did on the pretest under the same timed conditions.

Additionally, the standard deviations or dispersion of scores around the mean, for both the control and treatment groups decreased from pretest to posttest on all four outcome measures. This indicates that there was less variation in participants' scores on the posttest than on the pretest. It might also be worth noting that in general, standard deviations in the control group were higher than standard deviations in the treatment group. For example, on the number of words per text measure on the pretest, the standard deviation for the treatment group was 75.91, while in the control group, the standard deviation was a much higher, 118.07. This indicates that there was greater variability in the control group than in the treatment group on these fluency measures. This is something to keep in mind when the control and treatment group are compared throughout the study.

One possible explanation for this greater variability among control group participants might be that two of the individuals composed the pretest by hand with pen and paper whereas the others did so via computer. However it's also worth pointing out that there was still great variability in composition length between these two participants who handwrote the pretest essay. While one participant wrote 152 words in 30 minutes, the other composed 318 in the same amount of 
time. This suggests that the difference in length of written output could perhaps be idiosyncratic rather than attributed to the mode of written production.

Based on the assumption of non-normal distribution of data and the repeated measures research design, Wilcoxon tests were conducted for each of the four dependent measures of fluency to evaluate whether the treatment group's gains from pretest to posttest were statistically significant. Results of the Wilcoxon test for repeated fluency scores of treatment group participants are provided in Table 10. Although it's clear that participants' mean scores increased from pretest to posttest, this difference was not statistically significant for any of the four measures. This is apparent in the statistics listed under the Asymp.Sig (2-tailed) column. For the Wilcoxon test, this number is the P value. Thus, we maintain the null hypothesis and conclude that while descriptive statistics are indicative of a positive trend, the wikibased collaborative writing treatment did not have a significant effect on participants' written fluency.

Table 10: Results of Wilcoxon Test on Treatment Group Pre and Posttest Fluency Measures

\begin{tabular}{lllll}
\hline Measure & Test & Means & $\boldsymbol{Z}$ score & Asymp.Sig (2-tailed) \\
\hline Number of words per text & Pre & 281.37 & -1.26 & .208 \\
& Post & 341.75 & & \\
Average number of words per & Pre & 9.37 & -1.26 & .208 \\
minute & Post & 11.39 & & \\
& & & & \\
Number of T-units per text & Pre & 14.75 & -1.265 & .206 \\
& Post & 18.37 & & \\
Number of clauses per text & Pre & 36.37 & -1.54 & .123 \\
& Post & 48.12 & & \\
\hline
\end{tabular}

$p \leq .05$ 
Since the assumption of normality was not met for the data collected from the two categorical independent samples (i.e., treatment and control group) MannWhitney $\mathrm{U}$ tests were used to compare the distribution of scores between the groups on the four dependent fluency measures from pretest to posttest. This test ranked scores from lowest to highest and thus the group with the lowest mean rank indicates that it contained the greatest number of lower scores. Likewise, the group with the highest mean rank should contain a greater number of high scores. It can be useful to examine these rank scores prior to interpreting the statistical output as they allow us to immediately ascertain which group had the highest scores. The mean ranks of the treatment and control groups for pre and posttest fluency measures are displayed in Table 11 below.

Table 11: Mean Ranks of Treatment and Control Group on Pre and Posttest Fluency Measures

\begin{tabular}{|c|c|c|c|}
\hline \multirow[t]{2}{*}{ Fluency Measure } & \multirow[t]{2}{*}{ Test } & \multicolumn{2}{|c|}{ Group } \\
\hline & & Treatment & Control \\
\hline & & $\underline{\text { Mean Rank }}$ & $\underline{\text { Mean Rank }}$ \\
\hline \multirow[t]{2}{*}{ Number of words per text } & Pre & 6.13 & 7.25 \\
\hline & Post & 6.75 & 6.00 \\
\hline \multirow[t]{2}{*}{ Average number of words per minute } & Pre & 6.13 & 7.25 \\
\hline & Post & 6.75 & 6.00 \\
\hline \multirow[t]{2}{*}{ Number of T-units per text } & Pre & 5.75 & 8.00 \\
\hline & Post & 6.63 & 6.25 \\
\hline \multirow[t]{2}{*}{ Number of clauses per text } & Pre & 5.88 & 7.75 \\
\hline & Post & 6.38 & 6.75 \\
\hline
\end{tabular}

It's interesting to note that the mean ranks of the treatment group on the pretest for all four fluency measures were lower than the mean ranks of the control group. This suggests that at the onset of the study the writing of treatment group 
participants may have been less fluent overall than that of control group participants. This finding is consistent with the descriptive statistics displayed in Table 9. Alternatively on the posttest the mean ranks of the treatment group were higher than those of the control group on three of the four measures, with the exception being number of clauses per text. Basically, except for clauses per text, the control group and treatment group switched places form pre to posttest: the treatment group was lower on the pretest but higher on the posttest. This might suggest that collaborative writing in the wiki may be more beneficial for less fluent writers.

While the mean ranks provide data which seem to offer support for the wikibased collaborative writing treatment, they must be interpreted with caution. In order to draw conclusions that extend beyond this small data set, Mann-Whitney U tests were conducted to analyze the differences in the ranked positions of scores between the two groups. The test statistics for the four fluency measures are provided in Table 12.

Table 12: Results of Mann-Whitney U Test for Between Group Comparisons on Fluency Measures

\begin{tabular}{lllll}
\hline Measure & Test & U & Z score & $\begin{array}{l}\text { Asymp.Sig } \\
\text { (2-tailed) }\end{array}$ \\
\hline Number of words per text & Pre & 13.00 & -.510 & .610 \\
& Post & 14.00 & -.34 & .734 \\
& & & & \\
Average number of words per & Pre & 13.00 & -.510 & .610 \\
minute & Post & 14.00 & -.340 & .734 \\
Number of T-units per text & Pre & 10.00 & -1.02 & .307 \\
& Post & 15.00 & -.17 & .864 \\
Number of clauses per text & Pre & 11.00 & -.851 & .395 \\
\hline
\end{tabular}


$p \leq .05$

For these data, the Mann-Whitney tests were not significant (two-tailed) for any of the fluency measures on the pre or posttest. These findings indicate that group membership (treatment or control) did not have a statistically significant effect on individual L2 writers' fluency at the time of the pretest or posttest. That is, despite the higher posttest mean scores achieved by the treatment group on all four fluency measures, the distribution of scores should be interpreted as the same across both groups.

The absence of a statistically significant finding should be interpreted with caution. It's crucial to remember that statistical significance is not what makes research results important. Along the same lines, a research result should not be deemed unimportant simply because it's not statistically significant. When interpreting results of the fluency analysis, we should consider the practical significance of the findings. Since the mean scores increased on all four outcome measures for learners who participated in the wiki-based collaborative writing activities, we can view the findings as positive and encouraging for future exploration and potential implementation of wiki-based collaborative writing pedagogy. Additionally, since the control group did not receive any treatment, we can view wiki-based collaborative writing as beneficial, or at least not detrimental. 


\section{Summary of Fluency Findings \& Discussion}

Analysis of fluency measures revealed a positive but not significant effect for wiki-based collaborative writing activities on gains in fluency for measures of words per composition, average words per minute, T-units per composition, and clauses per composition. Based on the treatment group's overall lower mean scores on the pretest compared with the control group, we can speculate that at the onset of the study, learners in the treatment group may have been less fluent L2 writers than those in the control group. This in turn could suggest that collaborative writing in wikis might be more beneficial for less fluent writers. Additionally, the higher standard deviations observed in the control group seem to convey a greater degree of variability among participants as compared to the treatment group.

\section{Complexity}

Seven outcome measures of linguistic complexity were examined in the present study. Four of the measures were used to capture syntactic complexity and their focus of calculation was on length of production and amount of subordination. The other three were used to measure complexity at the lexical level; one looking at variation in lexis and the other two assessing the degree of sophistication or lexical richness. In addition to mean scores on the seven outcome measures of complexity, gain scores along with standard deviations are provided by group in Table 13. These statistics paint a very different picture than those reported for the fluency measures. With regard to syntactic complexity, mean scores for the treatment group decreased on both measures of production unit length (i.e., T-units and 
clauses) and one measure of subordination (i.e., ratio of dependent clauses to total clauses). Scores however did increase on the ratio measure of subordinate clauses to total clauses.

These differences are evident in the negative and positive gain scores for the repeated measures. Similar to the treatment group, mean scores for the control group also decreased on two of the four syntactic complexity measures. While they had positive gain scores on measures of T-unit length and ratio of dependent clauses to total clauses, their means decreased from pretest to posttest on ratio of subordinate clauses to total clauses and mean length of clause.

Table 13: Descriptive Statistics for Averaged Scores on Complexity Measures by Group

\begin{tabular}{|c|c|c|c|c|c|c|c|c|}
\hline \multirow{3}{*}{$\begin{array}{l}\text { Central focus } \\
\text { of Measure }\end{array}$} & \multirow{3}{*}{$\begin{array}{l}\text { Dependent } \\
\text { Variable }\end{array}$} & \multirow[t]{3}{*}{ Test } & \multicolumn{6}{|c|}{ Group } \\
\hline & & & Treatm & & & Contro & & \\
\hline & & & $\underline{\mathrm{N}=8}$ & & & $\underline{\mathrm{N}=4}$ & & \\
\hline \multirow{6}{*}{$\begin{array}{l}\text { Syntactic } \\
\text { Length of } \\
\text { Production }\end{array}$} & & & $\mathbf{M}$ & SD & Gain & $\mathbf{M}$ & SD & Gain \\
\hline & Mean length of & Pre & 20.41 & 3.86 & & 15.96 & 2.52 & \\
\hline & T-unit & Post & 19.11 & 3.53 & & 20.43 & 4.10 & \\
\hline & & & & & -1.3 & & & +4.47 \\
\hline & Mean length of & Pre & 8.00 & 1.16 & & 7.28 & .836 & \\
\hline & Clause & Post & 7.16 & .67 & -.84 & 6.97 & .87 & -.31 \\
\hline \multirow{4}{*}{$\begin{array}{l}\text { Amount of } \\
\text { Subordination }\end{array}$} & Ratio of & Pre & .56 & .07 & & .50 & .12 & \\
\hline & $\begin{array}{l}\text { dependent } \\
\text { clauses to total } \\
\text { clauses }\end{array}$ & Post & .58 & .05 & -.02 & .63 & .05 & +.13 \\
\hline & Ratio of & Pre & .26 & .09 & & .38 & .12 & \\
\hline & $\begin{array}{l}\text { Subordinate } \\
\text { Clauses to total } \\
\text { clauses }\end{array}$ & Post & .35 & .08 & +.09 & .27 & .06 & -.11 \\
\hline \multicolumn{9}{|l|}{ Lexical } \\
\hline \multirow{2}{*}{ Variation } & Type/token ratio & Pre & .50 & .04 & & .48 & .06 & \\
\hline & & Post & .43 & .03 & -.07 & .46 & .04 & -.02 \\
\hline
\end{tabular}




\begin{tabular}{lllllllll}
\hline Sophistication & $\begin{array}{l}\text { \%Academic } \\
\begin{array}{l}\text { Word List words } \\
\text { per words }\end{array}\end{array}$ & Pre & 7.17 & 1.50 & & 5.63 & $\begin{array}{l}3.3 \\
0\end{array}$ \\
& Post & 6 & 1.09 & -1.17 & 9.13 & $\begin{array}{l}2.7 \\
0\end{array}$ & +3.5 \\
& & & & & & 0 & \\
$\begin{array}{l}\text { \% K-1 Words per } \\
\text { words* }\end{array}$ & Pre & 84.76 & 2.01 & & 86.15 & 4.4 & \\
& & & & 1.78 & & 8 & -2.32 \\
& Post & 86.54 & 1.65 & & 83.83 & 5.1 & \\
& & & & & & 7 & \\
\hline
\end{tabular}

* a negative score indicates a decrease in basic words

It was interesting to see that both groups of learners achieved negative gain scores on the mean length of clause measure. Norris \& Ortega (2009) contend that for intermediate or advanced proficiency L2 learners, since increased subordination is often realized by pre- or post-modification within a phrase or increased nominalization, a metric such as mean length of clause might appropriately tap into the complexification at the phrasal level. This however was not realized for the present sample of intermediate and advanced L2 writers.

In terms of lexical complexity, descriptive statistics yielded mixed results for both treatment and control groups. It's important to note that the dependent variable $\%$ of $\mathrm{K}-1$ words per words in the text is essentially a measure of lexical basicness. K-1 words are the 1000 most frequent words in English and are likely to be used more often by less proficient L2 learners (Laufer \& Nation, 1995). Therefore, as learners' vocabulary develops their reliance on these words should decrease in favor of more rare and sophisticated vocabulary. Thus we can interpret a decrease in the percentage of K-1 words as an increase in lexical richness. 
On the type/token ratio measure of lexical variation, the mean scores of both the treatment $(\mathrm{T})$ and control $(\mathrm{C})$ groups decreased from pre to posttest $(\mathrm{T}=-.07, \mathrm{C}=-$ .02). One could speculate that this was a result of the negative relationship between type/token ratio and text length. That is, as the number of words produced in the composition increased, the ratio of word types decreased. Thus the relatively high mean gain scores on the measure of words per text for both groups (60.38 words for the treatment group and 23.25 words for the control group) might help to explain the decrease in type/token ratio.

On the posttest measures of lexical sophistication, the treatment group had a negative gain score for Academic Word List (AWL) words and a positive gain score for K-1 words. In a similar yet opposite fashion, the control group produced compositions with $3.5 \%$ more AWL words and $2.32 \%$ fewer K-1 words. Since K-1 words comprise the 1000 most frequent words in English and AWL words are a set of 570 word families that account for about $10 \%$ of all words in academic texts, (Coxhead, 2000) this inverse relationship of the measures is not surprising. That is, if a learner produces a writing sample which contains a higher percentage of sophisticated words, it must also mean that the composition contains a lower percentage of basic words (i.e., K-1 words). One final point of interest that can be gleaned from the descriptive statistics for complexity measures is the relative similarity between groups with respect to standard deviation. Contrary to the great variability of control group participants' scores on fluency measures, the mean 
standard deviations on the seven measures of complexity are quite similar across groups.

Within group comparisons on the repeated measures of linguistic complexity were conducted using Wilcoxon tests to confirm whether or not the difference in scores obtained prior to and following the wiki-based collaborative writing treatments was significant. The tests elicited statistically significant differences between pre and posttests on three complexity measures: ratio of dependent clauses to total clauses $(\mathrm{z}=-2.521, \mathrm{p}=.012)$, ratio of subordinate clauses to total clauses $(\mathrm{z}=-2.24, \mathrm{p}=.025)$ and type/token ratio $(\mathrm{z}=-2.316, \mathrm{p}=.021)$. It is certainly important to note that for the metrics of dependent clauses to total clause ratio and type/token ratio, the significant difference was for a decrease in complexity.

Table 14: Results of Wilcoxon Test on Treatment Group Pre and Posttest Complexity Measures

\begin{tabular}{|c|c|c|c|c|}
\hline Measure & Test & Means & $Z$ score & $\begin{array}{l}\text { Asymp.Sig } \\
\text { (2-tailed) }\end{array}$ \\
\hline \multirow[t]{2}{*}{ Mean length of T-unit } & Pre & 20.41 & -.70 & .484 \\
\hline & Post & 19.11 & & \\
\hline \multirow[t]{2}{*}{ Mean length of clause } & Pre & 8.00 & -1.54 & .123 \\
\hline & Post & 7.16 & & \\
\hline \multirow[t]{2}{*}{ Ratio of dependent clauses to total clauses } & Pre & .56 & -2.521 & $.012^{*}$ \\
\hline & Post & .26 & & \\
\hline \multirow[t]{2}{*}{ Ratio of subordinate clauses to total clauses } & Pre & .26 & -2.24 & $.025^{*}$ \\
\hline & Post & .35 & & \\
\hline \multirow[t]{2}{*}{ Type/Token Ratio } & Pre & .50 & -2.316 & $.021^{*}$ \\
\hline & Post & .43 & & \\
\hline \multirow[t]{2}{*}{$\%$ AWL words in text } & Pre & 7.17 & -1.4 & .161 \\
\hline & Post & 6 & & \\
\hline \multirow[t]{2}{*}{$\% \mathrm{~K}-1$ words in text } & Pre & 84.76 & -1.6 & .093 \\
\hline & Post & 86.54 & & \\
\hline
\end{tabular}

* Statistically significant difference between pre and posttest measures $(\mathrm{p} \leq .05)$. 
As noted earlier with regard to type/token ratio, this measure is sensitive to text length and will often decrease in the face of increased fluency. For the sample of the eight learners who participated in the collaborative writing treatments, this decrease in lexical variation was confirmed by the statistically significant finding returned from the Wilcoxon test. Although researchers have suggested that type/token ratio is a reliable measure of lexical complexity when time or conceptual limits are placed on production (Wolfe-Quintero et al., 1998), in order to avoid an undesirable result, an alternative measure should be explored. Recently, some researchers have used Guiraud's Index to measure vocabulary complexity since it accounts for the differences in length of responses (Sauro \& Smith, 2010; Sydorenko, 2011). Considering that the length of participants' pre and posttest compositions varied considerably (see Table 9 for standard deviations), choosing Guiraud's Index as a metric for lexical variation might have been more appropriate.

As shown in Table 14, statistical analysis of compositions written by learners following the collaborative writing treatments produced mixed results on measures of subordination. Again, Wilcoxon tests confirmed that differences between the pre and posttest with regard to the ratio of dependent clauses to total clauses $(\mathrm{z}=-2.521$, $\mathrm{p}=.012)$ and ratio of subordinate clauses to total clauses $(\mathrm{z}=-2.24, \mathrm{p}=.025)$ were statistically significant. Rather curiously however, while the ratio of subordinate clauses to total clauses increased significantly, the result for ratio of dependent clauses to total clauses indicated a significant decrease in complexity. This result however should be interpreted with caution considering that inconsistent findings 
have characterized previous empirical research which analyzed linguistic complexity (Norris \& Ortega, 2009; Wolfe-Quintero et al., 1998).

One possible explanation for the statistically significant decrease in the dependent clause to total clause ratio might be an increase in independent clause coordinations. A closer examination of the data collected for the present study revealed that six of the eight treatment group participants produced more independent clauses on the posttest composition than on the pretest. More specifically, two of these six learners doubled their production of independent clauses across the repeated measures. Since analyses of independent clause coordination were not conducted for the present study, we can only speculate as to whether or not learners favored coordination over subordination on the posttest. In light of this speculation, we might turn to Bardovi-Harlig (1992) who suggested the use of a coordination index as an alternative to subordination measures for syntactic complexity. The coordination index takes into account the number of both independent and subordinate clause coordinations within a composition. This method however has not often been employed by SLA researchers perhaps because it was recommended particularly for data at initial levels of L2 development (Norris \& Ortega, 2009). Despite the fact that learners in the present study were considered to be of intermediate to advanced proficiency levels, it would have been interesting to see if the statistically significant decrease in the ratio of dependent clauses to total clauses was matched by an increase in coordinated independent clauses. While moving from subordination to 
coordination seems counter-productive, after all, we cannot assume that the development of grammatical complexity in written language is a linear process. Finally, it's plausible that this negative statistically significant finding could be further explained through holistic analysis ratings which look at issues of textual coherence and concision.

In addition to the within-treatment group comparison of repeated complexity measures, between group comparisons were carried out using MannWhitney tests. Mean ranks of the scores achieved on repeated measures by both groups are presented in Table 15 below. These numbers provide us with a general idea of how the control and treatment group ranked on each measure with respect to one another.

Table 15: Mean Ranks of Treatment and Control Group on Pre and Posttest Complexity Measures

\begin{tabular}{llll}
\hline Measure & Test & & Group \\
\hline & & Treatment & Control \\
Mean length of T-unit & Pre & Mean Rank & Mean Rank \\
& Post & 6.0 & 3.5 \\
Mean length of clause & Pre & 7.13 & 7.0 \\
& Post & 6.5 & 5.25 \\
Ratio of dependent clauses to total & Pre & 7.13 & 6.5 \\
clauses & Post & 5.5 & 5.25 \\
Ratio of subordinate clauses to total & Pre & 5.31 & 8.5 \\
clauses & Post & 7.63 & 8.88 \\
Type/Token ratio & Pre & 6.88 & 4.25 \\
& Post & 5.81 & 5.75 \\
\% AWL words in text & Pre & 7.38 & 7.88 \\
& Post & 4.88 & 4.75 \\
\hline
\end{tabular}




\begin{tabular}{llll} 
& & & \\
\% K-1 words in text & Pre & 6.0 & 7.5 \\
& Post & 7.0 & 5.5 \\
\hline
\end{tabular}

We can see that in general, the treatment group contained higher scores on the pretest than the control group with the exception of subordinate clause to total clause ratio. It's also important to remember that the $\mathrm{K}-1$ words in text percentage should be interpreted as a lexical basicness measure, meaning that the control group, with a rank score of 7.5 on the pretest, produced a higher percentage of common words in their essays than the treatment group. These rankings suggest that at the onset of the study, lower scores were obtained by participants in the control group compared to the treatment group. This was quite different from what we saw on the fluency measures. However, an examination of the posttest ranks reveals that on five of the seven complexity measures, the control group contained a greater number of high scores than the treatment group. This inverse finding does not seem to suggest a benefit for the participants who engaged in wiki-based collaborative writing activities.

Table 16 provides the statistics returned from the Mann-Whitney U tests. They indicate that differences between the treatment and control groups were statistically significant on the pretest measure of mean length of $T$-unit $(U=4, p=.041)$ and the posttest measure of $\%$ AWL words in text $(U=3, p=.027)$. This tells us that on the pretest, participants in the treatment group received significantly higher scores on the complexity measure of T-unit length than the control group. On the other hand, participants in the control group received statistically significantly 
higher scores on the posttest measure of lexical sophistication (i.e. \% AWL words in text). The significant result for mean length of T-unit offers support for the argument hinted at earlier: at the onset of the study, participants in the control group were perhaps at a lower level of written language development than those in the treatment group.

Table 16: Results of Mann-Whitney U Test for Between Group Comparisons on Complexity Measures

\begin{tabular}{lllll}
\hline Measure & Test & $\mathbf{U}$ & Z score & $\begin{array}{l}\text { Asymp.Sig } \\
\text { (2-tailed) }\end{array}$ \\
\hline Mean length of T-unit & Pre & 4.0 & -2.042 & $.041^{*}$ \\
& Post & 14.0 & -.34 & .734 \\
Mean length of clause & Pre & 11.0 & -.849 & .396 \\
& Post & 16.0 & .000 & 1.00 \\
Ratio of dependent clauses to & Pre & 11.0 & -.851 & .395 \\
total clauses & Post & 8.0 & -1.364 & .173 \\
Ratio of subordinate clauses & Pre & 6.5 & -1.61 & .105 \\
to total clauses & Post & 7.0 & -1.53 & .126 \\
Type/Token ratio & Pre & 13.0 & -.51 & .608 \\
& Post & 10.5 & -.95 & .340 \\
\% AWL words in text & & & & \\
& Pre & 9.0 & -1.189 & .23 \\
\% K-1 words in text & Post & 3.0 & -2.21 & $.027^{*}$ \\
& & & & \\
& Pre & 12.0 & -.679 & .497 \\
& Post & 12.0 & -.679 & .497 \\
\hline
\end{tabular}

* Statistically significant difference between treatment and control groups ( $\mathrm{p} \leq .05)$.

\section{Summary of Complexity Findings \& Discussion}

Analysis of syntactic and lexical complexity measures for the wiki-based collaborative writing treatment group yielded mixed results which did not offer 
much support in favor of the treatment. Wilcoxon tests confirmed statistically significant decreases in the ratio of dependent clauses to total clauses $(\mathrm{z}=-2.521$, $\mathrm{p}=.012)$ and type/token ratio $(\mathrm{z}=-2.316, \mathrm{p}=.021)$ but a significant increase in the ratio of subordinate clauses to total clauses $(\mathrm{z}=-2.24, \mathrm{p}=.025)$. The between group comparison with Mann-Whitney U tests revealed significant differences between the treatment and control groups on the mean length of T-unit pretest measure $(\mathrm{U}=4$, $\mathrm{p}=.041)$ and the posttest measure of $\%$ AWL words in text $(\mathrm{U}=3, \mathrm{p}=.027)$.

Rather than speculate about the potential ineffectiveness of wiki-based collaborative writing activities on individual L2 writers' development, we should consider additional variables that may have contributed to this negative result. Perhaps it might be that for this group of learners, linguistic complexity was best achieved when working alone. It might have been that learners in the control group received some type of unreported outside instruction that enabled them to perform better on the posttest. Another explanation might be that the increase in fluency occurred at the expense of complexity. Finally, it is certainly possible that this result occurred entirely by chance.

\section{Accuracy}

Accuracy was measured multidimensionally in order to examine error-free structural units as well as the quantity and distribution of errors. As noted in the methodology chapter, details regarding operationalization of error can be found in Appendix N. Four metrics were used including a ratio of error-free clauses to total clauses, mean number of errors per text, mean number of errors per T-unit, and 
mean number of errors per clause. Additionally, an error classification system was used to determine the amount of various error types present in the compositions. First, I will present and discuss the descriptive and inferential statistical findings of the four ratio calculations. Then I will turn to the descriptive findings and discussion of error types.

Mean scores, gain scores, and standard deviations were calculated for the four accuracy measures mentioned above. Descriptive statistics are provided by group in Table 17. It's very important to remember that for accuracy, a decrease in score from pretest to posttest indicates greater accuracy. Thus negative gain scores for the repeated measures indicate an increase in accuracy. The data show that mean scores for the collaborative writing treatment group improved from pre to posttest on two of the four measures whereas the control group improved on three. One impressive finding based on the descriptive statistics is the decrease in mean number of errors per text for control group participants.

Table 17: Descriptive Statistics for Averaged Scores on Accuracy Measures by Group

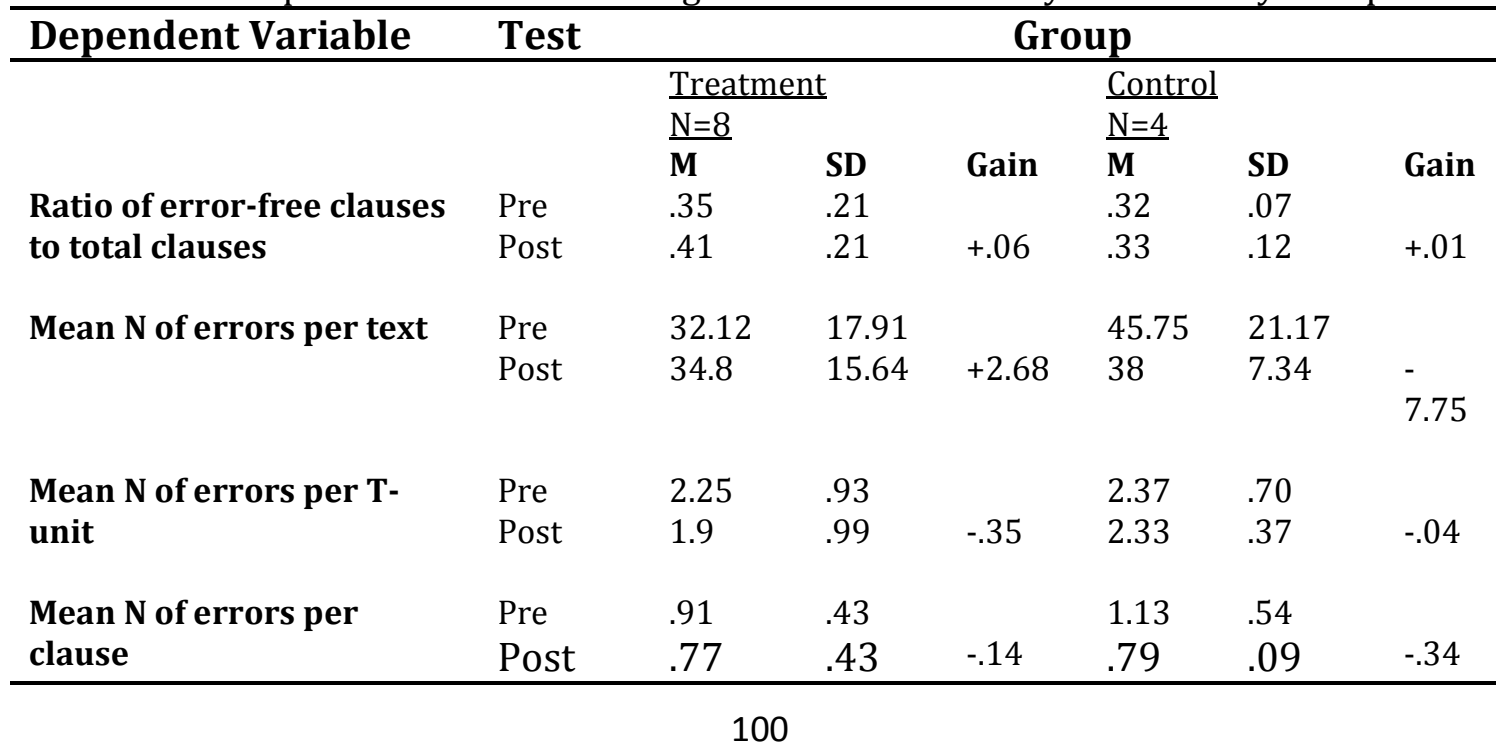


The gain score of -7.75 indicates that participants in this group made on average nearly 8 fewer errors in their posttest compositions compared to the pretests.

The dispersion of scores for each group on each measure appears to show less variation between and within the groups than the scores achieved for fluency and complexity. Additionally, the standard deviation for mean number of errors per text dropped considerably from pretest $(\mathrm{SD}=21.17)$ to posttest $(7.34)$ for the control group. This fluctuation (along with the high standard deviation observed for the control group on fluency measures) indicates that the control group was affected by outlier scores. That is, one participant in the control group either scored very high or very low with respect to the other group members.

Wilcoxon tests were used to compare the pre and posttest accuracy scores of learners who took part in the collaborative writing treatments. As shown in Table 18 , none of the differences on repeated measures were found to be statistically significant.

Table 18: Results of Wilcoxon Test on Treatment Group Pre and Posttest Accuracy Measures

\begin{tabular}{lllll}
\hline Measure & Test & Means & $\boldsymbol{Z}$ score & Asymp.Sig (2-tailed) \\
\hline $\begin{array}{l}\text { Ratio of error-free clauses to total } \\
\text { clauses }\end{array}$ & Pre & .35 & -1.12 & .26 \\
& Post & .41 & & \\
Mean N of errors in text & Pre & 32.12 & -.84 & .4 \\
& Post & 34.87 & & \\
Mean N of errors per T-unit & Pre & 2.25 & -1.4 & .16 \\
& Post & 1.96 & & \\
Mean N of errors per clause & Pre & .91 & -.98 & .32 \\
& Post & .77 & & \\
\hline
\end{tabular}

$p \leq .05$ 
Between group comparisons of accuracy scores were examined across pre and posttest measures. The mean ranks on repeated measures are reported by group in Table 19. We can notice that there is much less variability in the mean ranks for accuracy measures as compared to the mean ranks reported for fluency and complexity measures. This suggests that with regard to accurate written production, the two groups of learners might have been more similar than they were in terms of fluency and complexity.

Table 19: Mean Ranks of Treatment and Control Group on Pre and Posttest Accuracy Measures

\begin{tabular}{llll}
\hline Accuracy Measure & Test & \multicolumn{2}{c}{ Group } \\
\hline & & $\begin{array}{l}\text { Treatment } \\
\text { Mean Rank }\end{array}$ & $\begin{array}{l}\text { Control } \\
\text { Mean Rank }\end{array}$ \\
$\begin{array}{llll}\text { Ratio of error-free clauses to } \\
\text { total clauses }\end{array}$ & Pre & 6.44 & 6.63 \\
& Post & 6.81 & 5.88 \\
Mean N of errors in text & Pre & 5.63 & 8.25 \\
& Post & 6.38 & 6.75 \\
Mean N of errors per T-unit & Pre & 6.25 & 7 \\
& Post & 5.88 & 7.75 \\
Mean N of errors per clause & Pre & 5.88 & 7.75 \\
& Post & 6.25 & 7.00 \\
\hline
\end{tabular}

Mann-Whitney U tests confirmed this and did not yield statistically significant differences between the two groups on the repeated measures. Output from the statistical tests is provided in Table 20.

Since L2 learners may often sacrifice one linguistic dimension in favor of improving another (Foster \& Skehan, 1996) I initially hypothesized that accuracy scores for treatment group participants may have shown greater improvement and 
thus could perhaps explain the complexity scores. However, as MacKay (1982) suggests, there may also be a trade-off between fluency and accuracy. That is, as the rapidity with which learners produce language increases, so too does the likelihood of error. This explanation seems most relevant for the data examined in the present study.

Table 20: Results of Mann-Whitney U Test for Between Group Comparisons on Accuracy Measures

\begin{tabular}{lllll}
\hline Measure & Test & $\mathbf{U}$ & $\begin{array}{l}\text { Z } \\
\text { score }\end{array}$ & $\begin{array}{l}\text { Asymp.Sig } \\
\text { (2-tailed) }\end{array}$ \\
\hline $\begin{array}{llll}\text { Ratio of error-free clauses } \\
\text { to total clauses }\end{array}$ & Pre & 15.5 & -.08 & .93 \\
& Post & 13.5 & -.42 & .67 \\
Mean N of errors in text & Pre & 9 & -1.19 & .23 \\
& Post & 15 & -.17 & .86 \\
Mean N of errors per T-unit & & & & \\
& Pre & 14 & -.34 & .73 \\
& Post & 11 & -.84 & .39 \\
$\begin{array}{l}\text { Mean N of errors per } \\
\text { clause }\end{array}$ & Pre & 11 & -.851 & .39 \\
\hline & Post & 14 & -.34 & .73 \\
\hline
\end{tabular}

$p \leq .05$

Given that the four accuracy measures examined above could not capture the type and severity of errors within the compositions, an error classification system (see appendix N) was used to identify the type and quantity of each error in both the pre and posttests. The means and standard deviations for each error type on the repeated measures are displayed by group in Table 21 . One major trend we can see from the data is that across groups, there were five error types most frequent for the learners: lexical errors, prepositions, verb forms, missing words, and run-on sentences. Lexical errors, as explained in more detail in Appendix N, were typically 
realized by awkward phrasing or aberrant words. Inflection following modals and incorrect irregular forms were predominant among the verb form errors. Missing word errors occurred frequently when a subject was missing from an independent clause that was preceded by a dependent clause.

Table 21: Descriptive Statistics for Averaged Error Type Frequencies by Group

\begin{tabular}{|c|c|c|c|c|c|}
\hline \multirow[t]{3}{*}{ Error Type } & \multirow[t]{3}{*}{ Test } & \multicolumn{4}{|c|}{ Group } \\
\hline & & \multicolumn{2}{|c|}{$\begin{array}{l}\text { Treatment } \\
\mathrm{N}=12\end{array}$} & \multicolumn{2}{|c|}{$\begin{array}{l}\text { Control } \\
\mathrm{N}=4\end{array}$} \\
\hline & & M & SD & $\mathbf{M}$ & SD \\
\hline \multirow[t]{2}{*}{ Lexical } & Pre & 3.75 & 3.15 & 5 & 2 \\
\hline & Post & 5.5 & 1.77 & 3.25 & 1.89 \\
\hline \multirow[t]{2}{*}{ Tense/Aspect } & Pre & .875 & 1.12 & 1 & 0.81 \\
\hline & Post & .25 & 0.46 & 2.75 & 2.06 \\
\hline \multirow[t]{2}{*}{ Number } & Pre & 2 & 1.80 & 4.33 & 2.98 \\
\hline & Post & 2.87 & 3.60 & 1.75 & 2.36 \\
\hline \multirow[t]{2}{*}{ Parallel Structure } & Pre & .125 & 0.35 & 0 & 0 \\
\hline & Post & .375 & 0.51 & 0 & 0 \\
\hline \multirow[t]{2}{*}{ Preposition } & Pre & 4.75 & 4.18 & 3.5 & 3.31 \\
\hline & Post & 3.12 & 2.10 & 4 & 1.41 \\
\hline \multirow{2}{*}{ Referent } & Pre & 0 & 0 & .5 & 1 \\
\hline & Post & .125 & 0.35 & .75 & 0.95 \\
\hline \multirow[t]{2}{*}{ Subject-Verb Agreement } & Pre & 1.25 & 1.66 & 3.25 & 1.70 \\
\hline & Post & 1.75 & 1.83 & 3.5 & 2.38 \\
\hline \multirow[t]{2}{*}{ Article } & Pre & 2.875 & 2.23 & 2.75 & 1.70 \\
\hline & Post & 2.25 & 1.28 & 2.75 & 3.59 \\
\hline \multirow[t]{2}{*}{ Determiner } & Pre & 1.375 & 1.40 & 2.75 & 1.70 \\
\hline & Post & 1.125 & 2.10 & .5 & 0.57 \\
\hline \multirow[t]{2}{*}{ Word Form } & Pre & 3.625 & 3.50 & 1.5 & 1.73 \\
\hline & Post & 1.625 & 1.30 & 2 & 0.81 \\
\hline \multirow[t]{2}{*}{ Verb Form } & Pre & 3.125 & 1.80 & 3.25 & 1.70 \\
\hline & Post & 3.875 & 2.90 & 5 & 3.16 \\
\hline \multirow[t]{2}{*}{ Case } & Pre & .125 & 0.35 & 0 & 0 \\
\hline & Post & 0 & 0 & 0 & 0 \\
\hline \multirow[t]{2}{*}{ Missing Word } & Pre & 2.375 & 2.61 & 4.25 & 3.94 \\
\hline & Post & 5 & 3.77 & 3 & 2.44 \\
\hline Pronoun & Pre & .375 & 0.51 & .375 & 2 \\
\hline
\end{tabular}




\begin{tabular}{llllll}
\hline \multirow{3}{*}{ Coordinator/Subordinator } & Post & 0 & 0.74 & 0 & 0 \\
& Pre & 1.375 & 1.18 & 2.75 & 3.09 \\
\cline { 2 - 5 } Word Order & Post & 1.375 & 1.06 & 2 & 1.41 \\
\multirow{4}{*}{ Negation } & Pre & 3 & 0.92 & 2.75 & 2.21 \\
& Post & 1.875 & 1.72 & 1.75 & 0.5 \\
Run-on/Comma Splice & Pre & 0 & 0 & 0 & 0 \\
& Post & .25 & 0.46 & 0 & 0 \\
& Pre & 2.375 & 1.99 & 8.25 & 4.5 \\
& Post & 3.125 & 2.90 & 5 & 3.74 \\
\hline
\end{tabular}

On the pretest, errors in preposition were the most frequent for learners in the treatment group $(M=4.75)$ while learners in the control group made the most errors in run-on sentences or comma splices $(M=8.25)$. On the posttest, lexical errors were the most frequent for the treatment group $(M=5.5)$ as well as the control group $(\mathrm{M}=5)$. The control group also had a mean score of 5 for verb form errors. It was interesting to see that the error categories with the higher mean scores were generally those with the higher standard deviations. This might suggest that there was great variability in the frequency of errors in each of the categories depending on the participant.

Another observation that can be made from these data is that on error categories of word form and word order, the mean scores of both groups decreased from pretest to posttest. Although this does not suggest any clear benefit for the collaborative writing treatment group, it does suggest that both groups of learners made improvements on more global issues of accuracy. It's possible that this might have been reflected if a holistic scale had been used to evaluate the compositions. 


\section{Summary of Accuracy Findings \& Discussion}

Analysis of accuracy measures proved somewhat inconclusive with regard to the benefits of collaborative writing. While mean scores for the treatment group decreased on the measures of mean number of errors per T-unit and mean number of errors per clause, neither of these differences were statistically significant. Similarly, group comparisons with Mann-Whitney U tests did not elicit significant differences between the treatment and control groups on either pre or posttests. A descriptive examination of error types revealed that across group conditions, on both pre and posttests, five error categories were most problematic: lexical errors, prepositions, verb forms, missing words, and run-on sentences.

\section{Summary of Findings \& Discussion for Research Question 1}

In summary, the quantitative analyses conducted on dependent measures of linguistic complexity, accuracy, and fluency produced mixed results. Table 22 displays summary statistics for each of the dependent measures by group. Although descriptive statistics calculated for four fluency measures revealed promising gain scores in support of collaborative writing, the differences in scores between groups and across repeated measures within the treatment group were not significant. Results of the complexity measures analyses were characterized by inconsistencies. For the wiki-based collaborative writing treatment group, Wilcoxon tests confirmed statistically significant decreases in the ratio of dependent clauses to total clauses $(\mathrm{z}=-2.521, \mathrm{p}=.012)$ and type/token ratio $(\mathrm{z}=-2.316, \mathrm{p}=.021)$ but a significant 
increase in the ratio of subordinate clauses to total clauses $(\mathrm{z}=-2.24, \mathrm{p}=.025)$. The between group comparison with Mann-Whitney U tests revealed significant differences between the treatment and control groups on the mean length of T-unit pretest measure $(\mathrm{U}=4, \mathrm{p}=.041)$ and the posttest measure of $\%$ AWL words in text $(U=3, p=.027)$. Similarly, the findings based on outcome measures of accuracy were inconclusive with respect to affordances of collaborative writing. 
Table 22: Summary of Statistical Findings for each Linguistic Dimension by Group

\begin{tabular}{|c|c|c|c|c|c|c|c|}
\hline \multirow[t]{3}{*}{ Construct } & \multirow[t]{3}{*}{ Measures } & \multicolumn{6}{|c|}{ Group } \\
\hline & & \multicolumn{3}{|c|}{ Treatment $(n=8)$} & \multicolumn{3}{|c|}{ Control $(n=4)$} \\
\hline & & Test & Mean & Gain & Test & Mean & Gain \\
\hline \multicolumn{8}{|l|}{ Fluency } \\
\hline & \# of Words per text & $\begin{array}{l}\text { Pre } \\
\text { Post }\end{array}$ & $\begin{array}{l}281.37 \\
341.75\end{array}$ & +60.38 & $\begin{array}{l}\text { Pre } \\
\text { Post }\end{array}$ & $\begin{array}{l}308.00 \\
331.25\end{array}$ & $\begin{array}{l}+23.2 \\
5\end{array}$ \\
\hline & $\begin{array}{l}\text { Average \# of words } \\
\text { per min. }\end{array}$ & $\begin{array}{l}\text { Pre } \\
\text { Post }\end{array}$ & $\begin{array}{l}9.37 \\
11.39\end{array}$ & +2.02 & $\begin{array}{l}\text { Pre } \\
\text { Post }\end{array}$ & $\begin{array}{l}10.25 \\
11.04\end{array}$ & +.79 \\
\hline & \# T-units per text & $\begin{array}{l}\text { Pre } \\
\text { Post }\end{array}$ & $\begin{array}{l}14.75 \\
18.37\end{array}$ & +3.62 & $\begin{array}{l}\text { Pre } \\
\text { Post }\end{array}$ & $\begin{array}{l}19.50 \\
16.75\end{array}$ & -2.75 \\
\hline & \# Clauses per text & $\begin{array}{l}\text { Pre } \\
\text { Post }\end{array}$ & $\begin{array}{l}36.37 \\
48.12\end{array}$ & +11.75 & $\begin{array}{l}\text { Pre } \\
\text { Post }\end{array}$ & $\begin{array}{l}42.75 \\
48.25\end{array}$ & +5.5 \\
\hline \multicolumn{8}{|l|}{ Complexity } \\
\hline \multirow[t]{4}{*}{ Grammatical } & $\begin{array}{l}\text { Dependent } \\
\text { Clauses/Total Clauses }\end{array}$ & $\begin{array}{l}\text { Pre } \\
\text { Post }\end{array}$ & $\begin{array}{l}.56 \\
.58\end{array}$ & $-.02 * 1$ & $\begin{array}{l}\text { Pre } \\
\text { Post }\end{array}$ & $\begin{array}{l}.50 \\
.63\end{array}$ & +.13 \\
\hline & $\begin{array}{l}\text { Subordinate } \\
\text { Clauses/Total Clauses }\end{array}$ & $\begin{array}{l}\text { Pre } \\
\text { Post }\end{array}$ & $\begin{array}{l}.26 \\
.35 \\
\end{array}$ & $+.09 * 2$ & $\begin{array}{l}\text { Pre } \\
\text { Post }\end{array}$ & $\begin{array}{l}.38 \\
.27 \\
\end{array}$ & -.11 \\
\hline & Mean length of T-unit & $\begin{array}{l}\text { Pre } \\
\text { Post }\end{array}$ & $\begin{array}{l}20.41^{* 4} \\
19.11 \\
\end{array}$ & -1.3 & $\begin{array}{l}\text { Pre } \\
\text { Post }\end{array}$ & $\begin{array}{l}15.96^{* 4} \\
20.43 \\
\end{array}$ & +4.47 \\
\hline & Mean length of Clause & $\begin{array}{l}\text { Pre } \\
\text { Post }\end{array}$ & $\begin{array}{l}8.00 \\
7.16\end{array}$ & -.84 & $\begin{array}{l}\text { Pre } \\
\text { Post }\end{array}$ & $\begin{array}{l}7.28 \\
6.97 \\
\end{array}$ & -.31 \\
\hline \multirow[t]{3}{*}{ Lexical } & Type/token ration & $\begin{array}{l}\text { Pre } \\
\text { Post }\end{array}$ & $\begin{array}{l}.50 \\
.43\end{array}$ & $-.07 * 3$ & $\begin{array}{l}\text { Pre } \\
\text { Post }\end{array}$ & $\begin{array}{l}.48 \\
.46\end{array}$ & -.02 \\
\hline & $\%$ AWL words per text & $\begin{array}{l}\text { Pre } \\
\text { Post }\end{array}$ & $\begin{array}{l}7.17 \\
6^{* 5} \\
\end{array}$ & -1.17 & $\begin{array}{l}\text { Pre } \\
\text { Post }\end{array}$ & $\begin{array}{l}5.63 \\
9.13^{* 5}\end{array}$ & +3.5 \\
\hline & $\% \mathrm{~K}-1$ words per text & $\begin{array}{l}\text { Pre } \\
\text { Post }\end{array}$ & $\begin{array}{l}84.76 \\
86.54 \\
\end{array}$ & +1.78 & $\begin{array}{l}\text { Pre } \\
\text { Post }\end{array}$ & $\begin{array}{l}86.15 \\
83.83 \\
\end{array}$ & -2.32 \\
\hline \multicolumn{8}{|l|}{ Accuracy } \\
\hline & $\begin{array}{l}\text { Error-free } \\
\text { Clauses/Total Clauses }\end{array}$ & $\begin{array}{l}\text { Pre } \\
\text { Post }\end{array}$ & $\begin{array}{l}.35 \\
.41\end{array}$ & +.06 & $\begin{array}{l}\text { Pre } \\
\text { Post }\end{array}$ & $\begin{array}{l}.32 \\
.33 \\
\end{array}$ & .01 \\
\hline & \# of errors per text & $\begin{array}{l}\text { Pre } \\
\text { Post }\end{array}$ & $\begin{array}{l}32.12 \\
34.8 \\
\end{array}$ & +2.68 & $\begin{array}{l}\text { Pre } \\
\text { Post }\end{array}$ & $\begin{array}{l}45.75 \\
38.00 \\
\end{array}$ & -7.75 \\
\hline & $\begin{array}{l}\text { Mean \# of errors per } \\
\text { T-unit }\end{array}$ & $\begin{array}{l}\text { Pre } \\
\text { Post }\end{array}$ & $\begin{array}{l}2.25 \\
1.9 \\
\end{array}$ & -.35 & $\begin{array}{l}\text { Pre } \\
\text { Post }\end{array}$ & $\begin{array}{l}2.37 \\
2.33 \\
\end{array}$ & -.04 \\
\hline & $\begin{array}{l}\text { Mean \# of errors per } \\
\text { clause }\end{array}$ & $\begin{array}{l}\text { Pre } \\
\text { Post }\end{array}$ & $\begin{array}{l}.91 \\
.77\end{array}$ & -.14 & $\begin{array}{l}\text { Pre } \\
\text { Post }\end{array}$ & $\begin{array}{l}1.13 \\
.79\end{array}$ & -.34 \\
\hline
\end{tabular}

${ }^{* 1}$ statistically significant for Wilcoxon $(\mathrm{z}=-2.521, \mathrm{p}=.012)$

${ }^{*} 2$ statistically significant for Wilcoxon $(\mathrm{z}=-2.24, \mathrm{p}=.025)$

${ }^{*} 3$ statistically significant for Wilcoxon $(\mathrm{z}=-2.316, \mathrm{p}=.021)$

${ }^{*} 4$ statistically significant for Mann-Whitney on pretest $(U=4, p=.041)$

${ }^{*}$ statistically significant for Mann-Whitney on posttest $(U=3, p=.027)$ 
When attempting to explain these mixed findings, we might consider to what extent the three dimensions of accuracy, fluency, and complexity interact. Some researchers contend that fluency competes with accuracy for attention, while accuracy competes with complexity (Ellis, 1994; Foster \& Skehan, 1999). This speaks to the discontinuous progression of the three linguistic dimensions analyzed in the present study. One could reason that learners in the treatment group may have felt pressure to write faster and produce more output as a result of the timed collaborative writing activities. This condition may have raised their consciousness with regard to fluency, and in doing so, compromised accuracy and complexity. That is, perhaps learners chose to use more simplistic and readily accessible structures in an effort to write more, while simultaneously overlooking the dimension of accuracy.

Although the aim of the first research question was to investigate what impact collaborative writing and structured writing practice in pairs had on individual writing, with regard to the results, the control groups' gains cannot be ignored. In fact, the performance of the control group was quite remarkable especially since they received no treatment at all. Their mean scores improved on three of the four fluency measures, four of the seven complexity measures, and three of the four accuracy measures. Additionally, the control group improved (made fewer errors) on 8 of the 18 error types from pre to posttest. Although further statistical analysis of the control group's performance was not conducted for this study, it is certainly encouraged for future research. 
An implication of the overall mixed findings seems to be the necessity of measuring accuracy, fluency, and complexity multidimensionally. It appears that some measures may have been too broad to capture delicate differences in linguistic development, especially since the present study was relatively short and not all participants in the treatment group attended all collaborative writing sessions. We might also consider the attendance of participants when interpreting the findings. As noted in the previous chapter, only two of the eight treatment group participants attended all five collaborative writing sessions. Had all participants in the treatment group attended all the sessions, it's possible that the results would have been very different. Finally, it's possible to interpret the findings as chance results or simply an indication that for this sample of English language learners, individual work was more beneficial than collaborative work.

\section{Research Question 2}

How do learners in the study perceive wiki-based collaborative writing activities?

This research question aimed to gauge students' opinions and perceptions of the wiki-based collaborative writing activities. Seven of the eight treatment group participants responded to the survey immediately following the posttest. As discussed in the methodology chapter, a 5-point Likert scale ranging from 1(strongly disagree) to 5 (strongly agree) was used to measure students' views of the wiki and the study in general. The survey also contained four open-ended questions to which students could respond freely. The 16 items contained in the 
survey along with their mean score based on the Likert scale rankings are presented in Table 23.

The quantitative data revealed that overall, students had a positive experience participating in the study and using the wiki. The mean score of 5 for the first item indicates that all respondents strongly agreed that the study was beneficial for their English learning. Most students agreed that writing collaboratively in the wiki made it easier for them to develop their ideas and organize their writing.

Table 23: Mean Scores of Exit Survey on Perceptions of Wiki-based Collaborative Writing

\begin{tabular}{|c|c|}
\hline Survey Item & Mean Score \\
\hline $\begin{array}{l}\text { 1. Being a participant in this study was beneficial for my English language } \\
\text { learning. }\end{array}$ & 5 \\
\hline 2. The wiki is a useful tool for writing collaboratively with others. & 4.71 \\
\hline 3. The wiki was difficult to use. & 2.42 \\
\hline $\begin{array}{l}\text { 4. Writing essays in the wiki with a partner was easier than writing essays } \\
\text { alone. }\end{array}$ & 3.57 \\
\hline $\begin{array}{l}\text { 5. Writing collaboratively with a partner helped me improve my English } \\
\text { vocabulary. }\end{array}$ & 4.5 \\
\hline 6. Writing collaboratively with a partner made it easier to think of ideas. & 4.2 \\
\hline 7. Writing collaboratively with a partner made it easier to organize the essay. & 3.42 \\
\hline $\begin{array}{l}\text { 8. Writing collaboratively with a partner helped me improve my English } \\
\text { grammar. }\end{array}$ & 4.14 \\
\hline $\begin{array}{l}\text { 9. When I wrote with a partner, we could write a longer response than I could } \\
\text { write when I wrote by myself. }\end{array}$ & 3.42 \\
\hline 10. Talking with a partner about the essay was helpful. & 4.57 \\
\hline $\begin{array}{l}\text { 11. Being a participant in this study helped me prepare for the iBT TOEFL } \\
\text { writing test. }\end{array}$ & 4.42 \\
\hline 12. Writing collaboratively in a wiki was fun and educational. & 4.42 \\
\hline $\begin{array}{l}\text { 13. I would prefer to practice writing by myself rather than collaboratively } \\
\text { with others. }\end{array}$ & 2.42 \\
\hline $\begin{array}{l}\text { 14. Learning about brainstorming, outlining, transition words and expressions, } \\
\text { and essay organization helped me. }\end{array}$ & 4.85 \\
\hline $\begin{array}{l}\text { 15. I think my individual writing ability improved after participating in this } \\
\text { study. }\end{array}$ & 4.42 \\
\hline
\end{tabular}


16. In the future, I would like to participate in more collaborative writing activities using a wiki.

Also encouraging was the fact that most students found the wiki easy to use.

This was evident in the mean score of 2.42 on item 3: The wiki was difficult to use. That is, for the most part, students disagreed with this statement. In general, students agreed that writing collaboratively and talking with a partner about their essays was helpful. These results support the effectiveness of the wiki for collaborative writing and suggest that learners would prefer more practice writing collaboratively than writing alone.

With respect to specific language dimensions, the majority of students agreed that collaborative writing helped them improve their grammar and vocabulary; although results of the quantitative analyses on measures of accuracy and complexity suggest that these perceived improvements were not necessarily evident in their individually written posttests. There was also overall agreement that writing collaboratively enabled students to write longer responses than they could have when writing alone. Based on the overall gains in fluency scores from pretest to posttest for the treatment group, we might speculate that this affordance of collaborative writing was transferred to the individuals' compositions. Finally, most students agreed that the pair activities focusing on brainstorming, outlining, and essay organization were fruitful and educational. Moreover, students agreed that participating in the study helped them prepare for the iBT TOEFL writing test.

Open-ended questions were used to investigate additional learner perceptions of wiki-based collaborative writing and generate suggestions and 
feedback on the web-based tool. There was some consensus among participants regarding technical drawbacks of the wiki. Two participants mentioned the fact that they couldn't type simultaneously on the same wiki page slowed down their work. For example, one student commented, “since I can't type at the same time as my partner, it's annoying." Another learner responded, "I wish we could type on the same page together." These quotes speak directly to the asynchronous nature of the wiki and echo the findings reported by participants in Lee \& Wang (2013). Another learner expressed frustration with having to continually save the document after making edits: “I wonder why this wiki doesn't save my work automatically? I don't like to click save every time I edit." In terms of the wiki layout and design, one learner commented that the tool lacked a clear main menu and thus navigating the linked pages was confusing at times. He said: "If there was a main menu it would be easier to find all the pages. The side menu is not really obvious." Finally, two students responded that the wiki contained too many words and not enough images and icons that would have made searching the page easier. More specifically, one of these learners responded by saying, "the words are good but pictures can be didactic and I don't feel confused."

Despite these reported hindrances, participants' comments suggested that they had an overall positive experience using the wiki for collaborative writing activities. One student mentioned that it was beneficial to see the ideas of other people and find out what others were writing about. Specifically he commented, "I really liked reading the ideas of my classmates because sometimes we don't have 
time to share our opinions. In the wiki I can understand what they feel about some issues." Another participant commented on the usefulness of the notifications on the wiki-history page. That is, when anyone made an edit to a page in the wiki, the change was logged and the evolution of the text could be easily tracked. Finally, some participants commented that the wiki contained a lot practical information about writing which was easily accessible and served as a guide. One participant commented that "the extra information in the wiki about writing strategies and brainstorming and transitions was very helpful. Thank you very much for all the information you gave us."

\section{Summary of results pertaining to research question 2}

In summary, learners who participated in the wiki-based collaborative writing treatments indicated that they had a positive experience. Results of the Likert scale survey revealed that participants found the wiki easy to use and educational. They expressed their enjoyment for writing with a partner and felt that taking part in the study contributed to improvement in their own writing abilities. Aside from a few technical inconveniences, the learners found the wiki to be a useful tool for collaborative writing.

\section{Conclusion of results and discussion}

In this chapter I have presented and discussed the findings of the two research questions central to the present study: (1) Does collaborative writing in a 
wiki space impact the individual writing of intermediate to advanced level English L2 learners on measures of linguistic complexity, accuracy, and fluency? If so, how, and to what extent are these measures affected? (2) How do learners in the study perceive wiki-based collaborative writing activities? To answer the first research question I conducted statistical analyses on repeated measures of linguistic complexity, accuracy, and fluency in written compositions. I compared the differences between groups (treatment and control) as well as within groups (treatment only) across pre and posttest conditions. On measures of accuracy and complexity, findings did not provide much support to suggest the advantages of collaborative writing for individual writing development. In terms of fluency however, collaborative writing had a positive yet not statistically significant effect.

To answer the second research question, I administered an exit survey to participants who took part in the wiki-based collaborative writing activities. Their responses were analyzed both qualitatively and using descriptive statistics. In general, learners had positive perceptions about wiki-based collaborative writing and found the wiki to be a useful and educational tool. In the next chapter, I contextualize these findings within the broader discourses of second language writing instruction and technology for language learning. I also discuss the limitations of the present study and suggest future directions for research 


\section{CHAPTER 5: CONCLUSION}

In this chapter I reiterate the basic conclusions I have drawn about the impact of wiki-based collaborative writing on individual L2 writers' development. I then discuss some limitations of the present study and provide suggestions for future research directions. Finally, I present some pedagogical implications and discuss potential applications for wiki-based collaborative writing instruction in L2 classrooms.

\section{Summary of Findings}

Quantitative analysis of L2 learners' written compositions before and after a series of wiki-based collaborative writing treatments has allowed me to draw three conclusions. First, wiki-based collaborative writing seems to have a positive impact on individual writers' fluency, particularly those learners who are less fluent writers. Second, although collaborative writing in a wiki did not provide overall positive support for an increase in written complexity or accuracy, it also was not detrimental to learners' development. This was also reflected in the perception data obtained through the participant survey. Specifically, learners felt that writing collaboratively in the wiki helped improve their grammar, vocabulary, and overall writing ability. Thus analysis of exit survey data enabled me to conclude that learners had a positive experience with wiki-based collaborative writing.

The mixed results of quantitative analyses used to measure learning gains could be explained by a variety of factors. First, research has suggested that 
accuracy, complexity, and fluency do not develop at the same rate or uniformly (Housen \& Kuiken, 2009). While fluency has been shown to develop faster and achieve higher levels than complexity or accuracy, complexity has been shown to develop the least and L2 writers may favor fluency over accuracy (Leki, Cumming, \& Silva, 2008). This differential evolution of the three linguistic dimensions and learners' tendency to favor fluency over accuracy or complexity seems to serve as a plausible explanation for the results of the present study. While fluency gains were not statistically significant for treatment group participants on any of the four fluency measures, compared to accuracy and complexity, the gains were certainly consistent and positive. Moreover, since pretest scores suggested that treatment group participants were perhaps less fluent writers at the onset of the study yet obtained higher gain scores (posttest-pretest) than the control group, one could hypothesize that wiki-based collaborative writing might be more beneficial for less fluent L2 writers.

A second factor to consider when drawing conclusions about these findings is language proficiency level. Although participants in this study were members of an intact class, their writing proficiency levels had not been determined through formal assessment. While they were granted the opportunity to enroll in the course based on their performance on an English proficiency exam, the details of this test including its format and language skills assessed were not made available to the instructor. As Young (1995) has pointed out, various dimensions of language proficiency or development do not necessarily progress at the same rate. Therefore, 
at the onset of the study, it's reasonable to assume that some participants may have been more fluent but inaccurate writers, more accurate but less fluent writers, or even writers with complex syntax but a basic lexicon and vice versa. Consequently, these varying or vaguely defined proficiency levels of the participants involved might have contributed to the control and treatment groups' reversal of pre and posttest rankings.

\section{Limitations and Future Directions}

There are certainly limitations of this study that need to be acknowledged. In general, these limitations relate to the research design, the developmental measures used for analysis, and the selection of technology. I will briefly discuss each of these and offer suggestions to inform future research of a similar vein.

\section{Research Design}

In terms of research design, one limitation of this study is that the data were collected from a small convenience sample $(\mathrm{N}=12)$ of participants whose attendance was sporadic over the relatively short period of time that the study took place. While the sample of participants was representative of the target population I was interested in studying, the findings cannot be generalized to the larger population of L2 writers. Also, considering that attendance in the treatment group was inconsistent throughout the course of the study, it may be difficult to attribute any linguistic gains exclusively to the collaborative writing and instructional treatment. Finally, since the present study analyzed learners' performance on only one type of 
writing task under timed conditions, the results obtained cannot be generalized across tasks.

Another limitation is the research design. That is, since participants for the treatment and control groups were not randomly selected, there was the possibility of unintentionally allowing the following extraneous variables to affect the results of the study:

1. Outside instruction students were receiving in other classes may have interacted with the collaborative writing treatment in such a way to influence the results. As noted in the methodology chapter and displayed in Table 2, throughout the duration of the study, five students (two in the control group and three in the experimental group) were concurrently enrolled in a TOEIC preparation course.

2. Preexisting differences between groups rather than the treatment could affect changes in the dependent variables between groups. These might include student motivation, outside responsibilities and commitments, and differences in proficiency levels of students at the onset of the study.

3. Subject attrition may have impacted the overall results of the study. Three treatment group and two control group participants did not take the posttest and thus their scores were eliminated from the set of data analyzed. It might be worth noting that one of these learners in the treatment group whose data was excluded from the analysis had participated in four of the wikibased collaborative writing sessions. 
4. Control group rivalry may have caused participants in the control group to attempt to outperform those who participated in treatments. Since the control group was comprised of learners who were unable to attend the collaborative writing treatments as a result of their busy schedules, they may have been motivated to compensate their absence through individual study or practice.

5. The relatively short treatment might not allow enough time to produce noticeable effects. Additionally, since the post-test measurement was applied immediately following completion of the collaborative writing treatment, it would be misleading to conclude that the treatment also has longitudinal effects. That is, we cannot infer that collaborative writing positively impacts individual writing performance in the long-term. To do so, additional samples of participants' individual writing would need to be evaluated in the form of a delayed post-test.

A third limitation is related to the data analysis procedures and the rating of participants' compositions. Since I was the sole rater of the compositions there is the possibility of subjectivity or error affecting the scores. While employing trained raters and establishing interrater reliability is certainly the more desirable method, particularly when coding for errors, due to a lack of resources and the small scale of the present study, multiple raters were not an option. It's important to note that when scoring the compositions, I did follow a set of detailed coding guidelines 
informed by previous empirical research. Moreover, I included these guidelines in the appendix in an effort to make my research more replicable.

On this subject, future research studies should aim to increase reliability through utilization of a group of trained raters. In this way, when inconsistencies between raters surface, the cause for such disagreements can be discussed, resolved, and published. This will enable other researchers to anticipate problems when using similar methods and lead to more sustainable practices when measuring complexity, accuracy, and fluency in L2 writing. Additionally, considering the laborintensiveness of measuring these constructs, complexity in particular, other researchers should explore the possibility of using a computational tool that can automate this measurement. For example, Lu (2010) described a software program (L2 Syntactic Complexity Analyzer) with the capability of producing fourteen index measures of syntactic complexity based on input text. While experimental results have shown that the system is highly reliable, (Lu, 2010) I was unable to located published empirical research studies that have utilized the tool. Moreover, being a novice researcher myself, I felt it necessary that I engage in the assiduous process of manual analysis. Nonetheless, investigating the potential affordances of such a tool will serve to inform future research practices.

\section{Measures used for Analysis}

Another limitation is the simple fact that developmental index measures of complexity, accuracy, and fluency cannot cover the full trajectory of second language acquisition. That is, measures that distinguish between samples at broad 
stages of development may not be sensitive enough to capture differences between samples at one stage or between repeated measures (pretests and posttests) of the same group. In light of this limitation, I would urge future researchers to choose very focused and specific measurements of linguistic gains. That is, rather than approaching analysis from the global perspective of production units like clauses, sentences, and T-units, perhaps it would be more revealing to examine the development of particular structures and features such as the tense/aspect system or use of articles. Additionally, future studies might consider taking a more holistic approach to evaluation and look more closely at improvements in essay content, organization, and overall coherence. While I did not analyze these specific dimensions, while reading and coding the compositions, I got the impression that treatment group participants' writing improved from pre to posttest in the areas of content and organization. Furthermore, future research directions need to consider the performance of the control group as well as that of the treatment group. Conducting statistical analyses on treatment group data may provide researchers with additional insight into factors contributing to linguistic performance or development.

Although my study attempted to gain insight into error-type frequencies over the repeated measures, I did not conduct statistical tests to confirm the differences. Future research needs to take a more narrow approach to investigating the impact of collaborative writing activities on actual language learning. That is, we cannot simply assume that improved accuracy, fluency, or complexity scores on a posttest 
following treatment indicate actual learning. As hinted at previously, studies should be designed to measure specific linguistic features that were either discussed or focused on in the previous collaborative work. Given the small scope of the present study, analysis was limited to only the written compositions produced by individuals in the pre- and post-test samples. Future researchers could gain valuable insight into language development through further analysis of learner dialogue and textual revisions that ensue during the collaborative activities. This would allow the possibility of making generalizations about if or whether certain linguistic structures participants might use in a post-test writing assignment were picked up from their peers, internalized, and then accurately reproduced individually.

\section{Constraints of Wiki technology}

Another limitation is related to the use of a wiki as the medium of technology to support collaborative writing. Due to the fact that wikis are asynchronous, writers cannot simultaneously edit and update a page. While this may not be an issue for out-of-class collaborative writing assignments that focus on the writing process or evolve over a long period of time, when learners are composing joint texts in-class under timed conditions, a synchronous web-based tool such as Google Docs might be more effective for collaboration. This limitation was echoed by participants in the exit survey and a similar observation was noted by Lee \& Wang (2013) who reported that the delayed nature of ACMC was a factor hindering student engagement in wiki projects. Thus, future studies that compare the 
performance and perceptions of learners writing collaboratively via wikis to those using Google Docs might provide insight into the optimal venue for web-based collaborative writing.

In connection with this issue of appropriate venue, another limitation of this study is the inauthentic administration of the wiki-based collaborative writing treatments. Since the wiki is an online platform, it would have been possible for participants to fully engage in the experiment from various locations at different times. While this would illustrate the maximum potential of the wiki to function as an authentic place-independent collaborative environment, the situation could have also been problematic. That is, numerous extraneous variables such as control for time on task during the pre- and post-tests and collaborative writing activities and confirmation of the identity of participants making the contributions to the wiki page during the collaborative treatment, could have potentially affected the validity and reliability of the study. Furthermore, administering the treatment in a computer lab contributed to the overall reliability of the pre- and post-test assessments as the venue provided uniform and non-distracting conditions for participants.

\section{Pedagogical Implications}

Given the increased use of technology and collaborative tools in the second and foreign language classroom, this study provides several important implications for L2 writing instruction. The use of web technology and social tools has the 
potential to expand L2 writers' experiences and provide them with opportunities to engage in meaningful interaction that may facilitate their individual linguistic development. However, when making curricular decisions or implementing collaborative writing activities in the L2 classroom, it's important to consider which tasks and instructional practices will be most advantageous and well-received by the learners involved. As well, instructors should consider the length of time spent on wiki-based collaborative writing. Given the mixed results of the present study with regard to linguistic gains, it might be necessary for learners to engage in longer collaborative writing sessions that span the course of an entire semester.

Instructors should also look to their students to make suggestions. The perception data obtained in the present study can provide some valuable insight with regard to effective classroom practices. For example, the majority of participants strongly agreed that learning about brainstorming, outlining, transition words and essay organization helped them with their writing. From a pedagogical perspective, this suggests that the use of structured and scaffolded tasks within the wiki is important for facilitating a beneficial learning experience.

Another pedagogical implication stems from the feedback provided by learners on the exit survey. Participant suggestions can be very valuable for instructors who wish to implement either in-class or out-of-class web-supported collaborative writing activities into their curriculum. Decisions about methodological approaches and the most appropriate web platforms for the instructional context should be made with respect to the learners involved, as well 
as to the instructors' goals and assumptions about language learning. Instructors need to keep in mind learner variables such as proficiency level or learner needs and design tasks that are compatible with or complement these differences. At the same time, they need to consider whether they want the collaborative writing activities to focus on form as opposed to meaning, or writing product as opposed to writing process.

In conclusion, instructors and researchers alike should consider specific linguistic variables of interest and create opportunities for meaningful practice and research that best speak to their objectives. For instance, synchronous, in-class, time-restricted collaborative writing activities might be most effective to foster fluency development in less proficient L2 writers. However, asynchronous, out-ofclass collaborative writing projects that emphasize revision cycles may support the development of accuracy and complexity in more advanced L2 writers. Reflecting and taking action on these implications will enable instructors to practice more effectively and positively influence the learning outcomes of their students. 


\section{References}

Anton, M., \& DiCamilla, F. (1998). Socio-cognitive functions of L1 collaborative interaction in the L2 classroom. Canadian Modern Language Review, 54(3), 314342.

Arnold, N., \& Ducate, L. (Eds.) (2011). Present and future promises of CALL: From theory and research to new directions in language teaching. San Marcos, TX: CALICO.

Arnold, N., Ducate, L., \& Kost, C. (2012). Collaboration or cooperation? Analyzing group dynamics and revision processes in wikis. CALICO Journal, 29(3), 431448.

Arthur, B. (1979). Short-term changes in EFL composition skills. In C. Yorio, K. Perkins, \& J. Schachter (eds.), On TESOL '79: The learner in focus (pp. 330342). Washington, D.C.: TESOL.

Batstone, R. (Ed.). (2010). Sociocognitive perspectives on language use and language learning. Oxford: Oxford University Press.

Bardovi-Harlig, K. (1992). A second look at T-unit analysis: Reconsidering the sentence. TESOL Quarterly, 26, 390-395.

Bardovi-Harlig, K., \& Boffman, T. (1989). Attainment of syntactic and morphological accuracy by advanced language learners. Studies in Second Language Acquisition, 11(1), 17-34.

Brown, J. D. (1992). Statistics as a foreign language-Part 2: More things to consider in reading statistical language studies. TESOL Quarterly, 26(4), 629-664.

Chao, Y.J, \& Lo, H. (2011). Students' perceptions of wiki-based collaborative writing for learners of foreign language. Interactive Learning Environments, 19(4), p. 395-411.

Cobb,T. Web Vocabprofile [accessed xx Month 200x from http://www.lextutor.ca/vp/ ], an adaptation of Heatley, Nation \& Coxhead's (2002) Range.

Connor, U., \& Asenavage, K. (1994). Peer response groups in ESL writing classes: How much impact on revision? Journal of Second Language Writing, 3(3), 257276.

Coxhead, A. (2000). A new academic word list. TESOL Quarterly, 34(2), 213-138.

Dillenbourg, P. (1999). What do you mean by collaborative learning? In P. Dillenbourg (Ed) Collaborative-learning: Cognitive and Computational Approaches. (p.1-19). Oxford: Elsevier. 
Dobao, A.F. (2012). Collaborative writing tasks in the L2 classroom: Comparing group, pair, and individual work. Journal of Second Language Writing 21, 40-58.

Donato, R. (1994). Collective scaffolding in second language learning. In J. P. Lantolf \& G. Appel (Eds.), Vygotskian approaches to second language research (pp. 3356). Norwood, NJ: Ablex.

Educational Testing Services. (2009). The official guide to the TOEFL test ( $3^{\text {rd }}$ Ed.). Singapore: McGraw Hill.

Ellis, R. (1994). A theory of instructed second language acquisition. In N. Ellis (Ed.), Implicit and explicit learning of languages. (pp. 79-114). London, UK: Academic Press.

Ellis, R. (2003). Task-based language learning and teaching. Oxford: Oxford University Press.

Elola, I. \& Oskoz, A. (2010). Collaborative writing: Fostering foreign language and writing conventions development. Language Learning and Technology, 14(3), $51-71$.

Foster, P., \& Skehan, P. (1998). The influence of planning and task type on second language performance. Studies in Second Language Acquisition, 18(3), 299-323.

Foster, P., Tonkyn, A., \& Wigglesworth, G. (2000). Measuring spoken language: A unit for all reasons. Applied Linguistics, 21(3), 354-375.

Garcia Mayo, M. P. (Ed.). (2007). Investigating tasks in formal language learning. Clevedon, UK: Multilingual Matters.

Gass, S.M. \& Varonis, E.M. (1994). Input, interaction, and second language production. Studies in Second Language Acquisition, 16(3), 283-302.

Goodwin-Jones, R. (2003). Emerging technologies: Blogs and wikis environments for online collaboration. Language Learning and Technology, 7(2), 12-16.

Hakuta, K. (1976). A case study of a Japanese child learning English as a second language. Language Learning, 26(2), 321-351.

Heatley, A., Nation, I.S.P. \& Coxhead, A. (2002). RANGE and FREQUENCY programs. Available at http://www.victoria.ac.nz/lals/staff/paul-nation .

Housen, A., \& Kuiken, F. (2009). Complexity, accuracy, and fluency in second language acquisition. Applied Linguistics, 30(4), 461-473.

Housen, A., Kuiken, F., \& Vedder, I. (Eds.) (2012). Dimensions of L2 performance and proficiency: Complexity, accuracy, and fluency in SLA. Philadelphia, PA: John Benjamins B.V. 
Hubbard, P. (2011). Evaluation of courseware and websites. In N. A. Editor \& L. D. Editor (Eds.), Present and future promises of CALL: From theory and research to new directions in language teaching (407-440). San Marcos, TX: CALICO.

Kessler, G. (2009). Student-initiated attention to form in wiki-based collaborative writing. Language Learning and Technology, 13(1), 79-95.

Kessler, G., \& Bikowski, D. (2010). Developing collaborative autonomous learning abilities in computer mediated language learning: Attention to meaning among students in wiki space. Computer Assisted Language Learning, 23(1), 41-58.

Kim, Y. (2008). The contribution of collaborative and individual tasks on the acquisition of L2 vocabulary. The Modern Language Journal, 92(1), 114-130.

Kost, C. (2011). Investigating writing strategies and revision behavior in collaborative wiki projects. CALICO Journal, 28(3), 606-620.

Lafford, P.A., \& Lafford, B.A. (2005). CMC technologies for teaching foreign languages: What's on the horizon. CALICO Journal, 22(3), 679-709.

Lantolf, J. (Ed.). (2000). Sociocultural theory and second language learning. Oxford: Oxford University Press.

Larsen-Freeman, D. (1978). An ESL index of development. TESOL Quarterly, 12(4), 439-448.

Larsen-Freeman, D. (2006). The emergence of complexity, fluency, and accuracy in the oral and written production of five Chinese learners of English. Applied Linguistics, 27(4), 590-619.

Larsen-Freeman, D. (2009). Adjusting expectations: The study of complexity, accuracy, and fluency in second language acquisition. Applied Linguistics, 30(4), 579-589.

Lee, L. (2010). Exploring wiki-mediated collaborative writing: A case study in an elementary Spanish course. CALICO Journal, 27(2), 260-276.

Lee, H., \& Wang, P. (2013). Discussing the factors contributing to students' involvement in an EFL collaborative wiki project. ReCALL, 25(2), 233-249.

Leki, I. (1990b). Potential problems with peer responding in ESL writing classes. CATESOL Journal, 3, 5-19.

Leki, I., Cumming, A., \& Silva, T. (2008). A synthesis of research on second language writing in English. Routledge: New

Lennon, P. (1990). Investigating fluency in EFL: A quantitative approach. Language Learning, 40, 387-417. 
Long, M., \& Porter, P. (1985). Group work, interlanguage talk, and second language acquisition. TESOL Quarterly, 19(2), 207-228.

Lu, X. (2010). Automatic analysis of syntactic complexity in second language writing. International Journal of Corpus Linguistics, 15(4), 474-496.

Lund, A. (2008). Wikis: A collective approach to language production. ReCALL, 20(1), $35-54$.

MacKay, D. G. (1982). The problems of flexibility, fluency, and speed-accuracy tradeoff in skilled behavior. Psychological Review, 89, 483-506.

Mak, B., \& Coniam, D. (2008). Using wikis to enhance and develop writing skills among secondary school students in Hong Kong. System, 36(3), 437-455.

Murphy, K. R., \& Myors, B. (2004). Statistical power analysis. Mahwah, NJ: Erlbaum.

Nelson, G., \& Murphy, J. (1993). Peer response groups: Do L2 writers use peer comments in revising their drafts? TESOL Quarterly, 27(1), 135-141.

Norris, J. M., \& Ortega, L. (2009). Towards an organic approach to investigating CAF in instructed SLA: The case of complexity. Applied Linguistics, 30(4), 555-578.

Ohta, A. S. (1997). Rethinking interaction in SLA: Developmentally appropriate assistance in the zone of proximal development and the acquisition of L2 grammar. In J. Lantolf (Ed.), Sociocultural theory and second language learning (51-78). Oxford: Oxford University Press.

Ortega, L. (2003). Syntactic complexity measures and their relationship to L2 proficiency: A research synthesis of college-level L2 writing. Applied Linguistics, 24(4), 492-518.

Pallotti, G. (2009). CAF: Defining, refining and differentiating constructs. Applied Linguistics, 30(4), 590-601.

Polio, C. (1997). Measures of linguistic accuracy in second language writing research. Language Learning, 47(1), 101-143.

Richardson, W. (2010). Blogs, wikis, podcasts, and other powerful web tools for classrooms. Thousand Oaks, CA: Corwin Press.

Roschelle, J., \& Teasley, S. D. (1995). The construction of shared knowledge in collaborative problem solving. Computer Supported Collaborative Learning, 128, 69-97.

Sauro, S. \& Smith, B. (2010). Investigating L2 performance in text chat. Applied Linguistics, 31(4), 554-577. 
Shehadeh, A. (2011). Effects and students perceptions of collaborative writing in L2. Journal of Second Language Writing, 20(4), 286-305.

Storch, N. (1999). Are two heads better than one? Pair work and grammatical accuracy. System, 27(3), 363-374.

Storch, N. (2002). Patterns of interaction in ESL pair work. Language Learning, 52(1), $119-158$.

Storch, N. (2005). Collaborative writing: Product, process, and students' reflections. Journal of Second Language Writing, 14(3), 153-173.

Storch, N. (2007). Investigating the merits of pair work on a text editing task in ESL classes. Language Teaching Research, 11(2), 143-159.

Storch, N. (2013). Collaborative writing in L2 classrooms. Tonawanda, NY: Multilingual Matters.

Storch, N., \& Wigglesworth, G. (2007). Writing tasks: The effects of collaboration. In M. Garcia Mayo (Ed.), Investigating tasks in formal language learning (157-177). Clevedon, UK: Multilingual Matters.

Swain, M., (2000). The output hypothesis and beyond: Mediating acquisition through collaborative dialogue. In J. Lantolf (Ed.), Sociocultural theory and second language learning (97-114). Oxford: Oxford University Press.

Swain, M., \& Lapkin, S. (1998). Interaction and second language learning: Two adolescent French immersion students working together. Modern Language Journal, 82(3), 320-337.

Sydorenko, T. (2011). Exploring the potential of rehearsal via automatized structured tasks versus face-to-face pair work to facilitate pragmatic and oral development. (Doctoral dissertation). Michigan State University, East Lansing, MI.

Van Lier, L. (1988). The classroom and the language learner. New York: Longman.

Villamil, O. S., \& De Guerrero, M.C.M. (1998). Assessing the impact of peer revision on L2 writing. Applied Linguistics, 19(4), 491-514.

Vygotsky, L. S. (1978). Mind in society. The development of higher psychological processes. Cambridge, MA: Harvard University Press.

Wigglesworth, G., \& Storch, N. (2009). Pair versus individual writing: Effects on fluency, complexity, and accuracy. Language Testing 26(3), 445-466.

Wolfe-Quintero, K., Inagaki, S., \& Kim, H. (1998). Second Language Development in Writing: Measures of Fluency, Accuracy, and Complexity. Honolulu, Hawaii: University of Hawaii at Manoa. 
Woo, M. M., Chu, S. K. W., Ho, A., \& Li, X. (2011). Using a wiki to scaffold primaryschool students' collaborative writing. Educational Technology \& Society 14(1), 43-54.

Woo, M. M., Chu, S. K. W., \& Li, X. (2013). Peer-feedback and revision process in a wiki mediated collaborative writing. Education Technology Research and Development, 61(2), 279-309.

Young, R. (1995). Discontinuous interlanguage development and its implications for oral proficiency rating scales. Applied Language Learning, 6, 13-29.

Zhu, W. (2001). Interaction and feedback in mixed peer response groups. Journal of Second Language Writing, 10(4), 251-276. 


\section{Appendix}

\section{Appendix A: Document of Written Informed Consent}

You are being asked to participate in a research study by Gina Caruso, who is a graduate student at Portland State University in the Department of Applied Linguistics. The study is about how collaborative writing using an internet-based tool called a wiki might improve the individual writing of English language learners who are preparing for the iBT TOEFL test. Gina is conducting this research in order to fulfill the requirements for her M.A. in Teaching English to Speakers of Other Languages (TESOL), under the direction of Dr. Nike Arnold.

\section{What will I have to do?}

If you decide to take part in this project, you will agree to allow the researcher, Gina Caruso, to read and analyze the writing you compose individually during your TOEFL preparation class. You will spend about one hour each week in a computer lab for a period of four to six weeks. During this time, you will be typing answers to iBT TOEFL writing tasks, sometimes by yourself, and other times, with the help of other study participants. At the first meeting, you will type an answer to a specific TOEFL writing question in 30 minutes individually. Then you will be introduced to the internet-based writing tool (the wiki) and learn how to use its basic functions. During the next four or five meetings, you will be typing answers to other specific iBT TOEFL writing questions, reading the answers other participants have written, and working together to revise the answers. With the help of a partner, you will try to write the best possible answers you can to the questions you see in the wiki. On the last day of the study, (between four and six weeks after the first meeting) you will again type an individual response to another iBT TOEFL writing question. Like the first individual writing task, you will also have 30 minutes to type your answer. After you finish, you will complete a survey individually about your experience writing in the wiki. The survey will also ask you questions about your views and opinions of the collaborative writing activity and how it may or may not have helped you.

\section{Why have I been asked to participate in this study?}

You have been asked to participate in this study because you are currently preparing to take the iBT TOEFL test and you are not a native speaker of English. If you are not preparing for iBT TOEFL, you have been asked to participate because you are currently enrolled in this intermediate/advanced level TOEFL preparation class. You do not have to take part in this study. That means, your participation is voluntary and if you do not want your writing to be used for the research study, you do not have to sign the form.

\section{Are there any risks and what are you doing to protect me?}

There are very few risks for taking part in this study. There is a small risk that you will feel stressed about typing answers to questions in a computer lab. Remember, this study is voluntary as is your participation in this class, so if you become too stressed, you can quit at any time. There is also a small risk that you will feel uncomfortable having other participants read your answers to the questions. The researcher will do everything she can to protect your name and identity, but there is a very small risk that someone will find out your name and answers to the survey questions. To reduce this risk, you will be asked to choose a substitute name for yourself.

\section{What will I gain by taking part in this study?}


You will gain much practice writing answers to iBT TOEFL writing task questions. You will also learn how to use a free internet-based tool to interact with others who are also trying to improve their writing. Additionally, you will have many opportunities to read and comment on the writing of others and you will also receive feedback on your own writing. All of these things might help you to improve either your preparation for iBT TOEFL or your ability to write clear, detailed, and well organized responses to questions in English.

\section{What happens if I decide not to take part in this study?}

You do not have to take part in this study. Your participation is voluntary and you can choose to either not participate (decline to allow the researcher to use your data), or to quit the study at any time. Your decision will not affect your relationship with the researcher Gina Caruso, the Applied Linguistics Program, Portland State University, The National University of Colombia, your English teacher, or any of the colleges or universities where you are currently taking classes.

\section{What can I do if I have questions?}

If you have any questions about this study, this form, or the internet-based tool (wiki) used for writing, please contact Gina Caruso at 414-931-1230 or gcaruso@pdx.edu. If you have any questions or concerns about your rights as a research participant, please contact the Office of Research Integrity, 1600 SW $4^{\text {th }}$ Ave., Market Center Building, Ste. 620, Portland, OR 97207; phone (503) 725-2227 or 1 (877) 480-4400, or email hsrrc@lists.pdx.edu.

Please choose whether or not you agree to allow the researcher to use your writing for her study. You do not need to sign the form below but please respond to Gina via email (gcaruso@pdx.edu) to indicate that agree to participate.

Yes, I agree to participate in this research study.

Please keep this form for your records. 


\section{Appendix B: Wiki User Guide \\ Collaborative Writing Activity 1: How to use a Wiki}

\section{What is a Wiki?}

- A website (or collection of interlinked web pages) that allows users to create and edit a jointly produced document

- Wikipedia, the internet-based, user generated encyclopedia is the most well-known example of a collaboratively produced wiki.

- In addition to the created and edited web page(s), the wiki also has a history log and a discussion page.

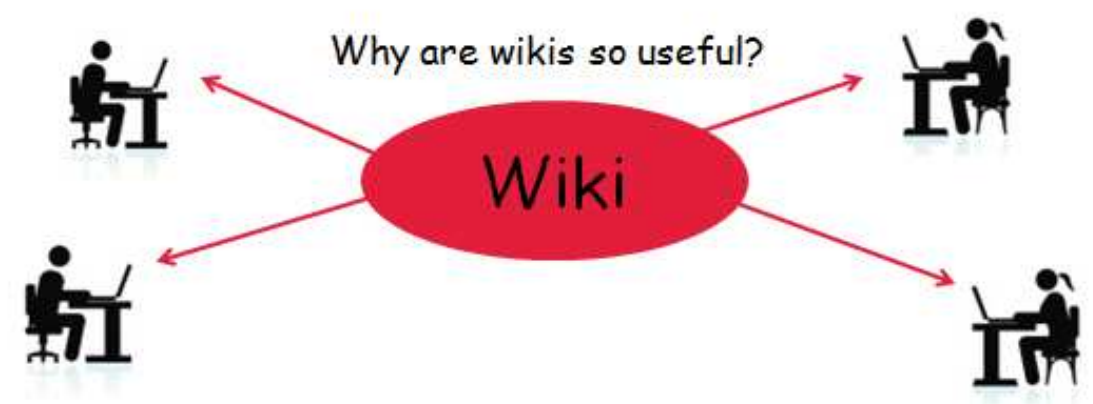

http://www.youtube.com/watch?v=-dnL00TdmLY

\section{Cooperation}

- Cooperation means the division of labor between individuals to complete a task.

- As participants in this study, your goal is not cooperation, but collaboration.

\section{Collaboration}

- Collaboration means the sharing of labor (co-labor).

- Collaborative writing is the co-authoring of a text by two or more writers.

1. Writers interact in all stages of the writing process

2. Writers share decision-making power and responsibility

3. Writers produce a single written document 


\section{How do I use a wiki?}

- Using a wiki is very easy.

- First you need to gain access.

Gaining Access

Gina Caruso gcaruso@pdx edu via bounce pbworks com

to me :

Click on this link to

gcaruso@odxedu has sent you an invitation to their workspace gain access to the wiki.

You may need to $\log$ in to edit. You can use your existing account.

Usemame: accaruso@gmail com

Password (your existing password)

View the workspace ibtcollaborativewriting.

Thanks.

Your PBworks Team

- You can set up your account by entering your name. Please enter the pseudonym (fake name) by which you want to be called for this study. Then choose a password and confirm it and click submit.

- Now you will see MY PBworks page with three tabs; home, profile, email.

My PBworks

B ocannoepdxedu - Log out

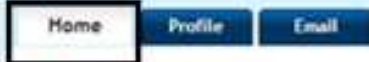

PBWORKS

My Workspaces

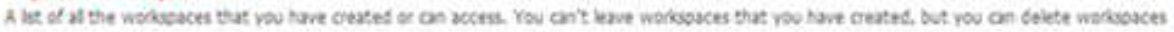

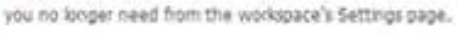

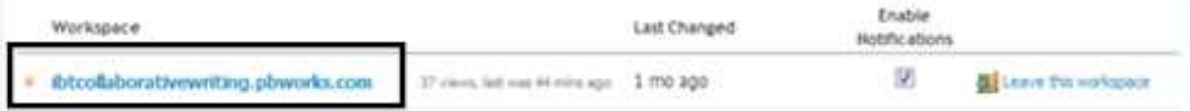

- To enter the work space, go to the home tab and click on the web address of our wiki:

ibtcollaborativewriting.pbworks.com

Click on the profile tab to add additional information about yourself, and if you want, you can upload a profile picture, but this is not necessary. 
The email tab will allow you to add another email address to your account (not necessary/not recommended) and here you can also change your password.

To enter the work space, go back to the home tab and click on the web address of our wiki:

\section{ibtcollaborativewriting.pbworks.com}

This will take you to the main page of our wiki

You will see a series of tabs running across the top of the page. In the top right corner of the page, you can see yourself logged in (the name you chose to use) and several other links to manage your account, log out, and request help.

There are four main tabs at the top left corner of the page. The Wiki tab is the main page and the Pages \& Files tab displays additional content and files within the wiki. You and your partners will collaborate on writing in the Pages \& Files content.

The pages and files contents can also be viewed in the side navigator on the right of the main page. Any files/photos that you upload to the wiki will appear in the pages \& files log. 


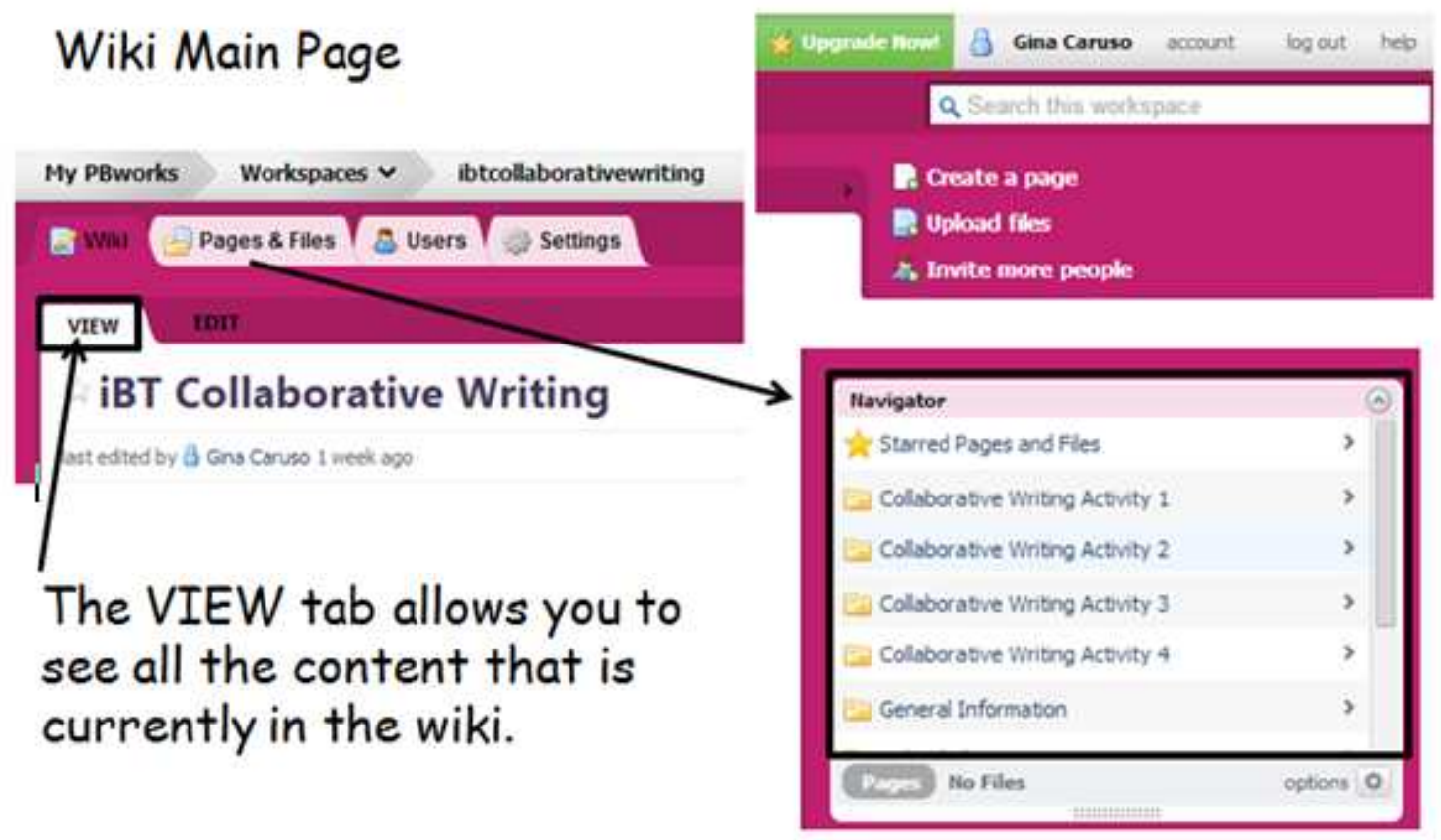

Below the two tabs (Wiki and Pages \& Files), you will see two more tabs (VIEW and EDIT). These are perhaps the most important tabs within the wiki.

The VIEW tab allows you to see all the content that is currently in the wiki. Once you click on the EDIT tab, you will see the same content as you do in the VIEW tab but you will now be able to click anywhere within the text to add or edit the content. We'll learn more about editing later. Now let's find out how to create a page in the wiki. 


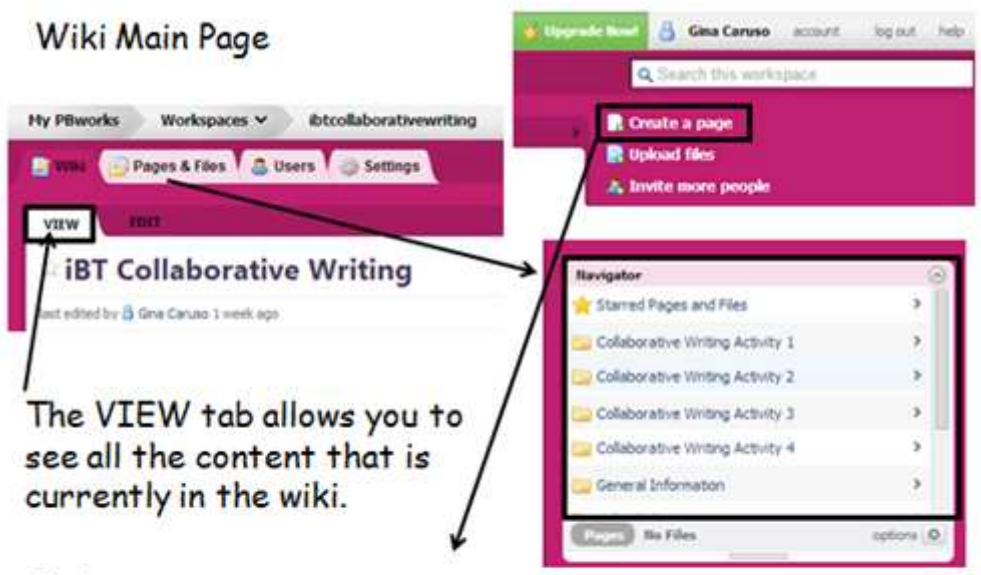

Click on create a page to start your collaborative writing project.

While in the Wiki/VIEW tab, you can see create a page at the top right of your screen. Click on create a page to start your collaborative writing project. Once you click on create a page, you will have a chance to name your page.

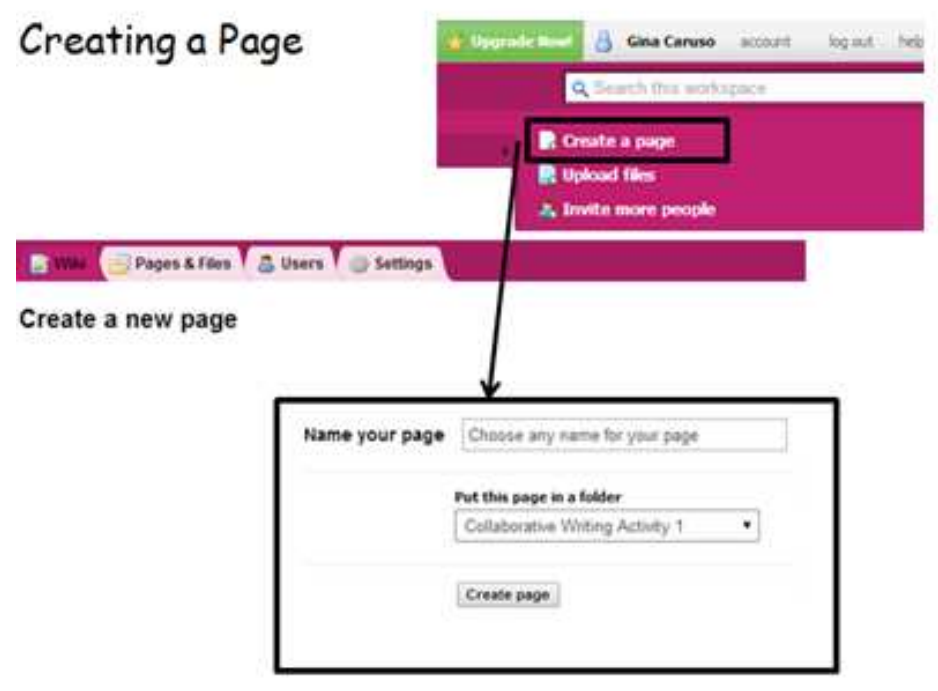

You can choose any name you would like. Your first page is for your first collaborative writing activity. After you name your page, click on the down arrow to put this page in a folder. You will see a drop-down menu appear. Please find Collaborative Writing Activity 1. In this folder you will see another folder with your name and your partner's name. Put your page into the appropriate folder. 
Please note that there are some character restrictions for page names. I have listed them below. The wiki will not allow you to use any of these characters in your page name.

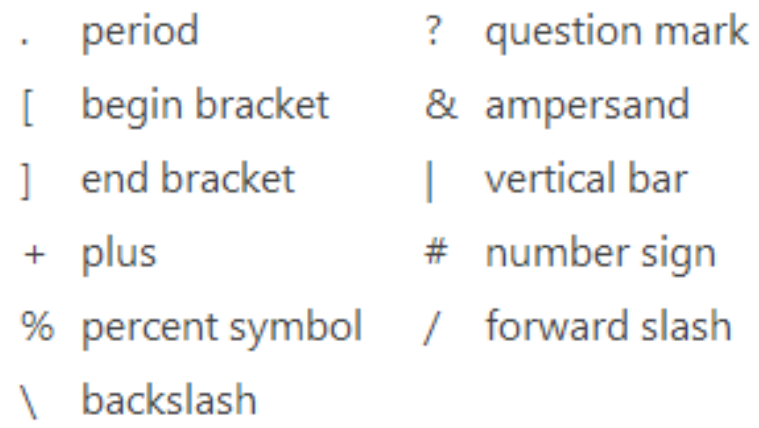

Please take a moment to create a page your own page.

Important: Each individual begins by creating their own page. You and your partner will create single shared page a little later.

Save your page in the appropriate folder under Collaborative Writing Activity 1 with you your name and the name(s) of your partners.

\section{Accessing your Page}

Your newly created page will look similar to the one below. You can start writing on your page now. After adding content, click the save button to be sure that your changes or additions are added to the wiki. This is VERY IMPORTANT! 


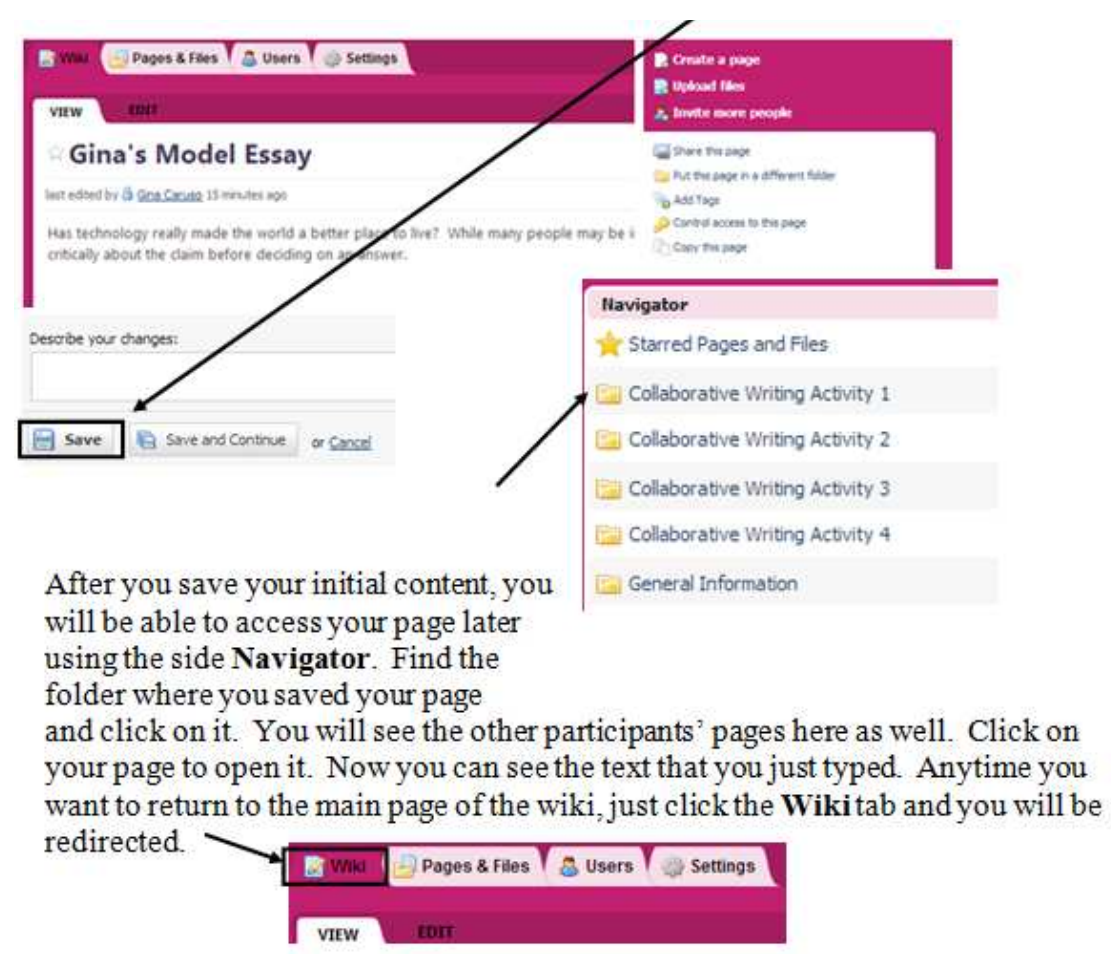

\section{Editing a Page}

Now let's learn about editing your page. Since you and your partner will be writing your essays together, you will frequently want to add or delete content. This is very easy to do. First you need to change from the VIEW tab to the EDIT tab. Simply click on the white EDIT tab and you are now able to add or delete writing.

\section{Editing a Page}
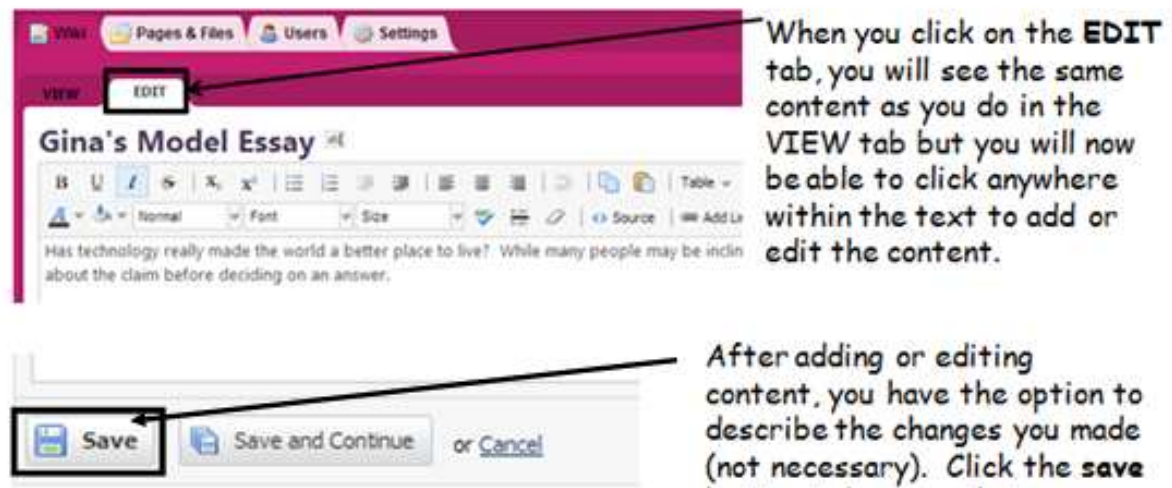

After adding or editing content. you have the option to describe the changes you made (not necessary). Click the save button to be sure that your changes or additions are added to the wiki.

\section{Tracking your Writing}

The wiki allows you and your partners to track the evolution of your writing using the page history link. When you have your page opened, at the top of the view tab on the right side you can click on the page history link. This link tells you who has made edits and when. 
You can also see the total number of revisions that have been made to the page since it was created. If you click Compare, you can see the changes that have been made from one version to another.

\section{Tracking your Writing}

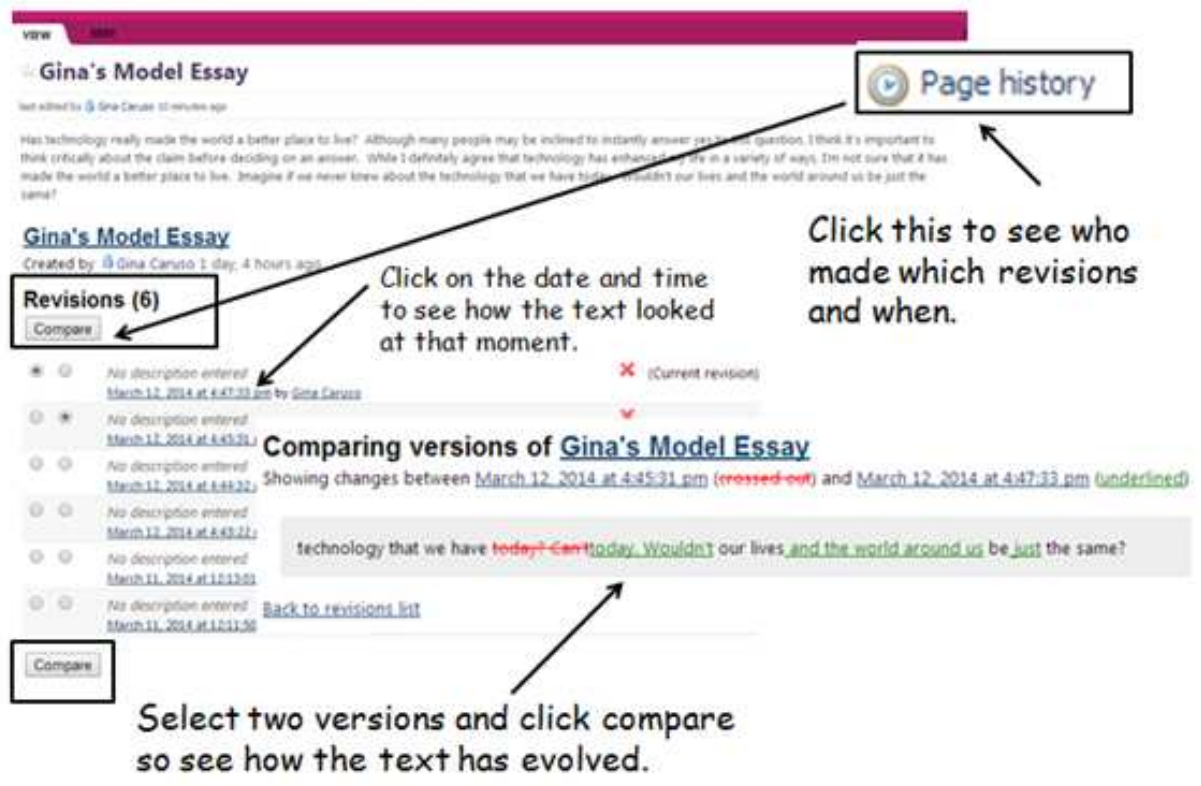

\section{Get Great Ideas!}

Scroll to the bottom of the Wiki main page to click on links to important information about the Structure of Collaborative Writing Task, the prompts, and the response.

\section{Get Great Ideas!}

The General Information folder contains pages about the Structure of Collaborative Writing Task, the prompts, and the response. Use these pages to help you develop strategies for planning and writing. 
You can copy and paste text freely within the wiki. Don't try to copy and paste text from outside sources.

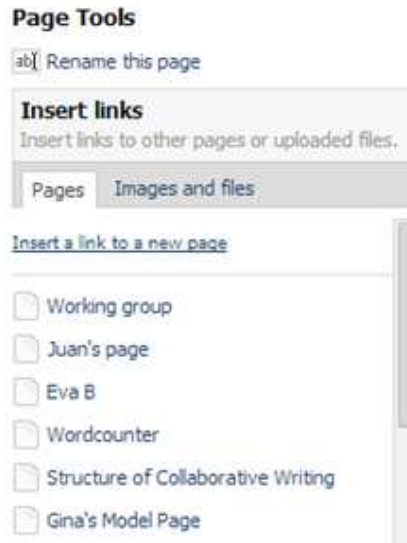

ips: To tum text into a link, highlight the text, hen cick on a page or fle from the list above.

\section{Word Counter Tool}

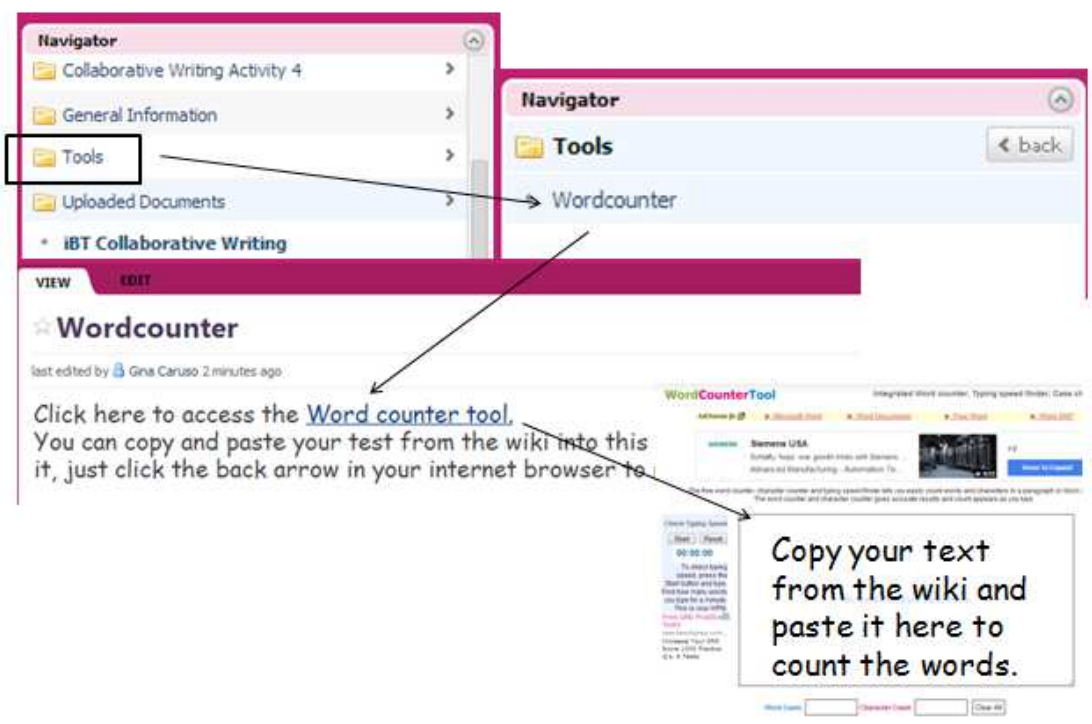




\section{Appendix C: Lesson Plan for Orientation and Collaborative Writing Treatment 1}

1. Begin by welcoming Ss and telling them how grateful I am to have them as participants in this project. Today we will spend about 30 minutes learning about the web-based tool and its affordances and how to use it for the purpose of collaborative writing. Please announce the pairings of Ss and have them sit next to their respective partners.

2. Ask Ss to open their email and find two messages from me, the researcher, Gina Caruso, sent from gcaruso@pdx.edu

Email 1: subject line: collaborative writing study -PDF of wiki user guide attached

Email 2: subject line: gcaruso@pdx.edu has invited you to join their workspace

Ask Ss to first open the email with the attached PDF and download it.

3. Begin with the first part of the user guide: What is a wiki? After reiterating the three bulleted points that essentially define the wiki, ask Ss to click on the YouTube link to watch the video about why wikis are useful for collaboration. You might also ask Ss if they know about Wikipedia and if they ever use it.

4. Scroll down in the PDF and ask Ss to read the bulleted points about cooperation and collaboration. Maybe ask Ss if they have ever thought about a difference between the two or if they have any experience writing either cooperatively or collaboratively. Please emphasize that the goal of this project is collaboration while writing. That is, Ss should not simply decide "you do this and I'll do that" but rather "let's try this and then do you think we should do this?"

5. The next step is gaining access to the wiki. Ask Ss to open the second email. I have already given them access as writers. They should just be able to click on the link in the body of the email and that will take them to the wiki main page.

\section{View the workspace ibtcollaborativewriting.}

You can use this guide to progress through the instruction for today and Ss can follow along with the PDF on their screens. 
6. The Wiki User Guide contains all the information Ss need to navigate the wiki, create and edit pages, and track the evolution of their writing. I have also uploaded this document to the wiki itself so Ss can access it whenever they are working. The main page of the wiki contains most of the important figures/images that will help students familiarize themselves with the tool.

Their username is their email address and they can choose their password.

7. Ss will be prompted to set up their account. They can enter their pseudonym, choose and confirm a password, and click SUBMIT.

8. Continue to scroll down in the PDF which will outline the upcoming procedures. Ss will now see MY PBworks page with three tabs; home, profile, email. To enter the workspace, students should be on the home tab and click on the web address of our wiki, ibtcollaborativewriting.pbworks.com.

9. Please check to see that all Ss are currently viewing the wiki homepage.

10. The next step is to become familiar with the main/most useful tabs (Wiki and Pages\& Files). Whenever you want to return the main page, just click the Wiki tab. The Pages $\&$ Files tab is where Ss will do the majority of their collaborative writing.

11. At this point, Ss can move between the user guide PDF and the wiki homepage itself. The user guide gives a slightly more detailed progression of how to use the wiki. The wiki homepage contains the most important images (also contained in the user guide).

12. Note that the pages and files contents can also be viewed in the side navigator on the right of the main page.

13. Note the difference between the VIEW and EDIT tab. Whenever Ss want to actually write in the wiki (input content), they must click on the EDIT tab and then save their changes.

14. Scroll down the user guide and explain how to create a page. I've already created 4 folders in which students will save their pages. These can be viewed in the sidebar 
navigator. The folders are titled Collaborative Writing Activity 1-4 and within each folder are separate folders labeled for each of the pairs.

15. When creating a page, both partners start by creating their own pages. These are used for the pre-writing and brainstorming phase and can also be used during the planning/collaborative writing phase. More on this in step X

16. Please note that there are some character restrictions for page names. I have listed them below and they are also noted in the wiki user guide.

17. Now it's time for each student to decide on a name for their first page. It's entirely up to them what they want to title their page, so long as they don't use any of the restricted characters. Please remind them that they will begin by each creating an individual page, but at some point during the writing process, they will create another page to draft, write, and revise their jointly authored response. Please circulate the room to confirm with each student that they have created a page and saved it under Collaborative Writing Activity 1 in their respective folder (folder with their name and their partner's name).

18. Once each student has created a page, continue on in the user guide. Ss will see the model page I created. If they are looking at the wiki, they can see that the three pilot participants here in Portland, (Juan Camilo, Eva, and Sarith) have also created pages.

19. Ask Ss to click the WIKI tab to take them back to the main page and then retrieve their page from the appropriate folder in the Navigator.

20. Ask Ss to open their newly created page again and once they do, click the white EDIT tab. The user guide elaborates on the function of this tab. Anytime Ss want to type in the wiki, they need to be in the EDIT mode.

21. Ask Ss to return to the user guide and look at the graphic entitled Tracking your Writing. Briefly explain to Ss that writing is a process and being aware of the fact that writing develops over time through multiple drafts is important to remember for this project. The graphic illustrates how the writing evolved on that particular page. Ss can click Page History on any of the pages they'd like and compare the versions for practice. 
22. Students can click on the links under Get Great Ideas. These will help scaffold their writing. The Structure of Collaborative Writing Task link provides an outline of the time frame for the collaborative activities.

23. Allow Ss some time to explore around the wiki a bit. They can read the pages that have been started by Juan Camilo, Eva, and Sarith. Maybe take a break before beginning the writing.

24. Ask Ss to click on the Structure of Collaborative Writing Task link at the bottom of the main page.

25. Explain that Ss will begin their work individually (reading the prompt, brainstorming, etc.) Ss should write their ideas in their own wiki page.

26. After 5 minutes, ask Ss to read their partner's page of ideas, and encourage them to make a comment on the page and talk about how they want to plan their essay together. Remind them that at some point, they need to create a single shared page. They can approach this however they choose. There are some models/suggestions included under the Drafting/Writing heading.

27. Check to see that all students understand the goal: Create one JOINTLY WRITTEN PAGE.

28. Tell them that this is a recommended time line but will help them stay on task under the 1 hour time limit. I sincerely hope that you will do your best to provide students with guidance.

Since this is probably Ss first time to use a wiki and maybe to write collaboratively, I anticipate that they might be inclined to just stay on their own pages. Remind them that they can copy text from their page and paste it into their partner's page or vice versa. This might help them initially as they are trying to transition from two individual pages to one joint page.

Just do your best! I will be online all day tomorrow so if you run into any issues while the treatment is underway, just message me. I'll be logged into the wiki as well so I can help out if you need me. Thank you! 


\title{
Appendix D: A Sampling of Screen Captures from Treatment 1
}

\author{
VIEW \\ Structure of Collaborative Writing Task \\ last edited by 3 Gina Caruso 1 month ago \\ (c) Page histor \\ The response you write is based on your personal knowledge and experience. Your task is to give your opinion of an issue or express your personal \\ preference. You have 60 minutes to complete a single essay with a partner and the recommended length is 300 words. Click here to access the \\ Word counter. \\ The writing task requires you to read a prompt (a topic) and express your opinion in your response. You response is based entirely on your own \\ knowledge and experience (you are not required to cite outside sources). \\ Skills / Goals for the Writing Task \\ 1. Understand the prompt and what it asks you to do. \\ 2. Brainstorm ideas and take notes on the ideas that you come up with \\ 3. Organize your ideas into an outline. \\ 4. Clearly state and explain your opinion or preference. \\ 5. Support your ideas with examples, reasons, and details. \\ 6. Write a unified, well-organized, and coherent response based on the prompt. \\ 7. Use correct grammar and sophisticated vocabulary. \\ 8. Use transitions so that one idea flows smoothly into another. \\ 9. Write a variety of sentence types. \\ 10. Edit your response for content, grammar, and mechanics (spelling, punctuation, capitalization, etc.) \\ Timing of the Writing Process (60 minutes total) \\ Pre-Writing (2-5 minutes individually-use your own page in the wiki) \\ --Read the prompt \\ --Think about the prompt \\ --Brainstorm and take notes \\ --Make an informal outline \\ Initial collaboration / Planning (5-7 minutes individually \& together) \\ --Read your partner's brainstorm notes/informal outline \\ --Make comments or edits \\ --Talk with your partner and decide on your thesis statement \\ Drafting / Writing (30-40 minutes-pairs now merging their writing into a new, single page) \\ --You can start the writing phase using your individual pages but by the end, you and your partner should create one \\ response on a single shared page. \\ --You and your partner decide how to share the work. \\ -- Maybe one of you starts to write the introduction while the other thinks of key points to support the thesis. \\ -- Then maybe you switch roles or take a moment to look at the other's content and give your feedback. \\ -- The approach is up to you and your partner. Just remember that once you create a single page, only \\ one user can add/edit content at a time. \\ Checking / Revising \\ --Look for and correct problems with content, grammar, and mechanics.
}




\section{Types of Prompts}

last edited by 8 Gina Caruso 1 month ago

(1) Page history

A prompt is similar to a question or thought provoking statement. It provides you with the topic and is rather general. It requires no special knowledge or experience. It will never be about a controversial topic.

There are 3 types of prompts used on the iBT TOEFL

1. Defend an opinion (choose one side to support)

2. Agree or disagree with a statement

3. Explain the importance of a development, invention, or phenomenon ("There are many important Xs in the world. What do you think is the most important and why?)

Visit the pre-writing page to find out about how to read and analyze the prompts. You can also check out practice exercises for reading and analyzing prompts.

\section{The Response}

last edited by $3 \hat{\text { Gina }}$ Caruso 1 month ago

(1) Page history

Your goal is to write a coherent response in about 300 words. It's very helpful to structure your response in an organized way. The outline below is a suggestion for how to organize your response.

Introduction

Paragraph 1

Introduction to the general topic

Statement of your opinion or preference (thesis statement)

Body

Paragraph 2

Key point \# 1 of the passage

Examples, reasons, and details that support your opinion or preference

Paragraph 3

Key point \#2 supporting your opinion or preference

Examples, reasons, and details that support your opinion or preference

Paragraph 4

Key point \# supporting your opinion or preference

Examples, reasons, and details that support your opinion

Conclusion

Paragraph 5

Summary statement showing the significance of your opinion 


\section{Appendix E: Lesson Plan and Sampling of Screen Captures for Collaborative Writing Treatment 2}

1. Please pair Ss with a different partner than they had last time. If this is impossible, then it's okay for repeats. Just to clarify, there were four pairs from last week:

\section{AFBF-Camduco \\ Fullhouse-Salvador Dali \\ Mr. Awesome-aparecido \\ Prideras-lucho}

2. Ask the pairs to sit at computers beside one another and login to the wiki. The web address is

http://ibtcollaborativewriting.pbworks.com/w/page/69433510/iBT\%20Collaborative\%2 0Writing

Ss should use the username (their email) and password they created last time.

3. Once all Ss are logged in, they will see at the top of the main page that I have linked some newly added pages. Under the second heading "Get Great Ideas!" ask Ss to click on the link to pre-writing strategies.

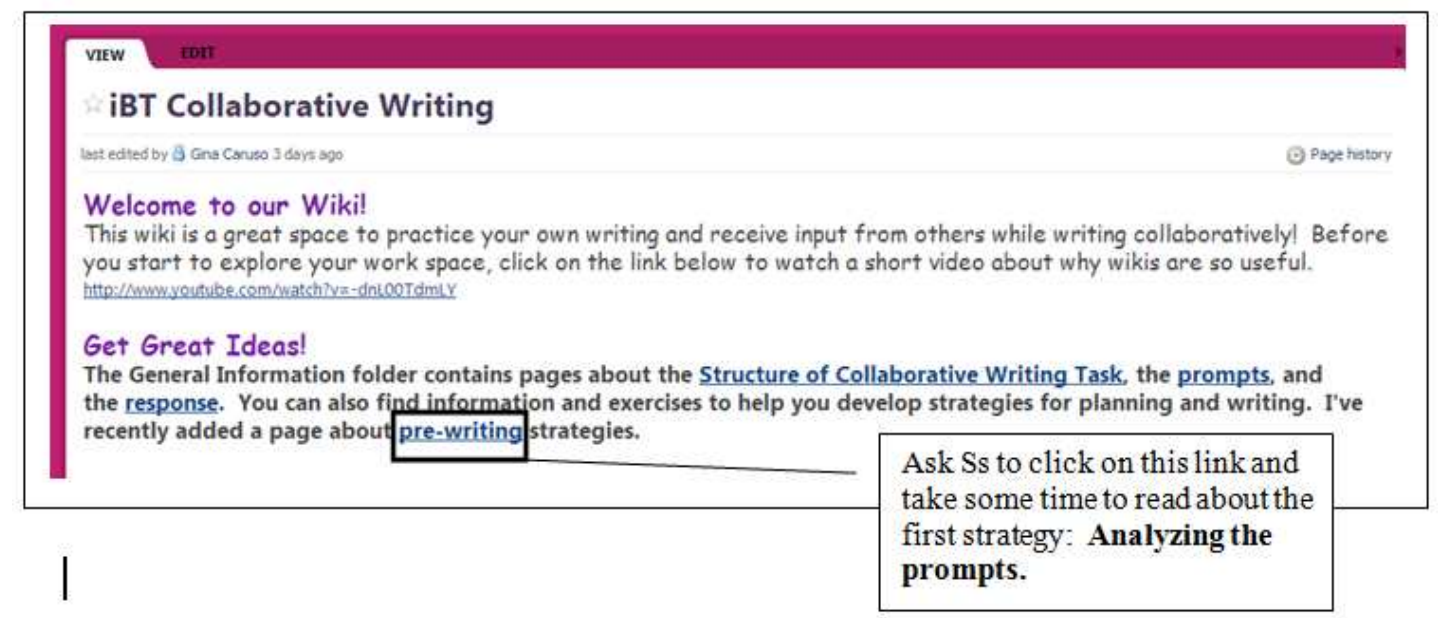

4. This link will take them to a new page that I created about pre-writing strategies. There are a couple of warm up exercises that Ss can do before they begin the collaborative treatment. I suggest that you allow Ss some time to read the first section: Analyzing the Prompts. You can even lead them in emphasizing the importance of understanding the question and what it asks them to do. 


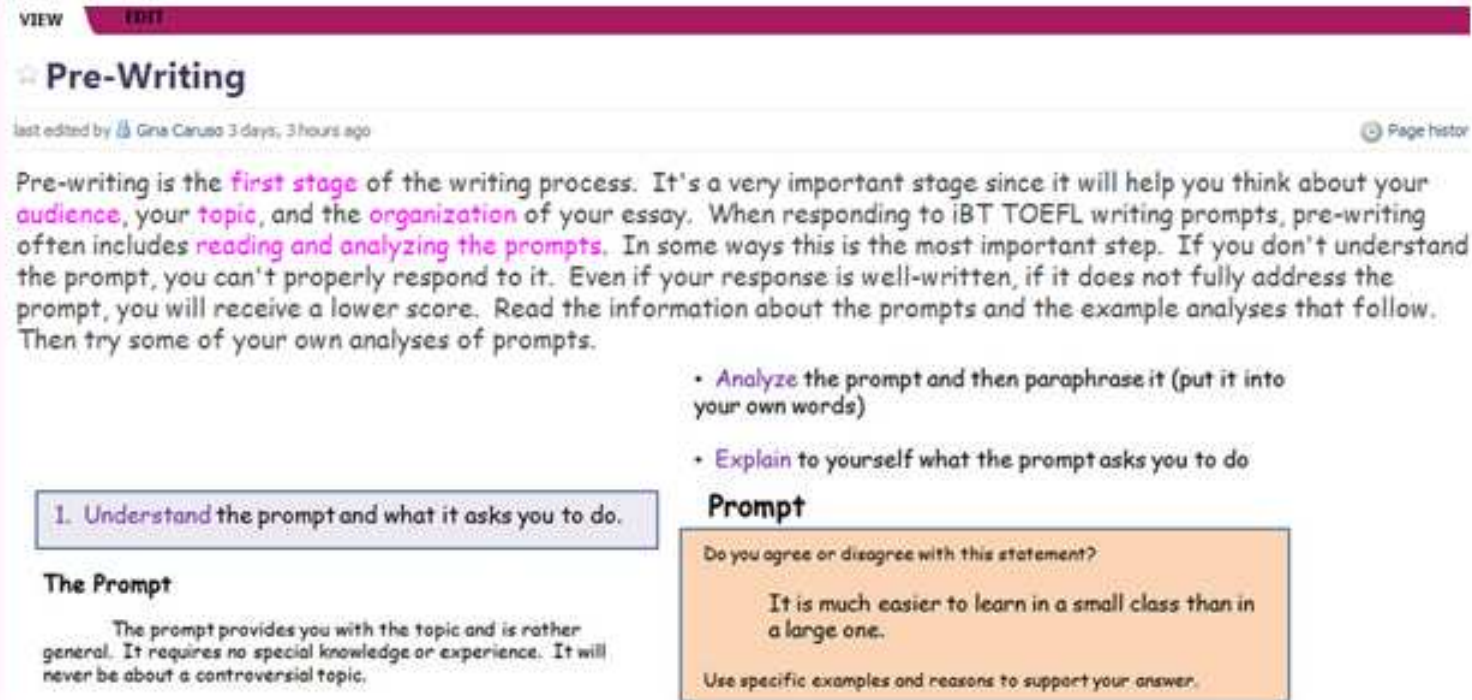

Pre-writing is the first stage of the writing process. It's a very important stage since it will heip you think about your audience, your topic, and the organization of your essay. When responding to iBT TOEFL writing prompts, pre-writing often includes reading and analyzing the prompts. In some ways this is the most important step. If you don't understand the prompt, you can't properly respond to it. Even if your response is well-written, if it does not fully address the prompt, you will receive a lower score. Read the information about the prompts and the example analyses that follow. Then try some of your own analyses of prompts.

5. After Ss have read the section about analyzing the prompts and have looked at the examples, ask them to create their own page in the wiki where they try to analyze the prompt. At the bottom of this section you will see Now You Try!

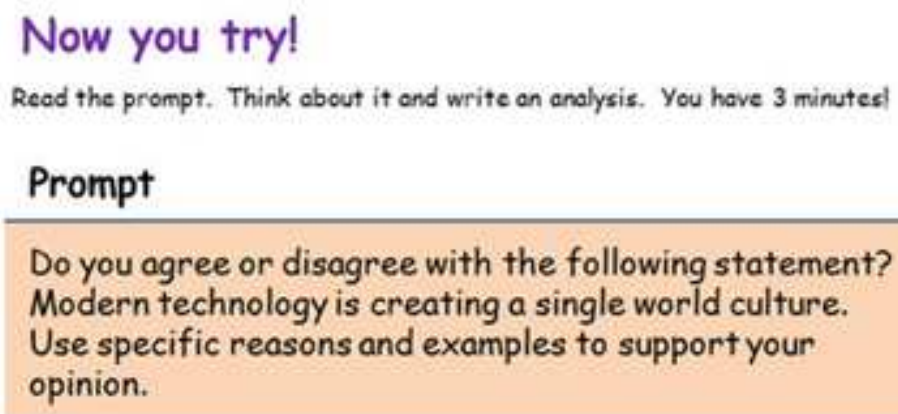

Ss should go to the top right and click Create a Page. They can save their page in the folder with their group number. They will find their group's folder within the folder "Collaborative Writing Activity 2." They can use the drop-down menu that appears when they create a page. This will be the individual page that they all start with today. This prompt that they will analyze is the collaborative prompt for today.

6. Allow Ss 3-4 minutes to compose an analysis of the prompt in their own wiki page. REMIND THEM TO SAVE THEIR WORK! Then you might ask them to read other Ss prompt analyses and compare them to their own. 
7. Direct Ss back to the pre-writing strategies page and have them continue reading the content about brainstorming.

\section{Brainstorming}

Brainstorming is a process that involves generating ideas on a topic. Take a moment to just think about the topic and write down any ideas that come to your mind. You might include things you have read online or in newspapers or magazines, things you've heard in classes, on television, or on the radio, or personal experiences. Just write down all ideas that you think of-even if they turn out to be useful or not.

Below is an example of some brainstorming notes for one of the sample prompts above.

Sorne endangered animals are forind only in goox would be extinct without joos

Costra lot of money tormaintain goor properly

Some beoble think that soor are unnatival

8. At the end of the brainstorming section, the Ss will see the same prompt again about technology creating a single world culture. Ask them to return to their own wiki page that just made to analyze the prompt and this time allow them 2 minutes to brainstorm ideas and type them into their wiki page.

Now you try brainstorming on the following topics. Spend only 2 minutes on each.

Do you agree or disagree with the following statement? Modern technology is creating a single world culture. Use specific reasons and examples to support your opinion.

Prompt: Many parts of the world are losing important natural resources, such as forests, animals, or clean water. Choose one resource that is disappearing and explain why it needs to be saved. Use specific reasons and examples to support your opinion.

9. Just like before, when the time is up, encourage Ss to read their partners' brainstorms.

10. Redirect Ss back to the pre-writing strategies page and ask them to read the section on Planning the Essay. This section also contains a link to a page about thesis statements. Ss can click on this link to read a little more about thesis statements. To return to the prewriting strategies page, they can just click back in their browser. 
11. Feel free to guide the Ss through this section on developing rough outlines. Spend about 10-15 minutes on this section.

12. NOW it's time for students to begin the 1 hour collaborative writing treatment. At this point, they can decide if they want to

1. Continue writing on their own separate pages for a bit, OR

2. Begin their collaborative page now

\section{PLEASE BE SURE THAT WHEN STUDENTS CREATE THEIR COLLABORATIVE PAGE, THEY USE BOTH OF THEIR PSEUDONMYS IN THE NAME OF THE PAGE AND SAVE IT IN THEIR RESPECTIVE NUMBERED FOLDER!}

This will really help me keep track of things.

13. Let Ss know that the prompt is the one they have been using during the pre-writing strategies focus (modern technology creating a single world culture). If they want to copy and paste this prompt into their page, they can find it in the PROMPTS folder in the side Navigator. It's listed on the page entitled Collaborative Prompt 2.

Also remind Ss that they can access the word counter tool in the tools folder. Remind them that they are aiming for 300 words.

Planning the Essay

Planing begins with the brainstorming process. After you have thought about the topic/prompt, it's time to choose your basic thesis. A thesis is the central or controlling idea of an essay. For the first two types of prompts, choosing a

thesis simply means choosing which side of the argument you support. For example:

"In my opinion, zoos serve several useful purposes."

"With the right teacher, large class size has little effect on learning."

"I believe that the development of jet airliners was extremely important."

A useful strategy might be to choose whatever side of the argument is easiest to support (there is no right or wrong thesis).

Once you have a thesis, you need to think of ways to support it. Look at your brainstorming notes and identify concrete details or compelling reasons that support your thesis. 


\section{Appendix F: Lesson Plan and Sampling of Screen Captures for Collaborative Writing Treatment 3}

1. Please pair Ss with a different partner than they had last time. If this is impossible, then it's okay for repeats. Just to clarify, there were three pairs from last week:

Group 1: Mr. Awesome \& Raulinho

Group 2: AFBP \& lfmeloa

Group 3: Camduco (It appears that he worked alone...is that correct?)

2. Ask the pairs to sit at computers beside one another and login to the wiki. The web address is

http://ibtcollaborativewriting.pbworks.com/w/page/69433510/iBT\%20Collaborative $\% 2$

0Writing

Ss should use the username (their email) and password they created last time.

3. Once all Ss are logged in, briefly remind them of the pre-writing strategies covered in last week's meeting. Ss are welcome to click on the pre-writing strategies link to refresh their memory about analyzing the prompts, brainstorming, and outlining. This week I've also added a new link under the second heading "Get Great Ideas!" Ask Ss to click on the link to expressing and supporting your opinions.

\footnotetext{
virw

iBT Collaborative Writing

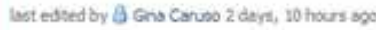

C Pogehistory

Welcome to our Wiki!

This wiki is a great space to practice your own writing and receive input from others while writing collaboratively! Before you start to explore your work space, click on the link below to watch a short video about why wikis are so useful.

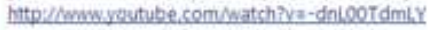

Get Great Ideas!

The General Information folder contains pages about the Structure of Collaborative Writing Task, the prompts, and the response. You can also find information and exercises to help you develop strategies for planning and writing. I've recently added pages about pre-writing strategies and effectively expressing and supporting your opinions.
}

4. Once they click on the link, they will see the content below includes information about giving opinions and expressing preferences. Each strategy is described and example expressions are provided. Allow Ss some time to read through the content on this page. You can choose to have them do this individually or if you think it will be more effective for you to somewhat lead the presentation/discussion, that's fine too. At the end of this page, Ss can click on the link Exercise-Expressing and Supporting your Opinions. 
Some people support the idea that we should generally do $A$ before we do B. In my experience, this is not necessarily true.

The statement says that $C$ is true. Some experiences from my own life support this idea.

How can we learn how to do $y$ ? For me, there have been at least three ways.

Now you Try!

Click on the link below for some practice using the expressions you've just read about. Exercise-Expressing and Supporting your Opinions.

5. This link will take Ss to another page where they can get some practice using the example expressions. The page looks like this:

\footnotetext{
viזw

Exercise- Expressing and Supporting your Opinions

last ed eded by 8 Gina Corves 7 ninutes ago

Think obout the strategies and example expressions for expressing and supporting your opinions. While completing the following exercises, you are welcome to refer back to the page by clicking this link for giving opinions.

1. Consider this prompt: Do you agree or disagree with the following statement?

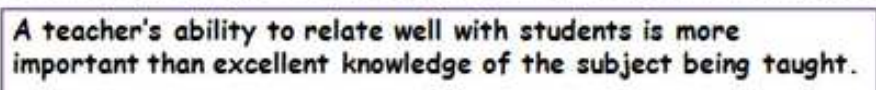

a) Write one sentence that states your opinion about the prompt.

b) Write one sentence using an expression of preference about the prompt.

c) Write one sentence that expresses your agreement or disagreement with the prompt.

d) Use an expression to create a sentence that supports your opinion.

c) Create one sentence that presents a specific example to support your opinion.

f) Create a sentence or two that include(s) a statement about your personal experience to support your opinion.
}

Ask pairs to have one student remain on the Exercise page and another to create a new page in the wiki where they can type their answers to the exercises. 
There is a folder entitled Collaborative Writing Activity $\mathbf{3}$ and within that folder is another folder entitled Practice Exercises. Have Ss save their group's exercises page in the Practice Exercises folder.

Ss can save their collaboratively written essays in the collaborative essays folder when the time comes.

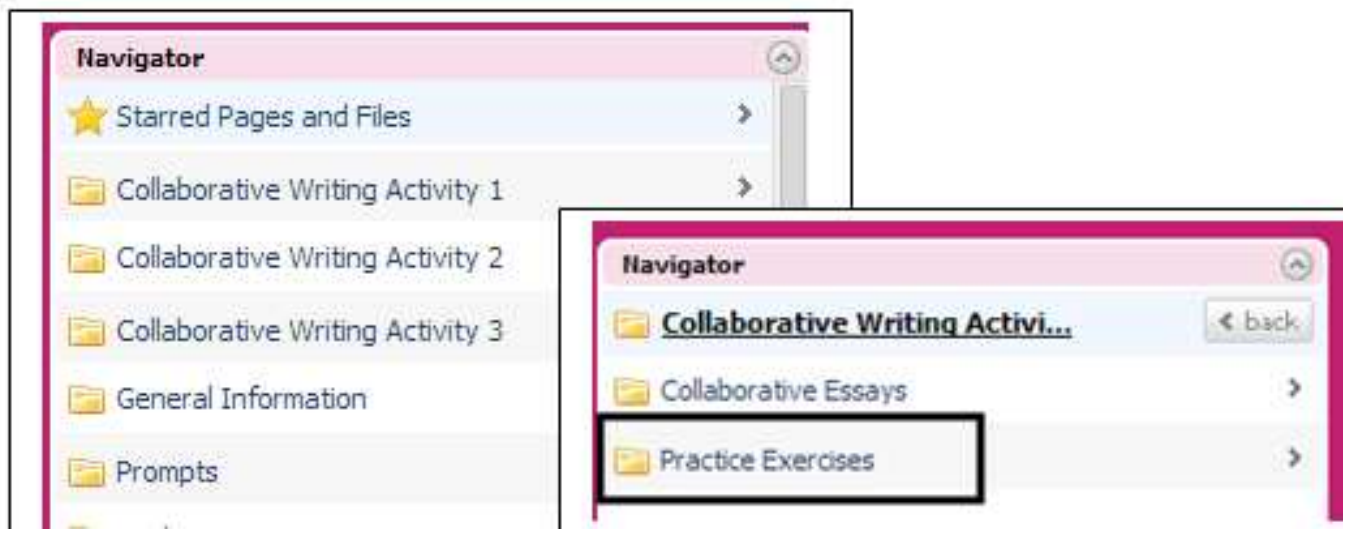

6. Allow Ss some time to complete the exercises. You can give them some suggestions on how to go about the task. For example:

One student is in charge of typing and the other might refer to the page in the wiki about giving opinions to find some example expressions.

7. Once it seems that most Ss have completed the exercises, discuss them as a class. Ask Ss to share their example sentences with the class and then discuss the items in the second task (identifying the expressions used in the model paragraphs).

8. Now direct Ss to the prompts folder and have them look at Collaborative Prompt 3. Pairs can read the prompt together and copy and paste it into their own page to begin the collaborative writing activity.

\section{Today's Collaborative Prompt:}

It has been said, "Not everything that is learned is contained in books." Compare and contrast knowledge gained from experience with knowledge gained from books. In your opinion, which source is more important? Why? 
It's their choice whether or not they want to each start with one page and then move into one or if they simply want to start with one page. Encourage Ss to use the content pages (pre-writing, expressing opinions, structure of the collaborative task, etc.) within the wiki to help guide them while they write.

9. Set the clock for 1 hour and set Ss free to write collaboratively. 


\section{Appendix G: Lesson Plan and Sampling of Screen Captures for Collaborative Writing Treatment 4}

1. Please allow Ss to choose their own partners today.

2. Ask the pairs to sit at computers beside one another and login to the wiki. The web address is

http://ibtcollaborativewriting.pbworks.com/w/page/69433510/iBT\%20Collaborative $\% 2$ 0Writing

3. Once all Ss are logged in, briefly remind them of the activity last time on useful expressions for giving opinions. Ask Ss to look at the main page of the wiki and notice the new link under Get Great Ideas. Ask Ss to click on the link transition words and phrases.

4. This will take them to a page that contains useful expressions for transitioning between paragraphs, sentences, and clauses. Expressions are organized according to their function and specific purposes of the various transition words are outlined. Allow Ss about 7-10 minutes to read the content quietly.

\section{Get Great Ideas!}

The General Information folder contains pages about the Structure of Collaborative Writing Task, the prompts, and the response. You can also find information and exercises to help you develop strategies for planning and writing. There are pages about pre-writing strategies and effectively expressing and supporting your opinions. You can also learn about how to effectively connect your ideas with transition words and phrases.

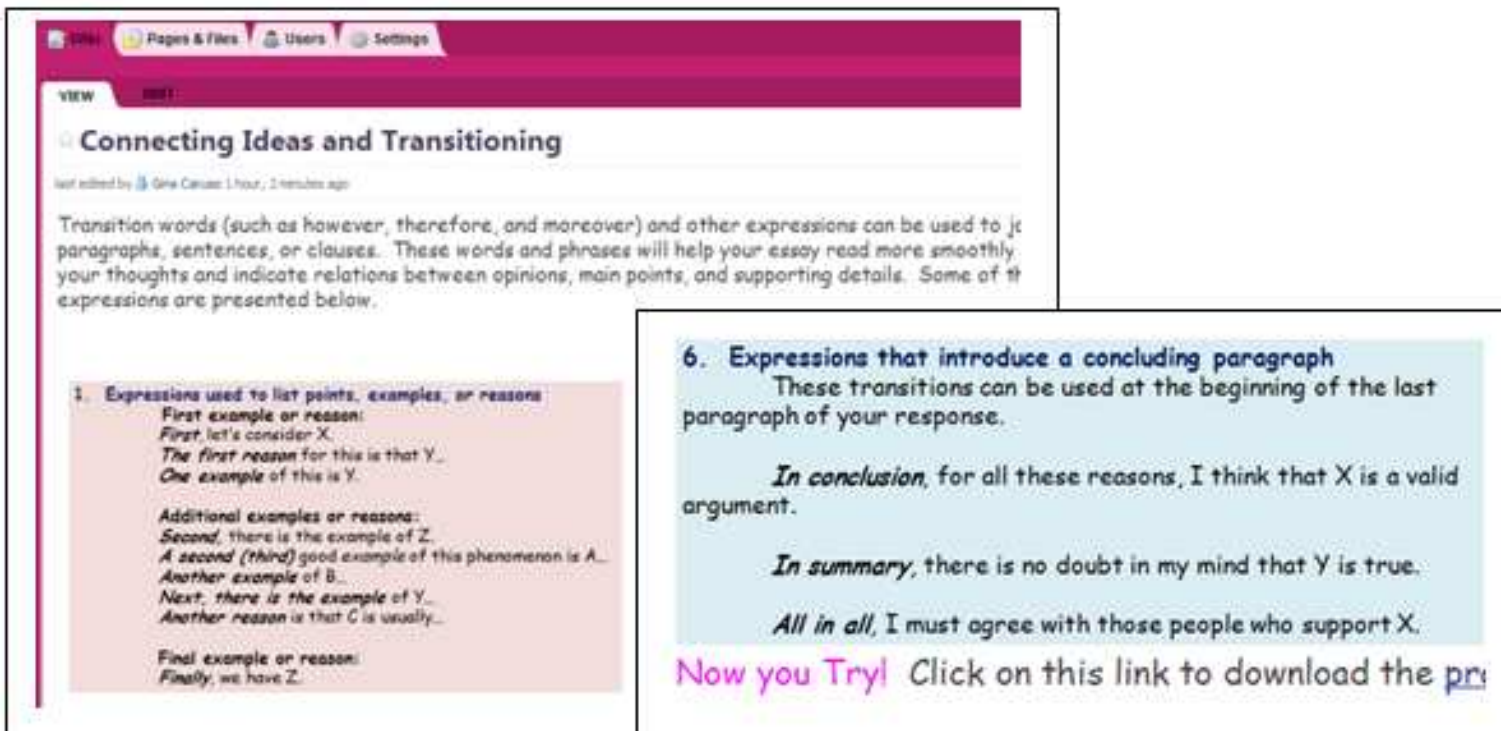

Now you Tryl Click on this link to download the practice exercise-connecting ideas and transitioning.

If you finish this exercise, you can try additional practice exercises using the vecabulary for giving opinions and connecting ideas. 
5. Once it appears that Ss have read or skimmed the content, ask them to click on the Now you Try! link at the bottom of the page. You will notice that there are two links. Ss should click on the first link. If time allows, they can click on the second link later.

6. This link will take them to a new page where I have linked the file as an MS Word document. This way, Ss can download it, open it, and type their answers into the Word doc while they peruse the wiki content they just read on transitions.

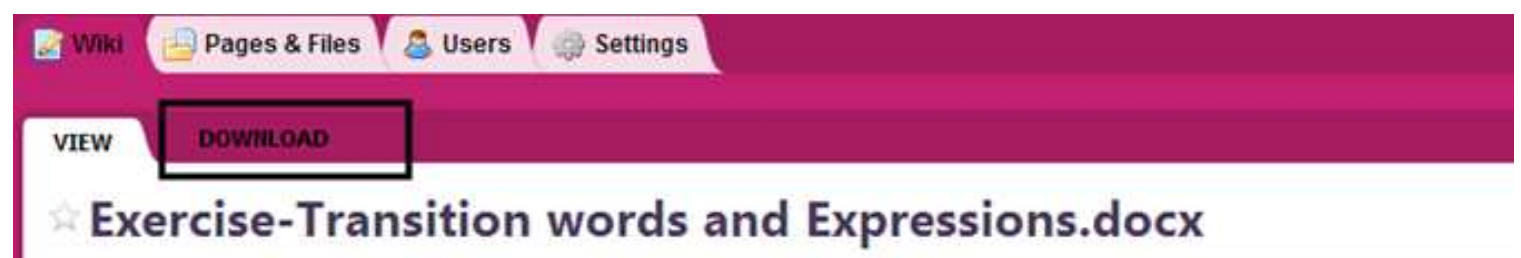

uploaded by 8 Gina Caruso 1 hour, 26 minutes ago

No preview is available for Exercise-Transition words and Expressions.docx. To view it click the "Download" tab above.

7. Ss simply need to click the DOWNLOAD tab and the Word Doc will download. I've attached the document to this email as well for your convenience. With their partners, ask Ss to complete the exercises as indicated. I don't think this will take them too long so if you notice that they are finishing quickly, feel free to discuss their answers as a class.

8. Depending on time, you can welcome Ss to click on the second link at the bottom of the Connecting Ideas and Transitioning Page. This will take them to a new page where they can download a 3 page PDF file with additional exercises. I've also attached that PDF to this email. Depending on time, allow students to work on the additional exercises in pairs or as a class. Just be sure to save an hour for the collaborative treatment.

9. As usual, I've made a folder in the side Navigator Bar entitled Collaborative Writing Activity 4. Pairs can create their page and save it in this folder. They can access the prompt in the prompts folder which is also available through the side Navigator. I've listed the prompt below for your convenience:

A university plans to develop a new research center in your country. Some people want a center for business research. Other people want a center for research in agriculture (farming). Which of these two kinds of research centers do you recommend for your country? Use specific reasons and examples to support your recommendation.

10. Set the clock for 1 hour and set the pairs free to collaborate. Remind them to save their work as they progress. 


\section{Appendix H: Practice Exercises-Connecting Ideas and Transitioning for Collaborative Writing Treatment 4}

The sentences below include some examples of the vocabulary used for giving opinions and connecting ideas.

- Underline the expressions and tell their function

expressing opinion/preference connecting ideas/transitioning

- Determine the exact purpose of the transitions

$$
\begin{aligned}
& \text { listing/adding examples } \\
& \text { showing result/conclusion } \\
& \text { showing contrast/similarity } \\
& \text { introducing a concluding paragraph }
\end{aligned}
$$

1. I completely agree with the idea of stricter gun control for a number of reasons. First, statistics show that guns are not very effective in preventing crime. Moreover, accidents involving gun frequently occur. Finally, guns can be stolen and later used in crimes.

2. I believe that a good salary is an important consideration when looking for a career. However, the nature of the work is more important to me. Thus, I would not accept a job that I did not find rewarding.

3. There are many reasons why I would rather live in an urban area than in a small town. The first and most important reason is that there are more professional opportunities for me in a big city than in a small town. Another is that the educational opportunities for my children are much better in a city. Third, a city offers cultural attractions such as museums, theaters, and good restaurants. Personally, I think that I would be bored living in a small town. Therefore, I agree with those people who prefer to live in big cities. 


\section{Appendix I: Practice Exercises-Using Vocabulary for Giving Opinions and Connecting Ideas for Collaborative Writing Treatment 4}

Focus: Using transition words and other expressions to connect ideas.

Directions: Complete each of the following sentences with one of the words or phrases below. Do not use any item more than once.

\begin{tabular}{|lrrr|}
\hline likewise & for example & personally & furthermore \\
however & therefore & on the other hand & similarly \\
\hline
\end{tabular}

1. I believe that women should have the right to serve in the military. , I don't believe that they should be assigned to combat roles.

2. Many actors, rock musicians, and sports stars receive huge amounts of money for the work that they do. a baseball player was recently offered a contract over twelve million dollars. , I feel that this is far too much to pay a person who simply provides entertainment.

3. The development of the automobile has had a great impact on people everywhere. , the development of high-speed trains has had an impact on people in many countries, including my home country of France.

4. I used to work in a restaurant when I was in college. I realize what a difficult job restaurant work is. , whenever I go out to eat, I try to leave a good tip for my waiter or waitress.

5. Many people would agree with the idea that the best use for the open space in our community is to build a shopping center. there are other people who feel we should turn this open space into a park.

6. In the United State, people celebrate their independence from Britain on July 4. we Mexicans celebrate our independence from Spain on September 16.

7. Corporations should do more to reduce air pollutions. , they should encourage recycling. 
Focus: Connecting ideas with transition words and other expressions.

Directions: Complete the following sentence in your own words.

1. Young children have a special talent for language learning; therefore,

2. Some forms of advertising serve a useful purpose; however,

3. Small classes are the best environments for learning, but

4. Some people relax by watching television; personally,

5. Although there are many ways to learn a language,

6. The use of computers has had a major impact on the banking industry; likewise,

Focus: Using the vocabulary of showing preference and connecting ideas.

Directions: Complete the following Independent Response with transition words/phrases and with verbs that show preference. For this exercise, you may use words from the list more than once time. In some cases, more than one word or phrase may be correct.

Note: You may have to change the form of the verb to fit the context of the sentence.

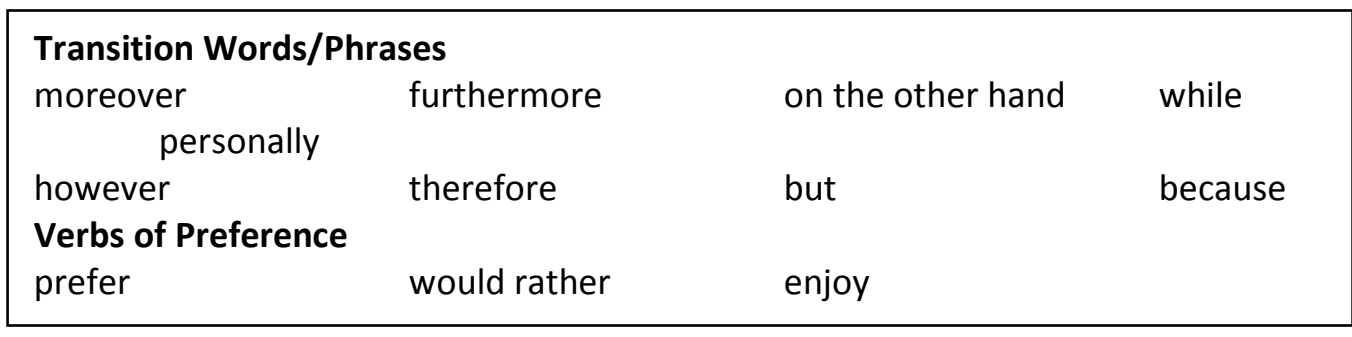

Some people like to go to the same place for their vacations. Other people like to take their vacations in different places. Which of these two choices do you prefer? Give specific reasons for your choice. 
There are certain people who to take their vacations in the same place. When they return from a vacation, they ask themselves, "When can I go back there again?" , there are people who visit many

places. they doing many different things on their vacations. When they return from a vacation, they ask themselves, "Where can I go next and what can I do there?"

My parents are perfect examples of this first kind of people. They always go to a lake in the mountains. They first went there on their honeymoon, and several years later they bought a vacation cabin there. They have gone there two or three times a year for over thirty years. They have made friends with the people who also own cabins there and often get together with them. My mother sailing and swimming my father -to go fishing. My parents like variety, they say they can get variety by going to their in the autumn when the leaves are changing color. I feel it's important to visit different places. Of course, when I was a child, I went to my parents' cabin with them for my vacation, when I got older, I began to want to travel to many different places. I skiing; the ski resorts in my country are very crowded and expensive. I go skiing in Switzerland or in Canada. My favorite subject at the university was history; I like to visit historic places. Several years ago, I traveled to Angkor Wat in Cambodia with my uncle and aunt. I also want to visit the pyramids in Egypt; , I'd like to see Machu Picchu in Peru.

My parents believe that you can never get to know a place too well. I understand their point of view. , I find that going to strange places is more exciting. I don't want to go to the same place twice the world is so huge and exciting. 


\section{Appendix J: Lesson Plan and Sampling of Screen Captures for Collaborative Writing Treatment 5}

1. Please allow Ss to choose their own partners today.

2. Ask the pairs to sit at computers beside one another and login to the wiki. The web address is

http://ibtcollaborativewriting.pbworks.com/w/page/69433510/iBT\%20Collaborative $\% 2$ oWriting

3. Once all Ss are logged in, briefly remind them of the activity last time on transition words and phrases. Ask Ss to look at the main page of the wiki and notice the new link under Get Great Ideas. Ask Ss to click on the link entitled organize your writing in the independent response.

\section{Get Great Ideas!}

The General Information folder contains pages about the Structure of Collaborative Writing Task, the prompts, and the response. You can also find information and exercises to help you develop strategies for planning and writing. There are pages about pre-writing strategies and effectively expressing and supporting your opinions. You can also learn about how to effectively connect your ideas with transition words and phrases. Other pages will help you understand how to prganize your writing in the independent response and how to check for errors and edit your essay.

4. This link will take Ss to the page pictured below. Ask them to click on the link to download the Word document.

VIEW

\section{Writing the Independent Response}

last edited by 8 Gna Caruso 29 minutes ago

Remember that although quality is always more important the quantity, tyf This page of the wiki will synthesize the important information about the to download the Word document and complete the exercises as you read .

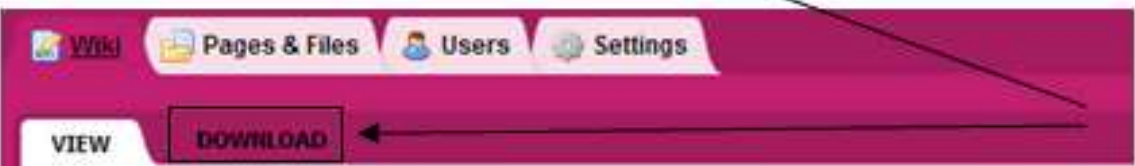

\section{Writing the Independent Response-Guiding |}

uploaded by 3 Gins Caruso 33 minutes ago

No preview is avalable for Writing the Independent Response-Guiding Handout.doex. T 
Ss can use this handout as a guide while they navigate the content in the wiki page. Once Ss have downloaded the word document, they can click back in their browser to return to the page on Writing the Independent Response.

5. Have Ss take some time individually to read the content on the page. Then it's their choice how they would like to complete the exercises on the accompanying handout. Each individual does not have to complete the handout. They can complete one per pair. You can see in the figure below some content in the wiki and how it corresponds to the guiding handout. I think this kind of information transfer task will be beneficial to Ss as it relates to paraphrasing requires Ss to interrelate their declarative and procedural knowledge.
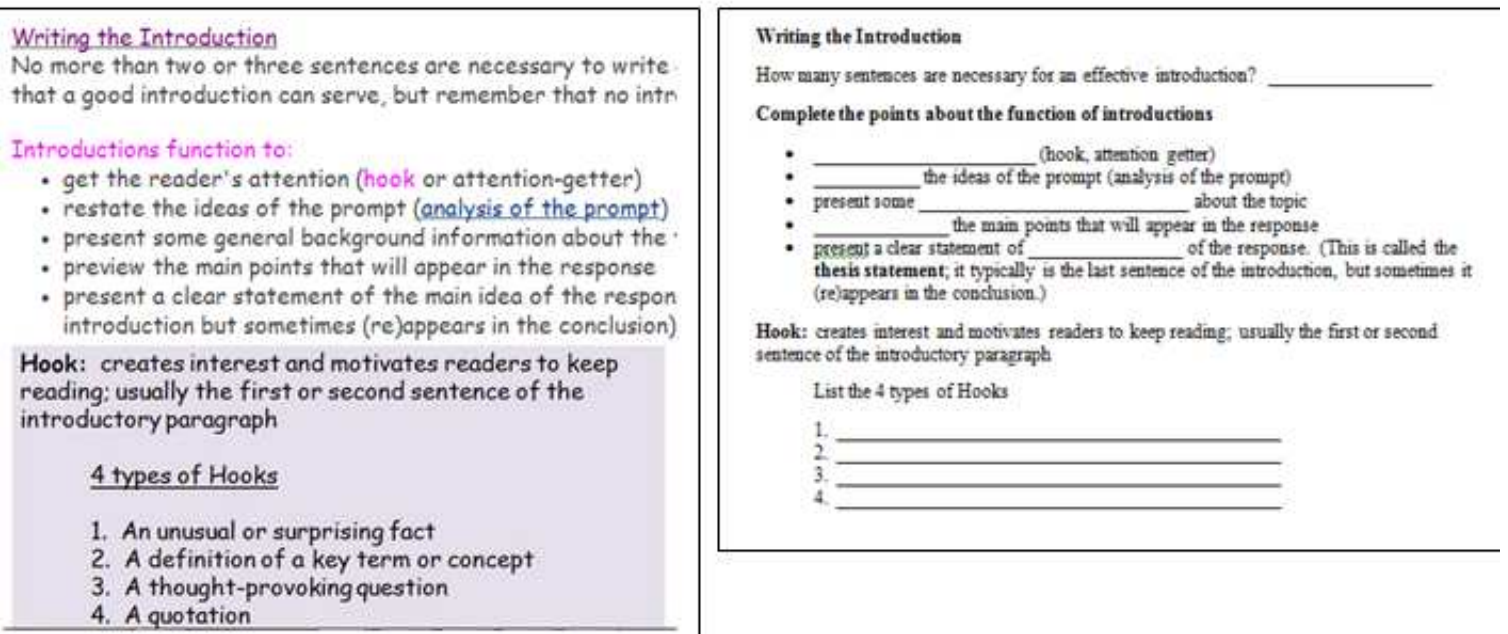

6. Once Ss come to the end of the page on Writing the Independent Response, they will see a link at the bottom to another page with tips for checking and editing the independent response. Ask Ss to click on this link and continue to fill in the handout as they read the content in the wiki.

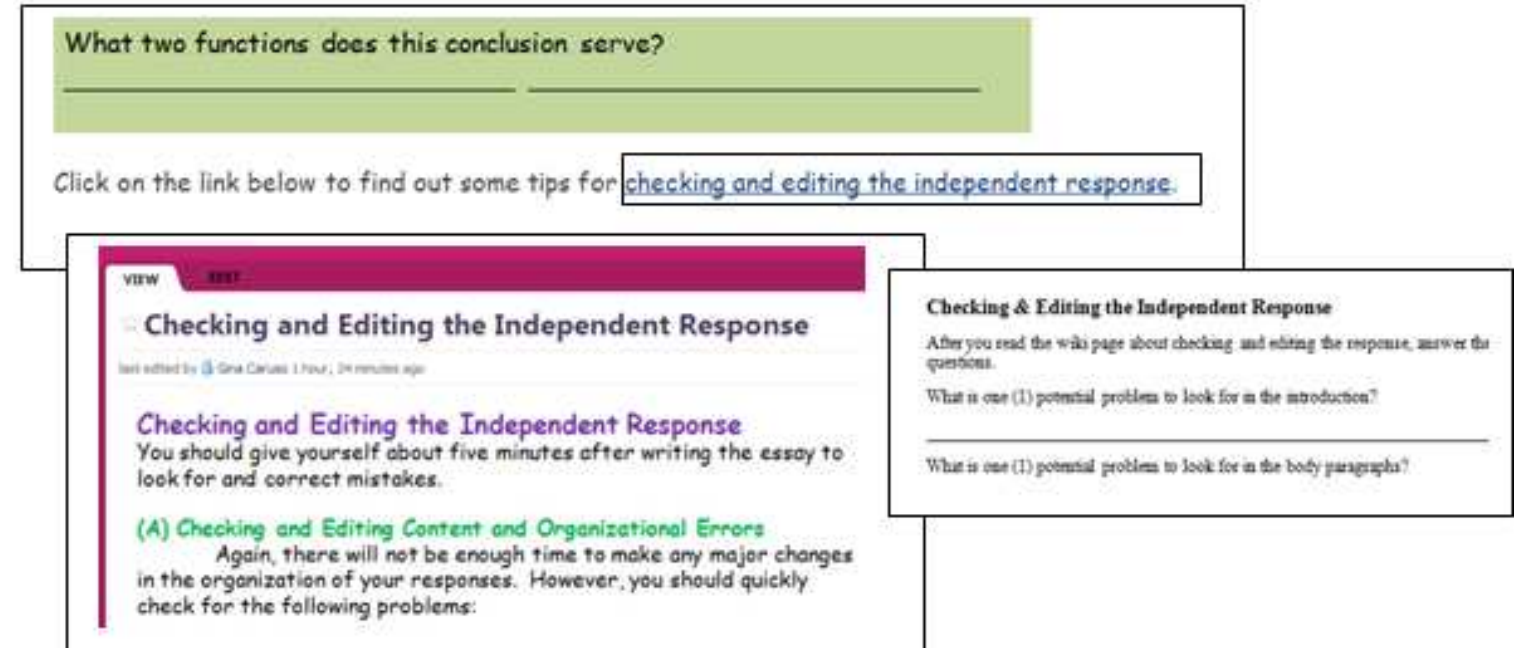


7. Once Ss have completed the handout they can save it for future reference. They do not need to email it to me but can if they would like. Feel free to discuss the handout with them if time allows.

8. As usual, Ss will find the collaborative prompt in the prompts folder within the page entitled Collaborative Prompt 5. Pairs can copy and paste this prompt into their own new page and save it in the folder Collaborative Writing Activity 5. Please be sure that Ss indicate their pseudonyms in the name of the page so that I know who worked with whom. I've included the prompt of the day below.

\section{Collaborative Prompt 5}

If you were asked to send one thing representing your country to an international exhibition, what would you choose? Why? Use specific reasons and details to explain your choice.

9. Set the clock for 1 hour and let the collaboration begin. Remind Ss that they are encouraged to use the content pages in the wiki as resources to guide them while writing. That is, they should feel welcome to look back at the transition words, opinion statements, pre-writing strategies pages, etc... 


\section{Appendix K: Writing the Independent Response-Guiding Hand-out for Collaborative Writing Treatment 5}

Remember that quality is more important than quantity, but typically only longer responses get top score.

\section{Writing the Introduction}

How many sentences are necessary for an effective introduction?

\section{Complete the points about the function of introductions}

(hook, attention getter)

- $\quad$ the ideas of the prompt (analysis of the prompt)

- present some about the topic

the main points that will appear in the response

- present a clear statement of of the response. (This is called the thesis statement; it typically is the last sentence of the introduction, but sometimes it (re)appears in the conclusion.)

Hook: creates interest and motivates readers to keep reading; usually the first or second sentence of the introductory paragraph

List the 4 types of Hooks

1.

2.

3.

4.

Thesis Statements

Where in the introductory paragraph does the thesis statement generally occur?

\section{Sample Introductions}

Read each of the sample prompts and introductions in the wiki. Complete the table with the appropriate information. For example, is the hook a quote or surprising fact? Is the thesis general or specific? 


\begin{tabular}{|l|l|l|l|}
\hline & Introduction 1 & Introduction 2 & Introduction 3 \\
\hline Type of Hook & & & \\
\hline $\begin{array}{l}\text { Type of Thesis } \\
\text { Statement }\end{array}$ & & & \\
\hline
\end{tabular}

Writing the Body of the Response

What three things should be included in each body paragraph?

Writing the Conclusion

Complete the points about the function of conclusions.

- To the thesis statement

- To the main points presented in the body

- To of the points made in the body

- To present why the writer's opinion is the correct one

After reading example conclusions $1 \& 2$ in the wiki, look at example 3 below and answer the questions that follow.

\section{Conclusion 3}

To summarize, the speed, the convenience, and the low cost of international jet travel have changed the world. Individual nations are not as isolated as they were in the past, and people now think of the whole planet as they once thought of their own hometowns.

What two functions does this conclusion serve?

\section{Checking \& Editing the Independent Response}

After you read the wiki page about checking and editing the response, answer the following questions.

What is one (1) potential problem to look for in the introduction?

What is one (1) potential problem to look for in the body paragraphs? 
What are three (3) common grammatical errors to look for?

What are two (2) common mechanical problems to look for? 


\begin{tabular}{|c|c|c|}
\hline \multicolumn{3}{|c|}{$\begin{array}{l}\text { Please answer the questions. All of your answers will be confidential. Thank you for } \\
\text { your time. }\end{array}$} \\
\hline Survey Items & $\begin{array}{l}\text { Question } \\
\text { Type }\end{array}$ & Options \\
\hline 1. What is your gender? & $\begin{array}{l}\text { Multiple } \\
\text { choice }\end{array}$ & male/ female/prefer not to say \\
\hline 2. How old are you? & Open response & - \\
\hline 3. What is your first/native language? & Open response & - \\
\hline $\begin{array}{l}\text { 4. What is your undergraduate major in } \\
\text { university? }\end{array}$ & Open response & - \\
\hline $\begin{array}{l}\text { 5. How many years have you been } \\
\text { studying English? }\end{array}$ & Open response & - \\
\hline 6. Have you ever taken iBT TOEFL? & $\begin{array}{l}\text { Multiple } \\
\text { choice }\end{array}$ & yes/no \\
\hline $\begin{array}{l}\text { 7. What is the highest score you have } \\
\text { achieved on iBT TOEFL? }\end{array}$ & $\begin{array}{l}\text { Multiple } \\
\text { choice }\end{array}$ & $\begin{array}{l}100-120 / 80-99 / 60-79 / 40-59 / 0-39 / \\
\text { I have never taken iBT TOEFL./I } \\
\text { recently took iBT TOEFL and haven't } \\
\text { received my score yet. }\end{array}$ \\
\hline $\begin{array}{l}\text { 8. When do you plan to take iBT TOEFL } \\
\text { next? }\end{array}$ & $\begin{array}{l}\text { Multiple } \\
\text { choice }\end{array}$ & $\begin{array}{l}\text { within 1-2 months/ within 3-4 months/ } \\
\text { within 5-6 months/ I don't plan to take } \\
\text { iBT TOEFL anytime soon. }\end{array}$ \\
\hline $\begin{array}{l}\text { 9. Have you taken any other English } \\
\text { language proficiency exams? }\end{array}$ & $\begin{array}{l}\text { Multiple } \\
\text { choice }\end{array}$ & Yes/No \\
\hline $\begin{array}{l}\text { 10. If you answered YES to the previous } \\
\text { question, please write the name of the } \\
\text { test you took and the highest score you } \\
\text { achieved. If you can't remember, just } \\
\text { guess. }\end{array}$ & Open response & ( \\
\hline $\begin{array}{l}\text { 11. How do you feel about typing an } \\
\text { essay on a computer in English? }\end{array}$ & $\begin{array}{l}\text { Multiple } \\
\text { choice }\end{array}$ & $\begin{array}{l}\text { Very comfortable/ Somewhat } \\
\text { comfortable/ Neither comfortable nor } \\
\text { uncomfortable (neutral)/ Somewhat } \\
\text { uncomfortable/ Very uncomfortable }\end{array}$ \\
\hline $\begin{array}{l}\text { 12. How often do you write in English } \\
\text { outside of your English class? }\end{array}$ & $\begin{array}{l}\text { Multiple } \\
\text { choice }\end{array}$ & $\begin{array}{l}\text { Very frequently (almost every day)/ } \\
\text { Somewhat frequently (3-4 days a } \\
\text { week)/ Sometimes (once or twice a } \\
\text { week)/ Rarely (a few times a month)/ } \\
\text { Never (I only write in English during } \\
\text { English class) }\end{array}$ \\
\hline $\begin{array}{l}\text { 13. Do you have any experience writing } \\
\text { collaboratively? (writing with a partner } \\
\text { or a group of people) }\end{array}$ & $\begin{array}{l}\text { Multiple } \\
\text { choice }\end{array}$ & Yes/No/ I don't know or I'm not sure \\
\hline $\begin{array}{l}\text { 14. Do you think it could be easier to } \\
\text { write with a partner rather than write } \\
\text { alone? }\end{array}$ & $\begin{array}{l}\text { Multiple } \\
\text { choice }\end{array}$ & Yes/No/Maybe/I'm not sure \\
\hline $\begin{array}{l}\text { 15. What do you think would help you } \\
\text { learn to write better in English? }\end{array}$ & Open response & - \\
\hline
\end{tabular}


Appendix M: Items for Experimental Group Participant Survey Please answer the questions. All of your answers will be confidential. Thank you for your time.

\begin{tabular}{|c|c|c|}
\hline Survey Items & $\begin{array}{l}\text { Question } \\
\text { Type }\end{array}$ & Options \\
\hline 1. What is your gender? & $\begin{array}{l}\text { Multiple } \\
\text { choice }\end{array}$ & male/ female/prefer not to say \\
\hline 2. How old are you? & $\begin{array}{l}\text { Open } \\
\text { response }\end{array}$ & - \\
\hline $\begin{array}{l}\text { 3. What is your first/native } \\
\text { language? }\end{array}$ & $\begin{array}{l}\text { Open } \\
\text { response }\end{array}$ & - \\
\hline $\begin{array}{l}\text { 4. What is your undergraduate } \\
\text { major in university? }\end{array}$ & $\begin{array}{l}\text { Open } \\
\text { response }\end{array}$ & - \\
\hline $\begin{array}{l}\text { 5. How many years have you } \\
\text { been studying English? }\end{array}$ & $\begin{array}{l}\text { Open } \\
\text { response }\end{array}$ & - \\
\hline $\begin{array}{l}\text { 6. Have you ever taken iBT } \\
\text { TOEFL? }\end{array}$ & $\begin{array}{l}\text { Multiple } \\
\text { choice }\end{array}$ & yes/no \\
\hline $\begin{array}{l}\text { 7. What is the highest score you } \\
\text { have achieved on iBT TOEFL? }\end{array}$ & $\begin{array}{l}\text { Multiple } \\
\text { choice }\end{array}$ & $\begin{array}{l}\text { 100-120/80-99/60-79/40-59/0-39/ I have } \\
\text { never taken iBT TOEFL./I recently took iBT } \\
\text { TOEFL and haven't received my score yet. }\end{array}$ \\
\hline $\begin{array}{l}\text { 8. When do you plan to take iBT } \\
\text { TOEFL next? }\end{array}$ & $\begin{array}{l}\text { Multiple } \\
\text { choice }\end{array}$ & $\begin{array}{l}\text { within } 1-2 \text { months/within } 3-4 \text { months/within 5- } \\
6 \text { months/ I don't plan to take iBT TOEFL } \\
\text { anytime soon. }\end{array}$ \\
\hline $\begin{array}{l}\text { 9. Have you taken any other } \\
\text { English language proficiency } \\
\text { exams? }\end{array}$ & $\begin{array}{l}\text { Multiple } \\
\text { choice }\end{array}$ & Yes/No \\
\hline $\begin{array}{l}\text { 10. If you answered YES to the } \\
\text { previous question, please write } \\
\text { the name of the test you took and } \\
\text { the highest score you achieved. } \\
\text { If you can't remember, just guess. }\end{array}$ & $\begin{array}{l}\text { Open } \\
\text { response }\end{array}$ & ( \\
\hline $\begin{array}{l}\text { 11. How do you feel about typing } \\
\text { an essay on a computer in } \\
\text { English? }\end{array}$ & $\begin{array}{l}\text { Multiple } \\
\text { choice }\end{array}$ & $\begin{array}{l}\text { Very comfortable/ Somewhat comfortable/ } \\
\text { Neither comfortable nor uncomfortable } \\
\text { (neutral)/ Somewhat uncomfortable/Very } \\
\text { uncomfortable }\end{array}$ \\
\hline $\begin{array}{l}\text { 12. How often do you write in } \\
\text { English outside of your English } \\
\text { class? }\end{array}$ & $\begin{array}{l}\text { Multiple } \\
\text { choice }\end{array}$ & $\begin{array}{l}\text { Very frequently (almost every day)/ Somewhat } \\
\text { frequently ( } 3-4 \text { days a week)/ Sometimes (once } \\
\text { or twice a week)/ Rarely (a few times a month)/ } \\
\text { Never (I only write in English during English } \\
\text { class) }\end{array}$ \\
\hline $\begin{array}{l}\text { 13. Before this class, did you } \\
\text { have any experience writing } \\
\text { collaboratively? (writing with a } \\
\text { partner or a group of people) }\end{array}$ & $\begin{array}{l}\text { Multiple } \\
\text { choice }\end{array}$ & Yes/No/I'm not sure \\
\hline \multicolumn{3}{|c|}{$\begin{array}{l}\text { For items 14-29, please decide the degree to which you agree or disagree with the } \\
\text { statement. }\end{array}$} \\
\hline $\begin{array}{l}\text { 14. Being a participant in this } \\
\text { study was beneficial for my } \\
\text { English language learning. }\end{array}$ & $\begin{array}{l}\text { Multiple } \\
\text { choice }\end{array}$ & $\begin{array}{l}\text { strongly agree/agree/neutral/disagree/strongly } \\
\text { disagree }\end{array}$ \\
\hline $\begin{array}{l}\text { 15. The wiki is a useful tool for } \\
\text { writing collaboratively with }\end{array}$ & $\begin{array}{l}\text { Multiple } \\
\text { choice }\end{array}$ & $\begin{array}{l}\text { strongly agree/agree/neutral/disagree/strongly } \\
\text { disagree }\end{array}$ \\
\hline
\end{tabular}




\begin{tabular}{|c|c|c|}
\hline others. & & \\
\hline 16. The wiki was difficult to use. & $\begin{array}{l}\text { Multiple } \\
\text { choice }\end{array}$ & $\begin{array}{l}\text { strongly agree/agree/neutral/disagree/strongly } \\
\text { disagree }\end{array}$ \\
\hline $\begin{array}{l}\text { 17. Writing essays in the wiki } \\
\text { with a partner was easier than } \\
\text { writing essays alone. }\end{array}$ & $\begin{array}{l}\text { Multiple } \\
\text { choice }\end{array}$ & $\begin{array}{l}\text { strongly agree/agree/neutral/disagree/strongly } \\
\text { disagree }\end{array}$ \\
\hline $\begin{array}{l}\text { 18. Writing collaboratively with } \\
\text { a partner helped me improve my } \\
\text { English vocabulary. }\end{array}$ & $\begin{array}{l}\text { Multiple } \\
\text { choice }\end{array}$ & $\begin{array}{l}\text { strongly agree/agree/neutral/disagree/strongly } \\
\text { disagree }\end{array}$ \\
\hline $\begin{array}{l}\text { 19. Writing collaboratively with } \\
\text { a partner made it easier to think } \\
\text { of ideas. }\end{array}$ & $\begin{array}{l}\text { Multiple } \\
\text { choice }\end{array}$ & $\begin{array}{l}\text { strongly agree/agree/neutral/disagree/strongly } \\
\text { disagree }\end{array}$ \\
\hline $\begin{array}{l}\text { 20. Writing collaboratively with } \\
\text { a partner made it easier to } \\
\text { organize the essay. }\end{array}$ & $\begin{array}{l}\text { Multiple } \\
\text { choice }\end{array}$ & $\begin{array}{l}\text { strongly agree/agree/neutral/disagree/strongly } \\
\text { disagree }\end{array}$ \\
\hline $\begin{array}{l}\text { 21. Writing collaboratively with } \\
\text { a partner helped me improve my } \\
\text { English grammar. }\end{array}$ & $\begin{array}{l}\text { Multiple } \\
\text { choice }\end{array}$ & $\begin{array}{l}\text { strongly agree/agree/neutral/disagree/strongly } \\
\text { disagree }\end{array}$ \\
\hline $\begin{array}{l}\text { 22. When I wrote with a partner, } \\
\text { we could write a longer response } \\
\text { than I could write when I wrote } \\
\text { by myself. }\end{array}$ & $\begin{array}{l}\text { Multiple } \\
\text { choice }\end{array}$ & $\begin{array}{l}\text { strongly agree/agree/neutral/disagree/strongly } \\
\text { disagree }\end{array}$ \\
\hline $\begin{array}{l}\text { 23. Talking with a partner about } \\
\text { the essay was helpful. }\end{array}$ & $\begin{array}{l}\text { Multiple } \\
\text { choice }\end{array}$ & $\begin{array}{l}\text { strongly agree/agree/neutral/disagree/strongly } \\
\text { disagree }\end{array}$ \\
\hline $\begin{array}{l}\text { 24. Being a participant in this } \\
\text { study helped me prepare for the } \\
\text { iBT TOEFL writing test. }\end{array}$ & $\begin{array}{l}\text { Multiple } \\
\text { choice }\end{array}$ & $\begin{array}{l}\text { strongly agree/agree/neutral/disagree/strongly } \\
\text { disagree }\end{array}$ \\
\hline $\begin{array}{l}\text { 25. Writing collaboratively in a } \\
\text { wiki was fun and educational. }\end{array}$ & $\begin{array}{l}\text { Multiple } \\
\text { choice }\end{array}$ & $\begin{array}{l}\text { strongly agree/agree/neutral/disagree/strongly } \\
\text { disagree }\end{array}$ \\
\hline $\begin{array}{l}\text { 26. I would prefer to practice } \\
\text { writing by myself rather than } \\
\text { collaboratively with others. }\end{array}$ & $\begin{array}{l}\text { Multiple } \\
\text { choice }\end{array}$ & $\begin{array}{l}\text { strongly agree/agree/neutral/disagree/strongly } \\
\text { disagree }\end{array}$ \\
\hline $\begin{array}{l}\text { 27. Learning about } \\
\text { brainstorming, outlining, } \\
\text { transition words and } \\
\text { expressions, and essay } \\
\text { organization helped me. }\end{array}$ & $\begin{array}{l}\text { Multiple } \\
\text { choice }\end{array}$ & $\begin{array}{l}\text { strongly agree/agree/neutral/disagree/strongly } \\
\text { disagree }\end{array}$ \\
\hline $\begin{array}{l}\text { 28. I think my individual writing } \\
\text { ability improved after } \\
\text { participating in this study. }\end{array}$ & $\begin{array}{l}\text { Multiple } \\
\text { choice }\end{array}$ & $\begin{array}{l}\text { strongly agree/agree/neutral/disagree/strongly } \\
\text { disagree }\end{array}$ \\
\hline $\begin{array}{l}\text { 29. In the future, I would like to } \\
\text { participate in more collaborative } \\
\text { writing activities using a wiki. }\end{array}$ & $\begin{array}{l}\text { Multiple } \\
\text { choice }\end{array}$ & $\begin{array}{l}\text { strongly agree/agree/neutral/disagree/strongly } \\
\text { disagree }\end{array}$ \\
\hline $\begin{array}{l}\text { 30. What do you think are the } \\
\text { drawbacks (negative points) } \\
\text { about the wiki? }\end{array}$ & $\begin{array}{l}\text { Open } \\
\text { response }\end{array}$ & - \\
\hline $\begin{array}{l}\text { 31. What do you think are the } \\
\text { benefits (good points) about the } \\
\text { wiki? }\end{array}$ & $\begin{array}{l}\text { Open } \\
\text { response }\end{array}$ & - \\
\hline $\begin{array}{l}\text { 32. What do you think is the best } \\
\text { way to improve your English }\end{array}$ & $\begin{array}{l}\text { Open } \\
\text { response }\end{array}$ & - \\
\hline
\end{tabular}




\begin{tabular}{|l|l|l|}
\hline writing ability? & \\
\hline $\begin{array}{l}\text { 33. Do you have any additional } \\
\text { comments you would like to } \\
\text { make about your experience } \\
\text { using a wiki or writing } \\
\text { collaboratively with others? }\end{array}$ & $\begin{array}{l}\text { Open } \\
\text { response }\end{array}$ & - \\
\hline
\end{tabular}




\section{Appendix N: Guidelines for Coding and Quantifying Textual Features}

\section{Lexical Counts \& Coding}

a. Copy and paste each individual writing sample into Lextutor Vocab Profiler (http://www.lextutor.ca/vp/) and click submit.

b. Note the system's replacement of contractions with constituent words (won't=will not), numerical figures with the word number, and elimination of all single letters with the exception of $a$ and $I$.

c. Record the output values reported for each of the following:

1. words in text (tokens)

2. different words in text (types)

3. type-token ratio

4. percentage of Academic Word List words (AWL)

5. percentage of $\mathrm{K}-1$ words (1-1000)

d. Calculate and record the average number of words per minute by dividing the number of tokens by 30 (time in minutes allotted to participants).

\section{T-unit Counts \& Coding}

a. The end of each T-unit is denoted by //.

b. A T-unit is defined as an independent clause and all its dependent clauses. (Hunt, 1970)

c. Count run-on sentences and comma splices as two T-units with an error in the first $\mathrm{T}$-unit. If several comma splices occur in a row, count only the last as error free.

1. i.e. My hometown is Bogota, // it is the capital city of Colombia.

$\begin{array}{ll}1 \mathrm{~T} \text {-unit } & 1 \mathrm{~T} \text {-unit } \\ 1 \text { error } & \text { error-free }\end{array}$

d. For sentence fragments, if the verb or copula is missing, count the sentence as $1 \mathrm{~T}$ unit with an error. (Missing word=MW)

1. If an NP is standing alone, attach it to the preceding or following T-unit as appropriate and count as an error. (Lex)

2. If a subordinate clause is standing alone, attach it to the preceding or following $\mathrm{S}$ and count it as $1 \mathrm{~T}$-unit with an error. (Lex)

e. When there is a grammatical subject deletion in a coordinate clause, count the entire sentence as $1 \mathrm{~T}$-unit. Count two coordinated independent clauses, both with subjects, as 2 T-units.

1. i.e. First we went to our school and then went out with our friends. (1 T-unit)

2. i.e. First we went to our school and then we went out with our friends. (2 T-units) 
f. Count both "so" and "but" as coordinating conjunctions. Count "so that" as a subordinating conjunction unless "so" is obviously meant. Watch for correlative coordinators (both [X] and [y], not (only) [x] but (also) [y]) used to link two independent clauses.

g. Do not count tag-questions as separate T-units.

h. Count S-nodes with a deleted complementizer as a subordinate clause as in: $I$ believe that $A$ and (that) $B=1$ T-unit.

i. But, direct quotes should be counted as:

$\begin{array}{cc}\text { John said, “A } & \text { and } B . ” \\ 1 \text { T-unit } & 1 \text { T-unit }\end{array}$

j. Assess the following type of structures on a case-by-case basis:

If $A$, then $B$ and $C$.

As a result, $A$ or $B$.

k. Count T-units in parentheses as individual T-units.

l. Count and record the total number of T-units in each composition.

\section{Clause Counts \& Coding}

a. Each clause is separated by $/$.

b. Distinguish between independent and dependent clauses.

1. Independent Clause: A grammatical structure which contains a subject and a tensed or modal verb and can stand on its own.

2. Dependent Clause: A grammatical structure which contains a finite or nonfinite verb and at least one additional clause element of the following: subject, object, complement or adverbial (Foster et al., 2000).

3. Do not code an -ing or to-infinitive non-finite complement clause standing alone without any other clause elements.

i.e. Technology allows the world to communicate.

1 independent clause non-clausal status

i.e. Technology allows the world to communicate important information.

1 independent clause $\quad 1$ non-finite dependent clause $(V+0)$

4. In a sentence that has a subject with only an auxiliary verb, do not count that subject and verb as a separate clause (or as a separate T-unit).

i.e. John likes to ski and Mary does too. $=1$ clause 


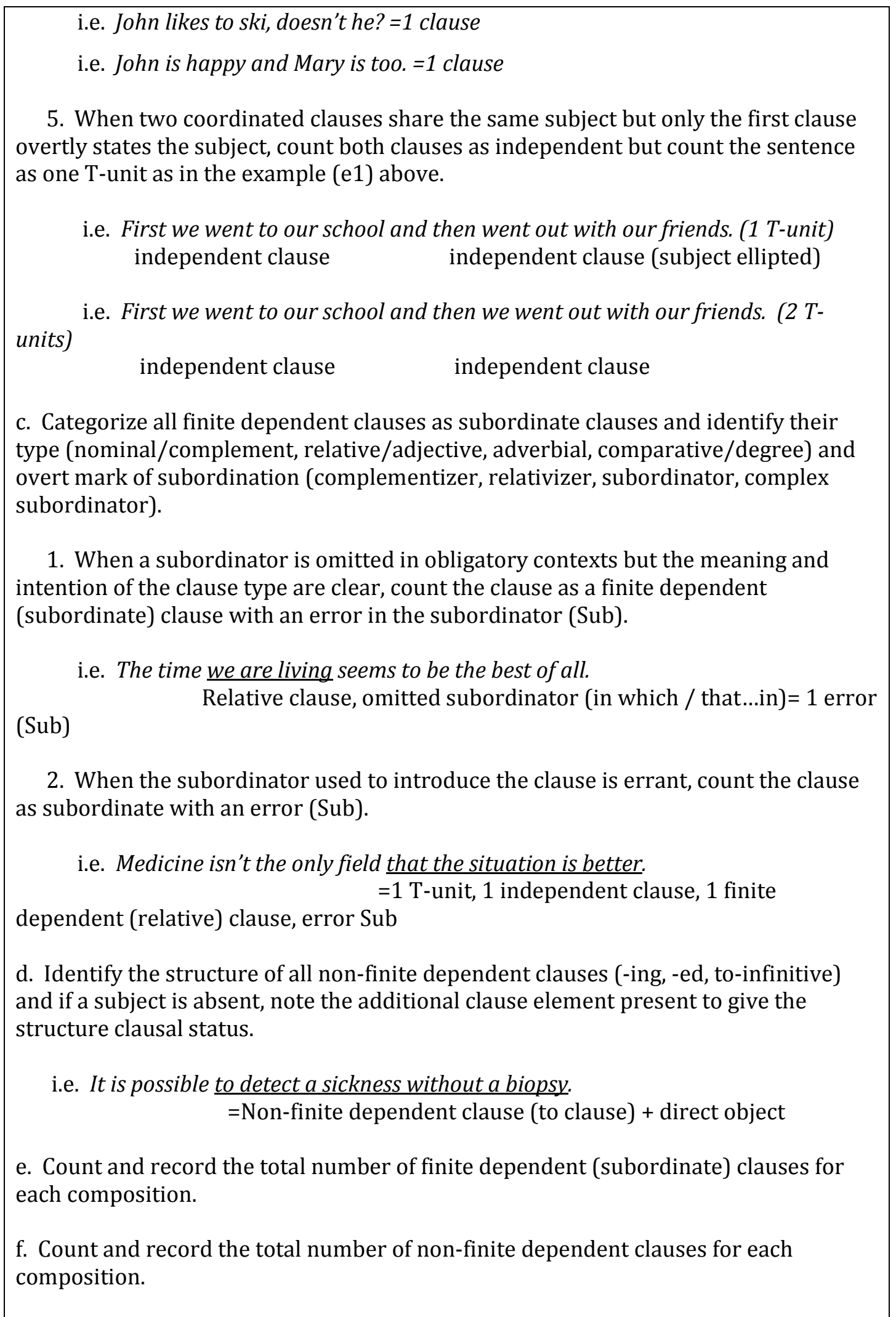


g. Count and record the total number of independent clauses for each composition.

h. Sum the values from e, f, \& g above and record the total clause count for each composition.

\section{Error Guidelines}

a. Do not count capitalization or spelling errors (including word changes like "there/their").

b. Any error excludes a clause from being error free (i.e. omitted plural -s, omitted preposition, omitted articles, run-on sentences or comma splices all count).

c. Differentiate error free clauses from error free T-units- i.e. if the T-unit has two clauses, one may be error free and counts as an error-free clause, the other may have an error, in which case the T-unit is not error free. Error-free T-units are therefore a subset of error-free clauses.

d. Base tense/reference errors on preceding discourse; do not look at the sentence in isolation.

e. Don't count British usages as errors (i.e. "in hospital," "at university," collective nouns as plural).

f. Count errors that could be made by native speakers (i.e. between you and I).

g. Do not count register errors related to lexical choices (i.e. lots, kids).

h. Disregard an unfinished sentence at the end of the essay.

\section{Error Counts \& Coding}

a. Lexicon, phrase, clause (Lex) (aberrant words, phrases, clauses, sentences, NP standing alone, subordinate clause standing alone, awkward phrasing)

b. Tense/aspect, voice (T/A)

c. Number of noun (Num) (including singular for plural \& plural for singular)

d. Parallel Structure (Par) (including infinitives, gerunds, clauses)

e. Preposition (Prep) (incorrect or missing)

f. Reference (Ref) (missing or incorrect, deixis problem)

g. Subject-Verb agreement (SV) (collective nouns can take singular or plural)

h. Article (Art) (missing or incorrect, used when unnecessary) 
i. Other determiner (Det) (include possessive det., quantifiers, demonstratives, genitives)

j. Word from (WF) (i.e adj for adv., adv. for adj, etc.)

k. Verb form (VF) (inflection following modals, infinitives missing to, incorrect irregular form)

l. Case (Case) (misuse of nominative, accusative, genitive)

m. Missing word (MW) (includes main/aux verbs, missing clause elements, , sentence fragments)

For sentence fragments, if the verb or copula is missing, count the sentence as $1 \mathrm{~T}$-unit with an error.

(Does NOT include preposition, determiners, coordinators, subordinators)

n. Pronoun (ProN) (incorrect, but not related to case or referent)

o. Coordinator/Subordinator (Coor/Sub) (incorrect, missing when obligatory, includes relative pronouns, complementizers)

p. Word order (WO)(includes misplaced negation, misplaced adverbs of frequency)

q. Negation (Neg) (including never, ever, any, some, either, neither)

Does NOT include misplaced negators

r. Run-on sentence (RO) (including comma splice)

Code as 2 T-units with an error in the first T-unit

If several comma splices occur in a row, count only the last as error free. 